\title{
MARGINAL FIT COMPARISON OF CAD/CAM CROWNS MILLED FROM TWO DIFFERENT MATERIALS
}

by

\section{Atousa Azarbal}

Doctor of Dental Surgery, Shahid Beheshti University, Faculty of Dentistry, 2010

\author{
Submitted to the Graduate Faculty of \\ School of Dental Medicine in partial fulfillment \\ of the requirements for the degree of \\ Master of Dental Science
}

University of Pittsburgh

2015 


\section{UNIVERSITY OF PITTSBURGH \\ SCHOOL OF DENTAL MEDICINE}

This thesis was presented

by

Atousa Azarbal, DDS

It was defended on

December $1^{\text {st }}, 2015$

And approved by

Moshen Azarbal, DMD, MDS, FACP, Associate Professor, Director Advanced Education in the Department of Prosthodontics

Robert Engelmeier, DMD, MS, FACP, FAAMP, Chairman, Department of Prosthodontics

Thomas Kunkel, DMD, Assistant Professor, Department of Prosthodontics

Robert J. Weyant, DMD, DrPH, Professor and Chair Department of Dental Public Health

Nilesh Shah, PhD, Assistant Professor, Department of Dental Public Health

Thesis Advisor: Moshen Azarbal, DMD, MDS, FACP, Associate Professor, Director Advanced

Education in the Department of Prosthodontics 
Copyright $($ ) by Atousa Azarbal 2015 


\title{
MARGINAL FIT COMPARISON OF CAD/CAM CROWNS MILLED FROM TWO DIFFERENT MATERIALS
}

\author{
Atousa Azarbal, DDS \\ University of Pittsburgh, 2015
}

\begin{abstract}
Objective: This study evaluated the marginal fit of CAD/CAM copings milled from Hybrid ceramic (Vita Enamic) blocks and lithium-disilicate (IPS e-max CAD- Ivoclar Vivadent) blocks. It also evaluated the effect of crystallization firing on the marginal fit of lithium-disilicate copings.
\end{abstract}

Method and Material: A standardized metal die with a $1 \mathrm{~mm}$ wide shoulder finish line was imaged using the CEREC® AC Bluecam (Sirona). The coping was designed utilizing CEREC 3 software. The design was used to fabricate 15 lithium-disilicate and 15 hybrid ceramic copings. Design and milling were accomplished by one operator. The copings were seated on the metal die utilizing a pressure clamp with a uniform pressure of 5.5 Ibs. A Macroview Microscope was used for direct viewing of the marginal gap. Four areas were imaged on each coping (buccal, distal, lingual and mesial). Image analysis software was used to measure the marginal gaps in micrometers in 15 randomly selected points on each of the four surfaces. A total of sixty measurements were made per sample. For lithium-disilicate copings the measurements for marginal gap were made before and after firing. Data was analyzed by paired t-test.

Results: The overall mean difference in marginal gap between the hybrid ceramic and crystallized lithium-disilicate copings was statistically significant $(\mathrm{p}<0.01)$. The overall mean difference in marginal gap before and after firing (pre-crystallized and crystallized lithium-disilicate copings) showed an average of 62 microns increase in marginal gap after firing. This difference was also significant $(\mathrm{p}<0.01)$. 
Conclusion: This study concluded that crystallization firing can result in a significant increase in the marginal gap of the lithium-disilicate CAM/CAM crowns. In addition a significant difference exists in the marginal gap discrepancy when comparing hybrid ceramic and lithium disilicate CAD/CAM crowns. 


\section{Table of contents}

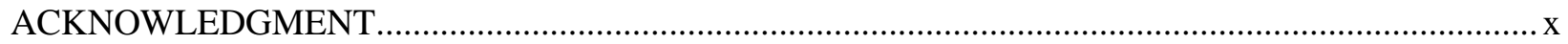

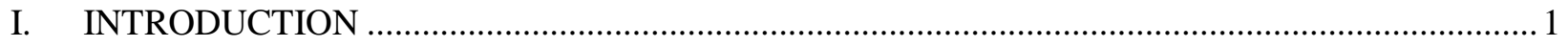

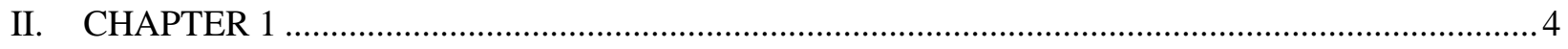

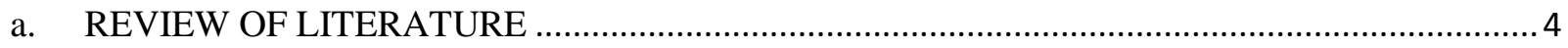

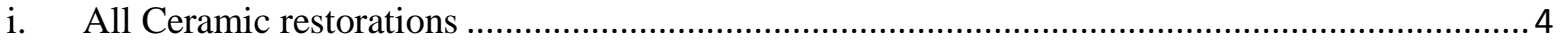

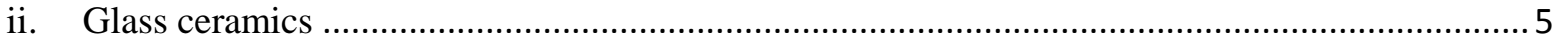

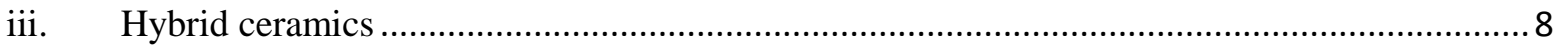

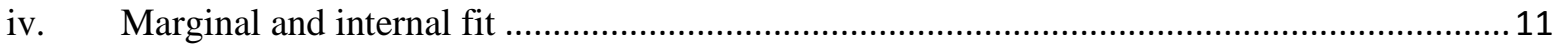

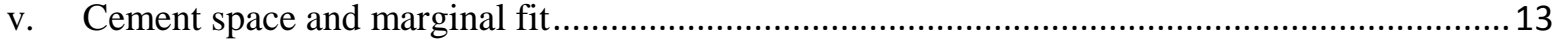

vi. $\quad$ Type of finish line and marginal fit................................................................................ 13

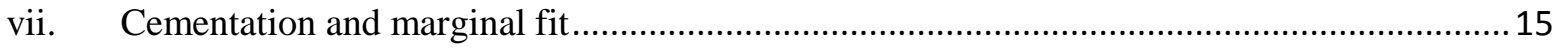

viii. $\quad$ Measurement methods for marginal fit ............................................................................. 16

ix. $\quad$ Experimental set-up for marginal gap measurement ....................................................... 24

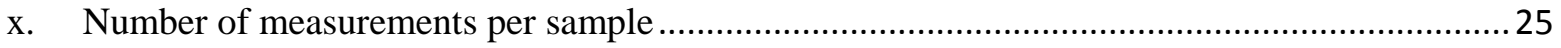

b. REVIEW OF COMPUTER-AIDED DESIGN/COMPUTER-AIDED MANUFACTURING

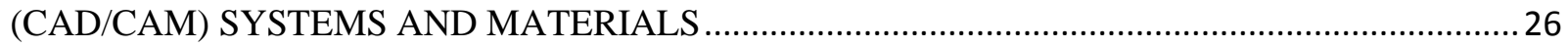

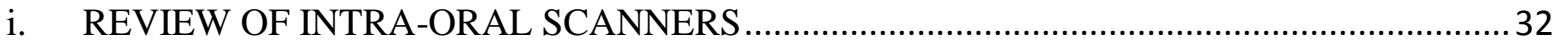

ii. CEREC® BY SIRONA DENTAL SYSTEM GMBH (DE) CEREC® (an acronym for Chairside

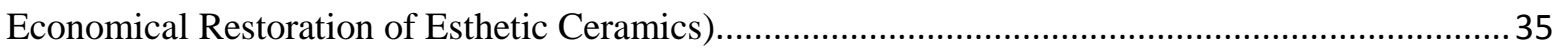

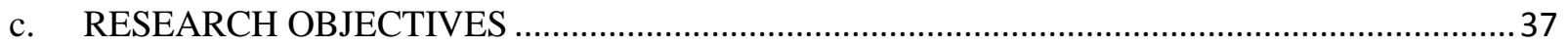

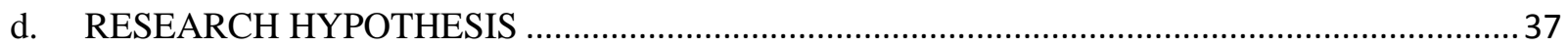

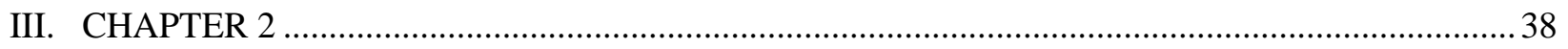

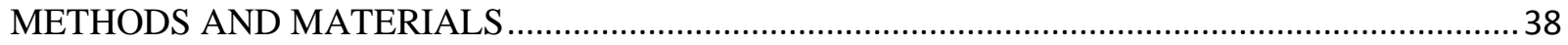

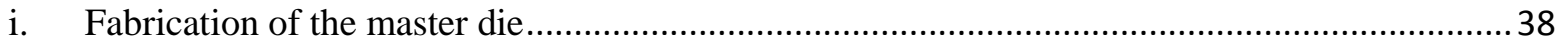




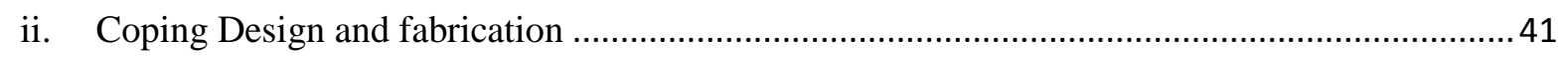

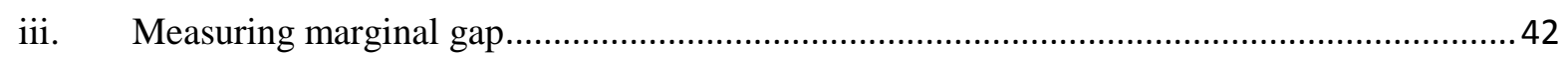

iv. Crystallization firing for lithium disilicate copings ......................................................... 43

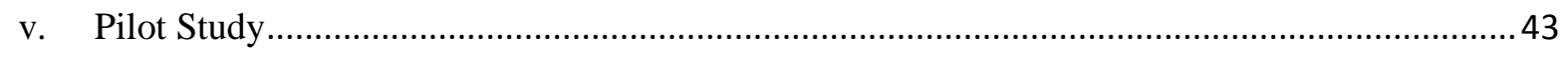

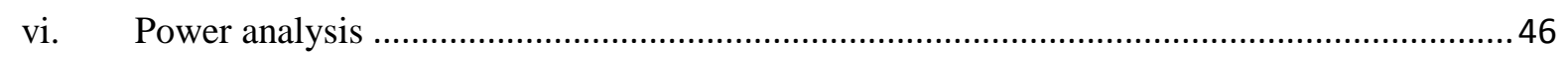

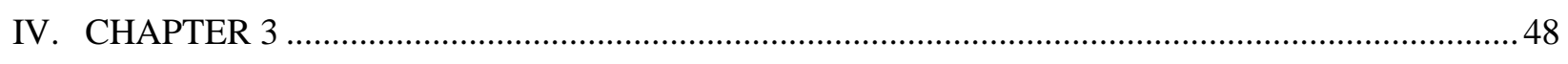

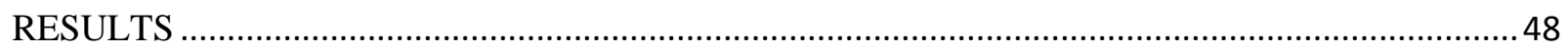

i. A comparison of the marginal gap of copings milled from lithium disilicate blocks before and

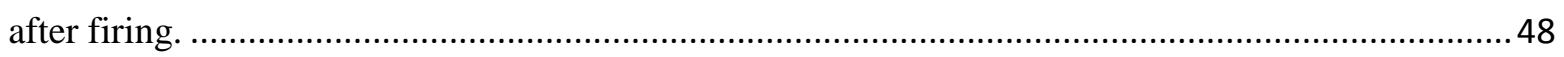

ii. A comparison of marginal gap of pre-crystallized lithium disilicate copings and hybrid ceramic

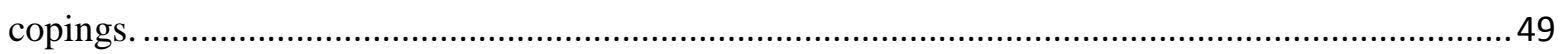

iii. A comparison of marginal gap of crystallized lithium disilicate copings and hybrid ceramic

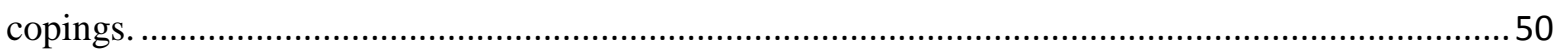

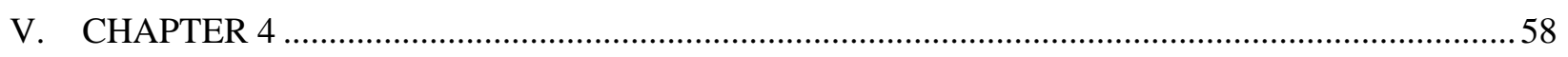

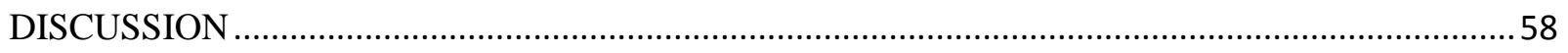

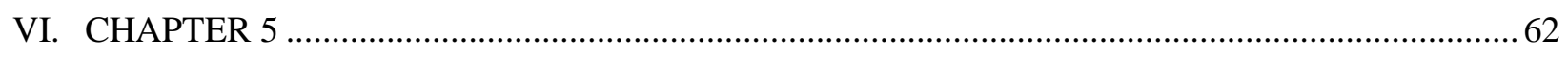

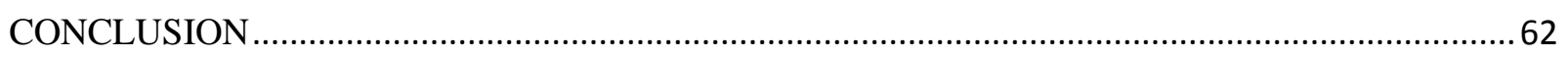

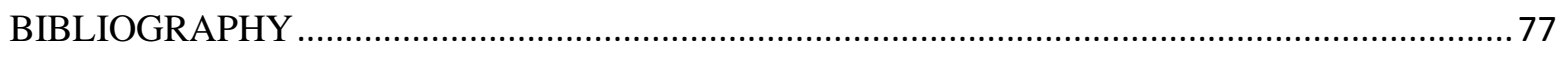




\section{List of tables}

Table 1: IPS e.max CAD physical properties (Ivoclar Vivadent, Schaan, 2005) .................................... 7

Table 2: summary of physical and mechanical properties of Vita Enamic............................................ 10

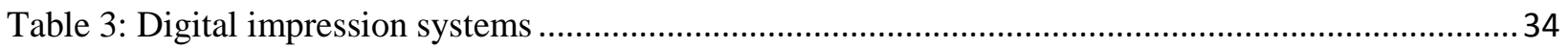

Table 4: mean measurements for marginal gap between the lithium disilicate (IPS-Emax) pre-crystallized

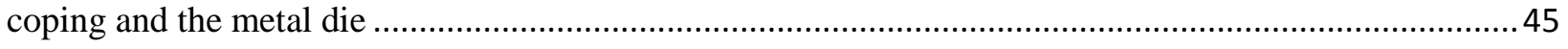

Table 5: mean measurements of marginal gap between the lithium disilicate (IPS-Emax) crystallized

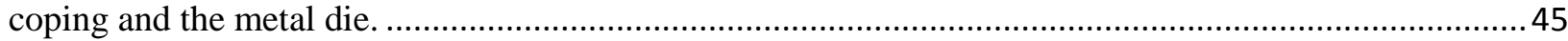

Table 6: Emax (lithium disilicate group): pre-crystallized (unfired) copings vs. crystallized (fired) copings

Table 7: Emax (lithium disilicate group) before firing vs. Enamic (hybrid ceramic group) ..................... 49

Table 8: Emax (lithium disilicate group) after Firing vs. Enamic (hybrid ceramic group) .......................50 


\section{List of figures}

Figure 1: comparison of modulus of elasticity of different CAD/CAM material ...................................... 9

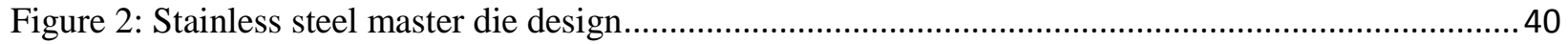

Figure 3: Mean marginal gap of pre-crystallized Lithium disilicate (e-max unfired) samples \#1-15 ........51

Figure 4: Mean marginal gap of crystallized Lithium disilicate (e-max fired) samples \#1-15 ..................52

Figure 5: Mean marginal gap of hybrid ceramic (Enamic) samples \#1-15 ..............................................53

Figure 6: Bar chart summarizing the mean marginal gap differences between pre-crystallized lithium

disilicate, crystallized lithium disilicate and hybrid ceramic copings ....................................................5 54

Figure 7: Comparison of the mean buccal marginal gaps in 3 groups....................................................56

Figure 8: Comparison of the mean distal marginal gaps in 3 groups......................................................56

Figure 9: Comparison of the mean lingual marginal gaps in 3 groups ....................................................5

Figure 10: Comparison of the mean mesial marginal gaps in 3 groups ................................................5

Figure 11: A and B, stainless steel master die mounted in stone ....................................................... 64

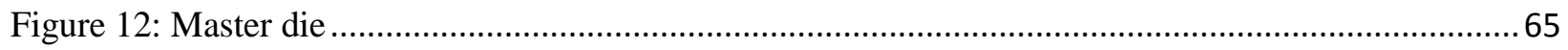

Figure 13: CEREC (Sirona) unit with Bluecam scanner and CEREC inLab (Sirona) milling unit............ 66

Figure 14: Initial settings for coping design (CEREC software version 4.3.1) ......................................67

Figure 15: image acquisition of master die and biogeneric copy assembled .........................................68

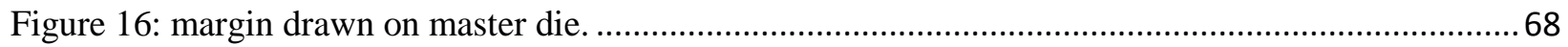

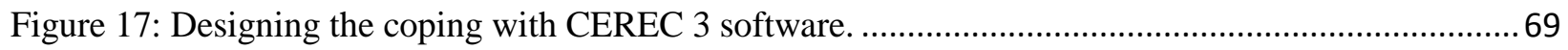

Figure 18: Copings were milled using (A) IPS e-max CAD and (B) Enamic, (C) burs for the.................70

Figure 19: lithium disilicate coping in blue phase seated in the mater die with standardized pressure...... 71

Figure 20: Olympus MVX10 Macroview Microscope (Olympus America, Center Valley PA) used for

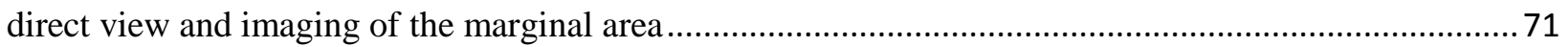

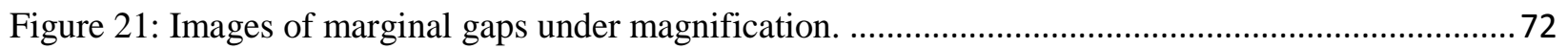

Figure 22: Calibration of image distances in micrometers. ................................................................... 73

Figure 23: line measurements of marginal gap area made using image analyzing software ..................... 74

Figure 24: Furnace used for crystallization firing cycle of lithium disilicate copings............................. 75

Figure 25: A. labeled lithium disilicate copings mounted on the crystallization tray............................... 76 


\section{ACKNOWLEDGMENT}

I would like to acknowledge Department of Prosthodontics at the University Of Pittsburgh School Of Dental Medicine for providing the opportunity and facilities for this research.

I wish to express my sincere gratitude to my thesis advisor Dr. Mohsen Azarbal for his guidance and mentorship. Thank you for all you have so patiently taught me.

I would like to thank Dr. Robert Engelmeier and Dr. Thomas Kunkel for their time and recommendations throughout this project.

And Special thanks to Ivoclar Vivadent and Vita Corp. for generous donation of their products to this project. 
(تقديم باه يدر و مادرم)

Dedicated to my loving parents Dr. Mansour Azarbal and Minoo Hashemian.

I am grateful to your endless support, love and sacrifices. You taught me how to become a strong and passionate person and encouraged me to follow my dreams. 


\section{INTRODUCTION}

Current trends in dentistry have seen higher demands for metal free posterior restoration materials. All ceramic restorations have the advantages of improved esthetics, biocompatibility and resistance to compressive forces during mastication. Their durability is comparable to metal ceramic crowns (1-12).

Essential requirements for successful all-ceramic crown restorations are such things as good esthetics, high fracture resistance and perfect marginal fit (1). Dissolution of the luting agent and microleakage are associated with increased marginal crown discrepancies (2). Subsequent microleakage can lead to irritation and inflammation of a vital pulp leading to endodontic problems $(3,4)$. Poor marginal adaptation can lead to secondary caries (5) and affect the health of the periodontium by contributing to increased plaque retention and changes in the subgingival microflora $(6,7$, and 8$)$. Areas of stress concentration can be created in a restoration related to variations in fit resulting from poor margin adaptation. This can decrease the strength and longevity of a restoration (9).

Holmes et al. introduced a classification for marginal gap in 1989 (13). According to their classification "the perpendicular measurement from the internal surface of the casting to the axial wall of the preparation is called the internal gap. The same measurement at the margin is called the "marginal gap". In this study the different locations of "misfit" are measured. The terms of internal gap, marginal gap, vertical marginal discrepancy, horizontal marginal discrepancy, overextended margin, underextended margin, absolute marginal discrepancy and seating discrepancy are used for different areas of measurement (13). Different values for marginal fit have been reported throughout the literature. They range from 7.5 um to 206.3 um $(11,12)$. 
Computer aided design-computer assisted manufacturing (CAD/CAM) technology was introduced to dentistry in 1971. Advancements in digital impression systems and CAD/CAM milling technologies have enabled fabrication of more accurately fitting restorations (14).

The advantages of using CAD/CAM technology to fabricate crowns are (15):

-less chair time required

-elimination of a second delivery appointment/ elimination of provisionalization

-elimination of errors caused by materials and impression techniques.

-Improved communication between the clinician and the laboratory.

A principle concern surrounding CAD/CAM technology is the accuracy of fit of the ceramic crowns fabricated using CEREC system (10). A wide range of variables can affect the marginal accuracy of $\mathrm{CAD} / \mathrm{CAM}$ restorations such as; the scanning process, software design, milling and shrinkage following final firing of the restoration $(16,17)$.

Both in vivo and in vitro studies have reported a wide range of marginal gaps seen with CAD/CAM restorations fabricated by means of the CEREC system (18-21).

In general, research has shown that CAD/CAM crowns fabricated via the CEREC 3 system demonstrate better marginal fit compared to CEREC 1 and CEREC 2 generated restorations (22).

A study by Ellingsen et al. compared the marginal adaptation of CAD/CAM ceramic crowns using CEREC 2 vs. CEREC 3 software and hardware systems. This study concluded that the marginal adaption of CAD/CAM crowns fabricated using the CEREC 3 system was significantly better than those crowns fabricated with the CEREC 2 system (22).

Several studies evaluated the correlation between finish line design and accuracy of fit of CAD/CAM crowns $(23,24)$. Tsitrou et al. compared three different margin designs of composite CAD/CAM crowns 
fabricated utilizing the CEREC 3 system. They concluded that there were no statistically significant differences in marginal gap between bevel, chamfer and shoulder finish lines (23).

Fabrication procedures such as porcelain firing cycle can affect the marginal fit of all ceramic restoration and influence their ultimate success $(25,28)$. There have also been studies which have found that the marginal fit of CAD/CAM restorations are comparable to those generated from traditional impressions (29-31).

Different studies have utilized different testing methods to evaluate the marginal gap of crowns. This difference in testing techniques has resulted in variability of the marginal gap values found for CEREC crowns. In general the methods for measuring marginal gap can be divided into two groups.

1. Invasive or destructive methods such as cross sectioning to measure the film thickness $(22,32-34)$.

2. Non-invasive or non-destructive methods such as direct viewing and replica techniques (22, 33-35).

Nawafleh, et al. reviewed 183 articles evaluating the accuracy and reliability of methods used to measure marginal adaptation of crowns and FPDs (36). According to this study six different methods have been used to measure the marginal fit of restorations; direct view technique, cross sectioning, replica technique, profile projector, digimatic micrometer, micro CT, and combinations of two of these methods (36). The direct view technique was reported as the most popular method followed by cross-sectioning, and the impression replica technique (36).

With the advent of new restorative CAD/CAM materials, there is a growing need to explore the accuracy, durability, and patient satisfaction with restorations fabricated from those materials. The purpose of this study was to compare the marginal accuracy of two of these materials. 


\section{CHAPTER 1}

\section{a. REVIEW OF LITERATURE}

\section{i. All Ceramic restorations}

In 1903 Land introduced the first feldspathic porcelain crown. Since then there has been an exponential growth in demand for non-metallic restorations (37).

In 1965, McLean achieved significant improvement in mechanical and physical properties by adding aluminum oxide to feldspathic porcelain (38).

In 1969 Helmer and Driskell published the first paper on biomedical application of zirconia (39).

In 1988, Christel presented the use of ziconia to fabricate artificial femoral heads in total hip replacedment.(40).

Kelly believed that dental ceramics can be categorized into three main domains. A. A predominantly glassy material, which has similar optical properties as enamel and dentin. B. A material where filler particles are added to improve mechanical and optical properties (Particle filled glasses). One of the first fillers to be used in dental ceramics was Leucite $(41,42)$. One subset of this group is the glass-ceramics. Examples are Dicor (Dentsply) and Empress 2 (Ivoclar-Vivadent). C. Polycrystalline ceramics, Which have densely packed atoms in regular arrays. They are much tougher and stronger but relatively opaque compared to glass ceramics. Polycrystalline ceramics can serve as substructure materials which can be veneered with glass ceramics for better esthetics (43). 


\section{ii. Glass ceramics}

The development of IPS Empress evolved at the University of Zurich, Zurich, Switzerland, in 1983. In 1990 Ivoclar Vivadent introduced it to the dental profession $(44,45)$.

IPS Empress (Ivoclar Vivadent, AG, Schaan, Liechtenstein) is a leucite reinforced glass ceramic. This material is best suited for single unit restorations, inlays, onlays, and veneers. Restorations can be made with IPS Empress following two techniques. One is the lost wax technique. This technique is similar to metal casting. An IPS Empress ingot in placed in a furnace and is pressed at a temperature of $1200{ }^{\circ} \mathrm{C}$ (combination of heat and pressure). To achieve the desired hade the product can be stained. This technique is typically used for fabrication of inlays and onlays. The other is a layering technique, were a dentinal core is fabricated through casting. For optimal esthetic outcomes the enamel layer of an appropriate shade and translucency is added to the dentinal core $(45,46)$.

In 1998 Ivoclar Vivdent introduced IPS Empress 2, a lithium disilicate glass ceramic (SiO2-Li2O). The fabrication process is a combination of the lost-wax and heat pressed techniques. Flexural strength has been improved over IPS Empress by a factor of three. This material is suggested for use in the fabrication of anterior fixed partial dentures which can extend to the second premolar (47).

Lithium disilicate glass ceramic material was introduced by Ivoclar Vivadent (Amherst, N.Y.) for fabricating anterior or posterior crowns, inlays, onlays or veneers. There are two types of this material available. An ingot that can be press-fit (IPS e-max Press, Ivoclar Vivadent) or as a block, that can be milled using CAD/CAM technology (IPS e-max CAD, Ivoclar Vivadent) (48). There is a two stage crystallization process for milled lithium disilicate blocks. Lithium metasilicate crystals are precipitated during the first stage of the process comprising $40 \%$ of the glass ceramic volume. The glass ceramic has crystal sizes ranging from 0.2-1.0 micrometers. The blue-violet colored pre-crystallized blocks can be easily milled to the desired form without excessive diamond bur wear or damage to the restoration. The 
final milled restoration is then crystallized under a vacuum at $850{ }^{\circ} \mathrm{C}$ to form lithium disilicate. In this final process the blue shade converts to the final desired tooth shade. The end product is a fine-grained glass ceramic with grain size of $1.5 \mu \mathrm{m}$ and is $70 \%$ crystal by volume incorporated in a glass matrix (49, 50). The Mechanical properties of this material are superior to IPS Empress 2. It possess high flexural strength of $360 \mathrm{MPa}$ to $440 \mathrm{MPa}$, high fracture toughness of 2-3 MPa and a high thermal shock resistance due to the low thermal expansion (48).

Standard Composition of IPS e.max CAD (Ivoclar Vivadent) by weight is (50)

$\begin{array}{ll}\mathrm{SiO} 2 & 57.0 \%-80.0 \% \\ \mathrm{Li} 2 \mathrm{O} & 11.0 \%-19.0 \% \\ \mathrm{~K} 2 \mathrm{O} & 0.0 \%-13.0 \% \\ \mathrm{P} 2 \mathrm{O} 5 & 0.0 \%-11.0 \% \\ \mathrm{ZrO} 2 & 0.0 \%-8.0 \% \\ \mathrm{ZnO} & 0.0 \%-8.0 \%\end{array}$

Other and coloring oxides $\quad 0.0 \%-12.0 \%$

The table below was extracted from Scientific Documention of IPS e.max CAD published by Ivoclar Vivadent company which summarizes the physical properties of IPS e.max CAD (Ivoclar Vivadent ) (50). 
Table 1: IPS e.max CAD physical properties (Ivoclar Vivadent, Schaan, 2005)

\begin{tabular}{|c|c|c|}
\hline Physical properties & $\begin{array}{l}\text { Partially crystallized } \\
\text { State }\end{array}$ & Fully crystallized state \\
\hline Biaxial strength (ISO 6872) & $130 \pm 30 \mathrm{MPa}$ & $360 \pm 60 \mathrm{MPa}$ \\
\hline Fracture toughness (SEVNB) & $0.9-1.1 \mathrm{MPa} \mathrm{m} 1 / 2$ & $2.0-2.5 \mathrm{MPa} \mathrm{m} 1 / 2$ \\
\hline Vickers hardness & $5400 \pm 100 \mathrm{MPa}$ & $5800 \pm 100 \mathrm{MPa}$ \\
\hline Modulus of elasticity & & $95 \pm 5 \mathrm{GPa}$ \\
\hline CTE $\left(100-500^{\circ} \mathrm{C}\right)$ & & $10.45 \pm 0.2510-6 / \mathrm{K}-1$ \\
\hline Density & & $2.5 \pm 0.1 \mathrm{~g} / \mathrm{cm} 3$ \\
\hline $\begin{array}{l}\text { Linear shrinkage during the } \\
\text { tempering process }\end{array}$ & $0.2 \%$ & \\
\hline Chemical solubility & $100-160 \mu \mathrm{g} / \mathrm{cm} 2$ & $30-50 \mu \mathrm{g} / \mathrm{cm} 2$ \\
\hline
\end{tabular}

Full contour bridges have been recommended as another indication for e.max anterior and posterior FPDs

(51). Following a ten year study of three unit fixed partial dentures milled from monolithium disilicate ceramic blocks, Kern et al. concluded that the survival rate of posterior e.max fixed partial dentures are comparable to those fabricated from porcelain fused to metal (52).

The e.max CAD (Ivoclar Vivadent) blocks are available with different levels of translucency. High translucency blocks are intended for inlays and onlays to help blend the restoration with the surrounding tooth shade. The low translucency blocks are used for full coverage crowns (51).

There are some concerns regarding the use of e.max for fabricating fixed partial dentures. Appropriate size and thickness of the connector area is essential. However, connectors of adequate strength can compromise esthetics, especially in the case of anterior fixed partial dentures (51). 


\section{iii. Hybrid ceramics}

Vita Enamic is the first dental Hybrid ceramic possessing a dual network structure. The dominant ceramic network is reinforced with a polymer network. Each network penetrates the other to create a hybrid material (53). The inorganic ceramic portion comprises $86 \%$ by weight of this material. The organic polymer part comprises $14 \%$ by weight of the structure mass (54). This combination exhibits the positive characteristics of both a ceramic and a composite (53).

The manufacturer recommends the use of this material to restore posterior teeth especially where there is limited space available and need for minimally invasive restorations. This material exhibits: high strength, excellent edge stability after milling which ensures precision fit restorations, excellent milling properties, minimal wear of milling tools, and allows for minimal tooth reduction (53).

Due to the ceramic polymer network, hybrid ceramic blocks possess similar physical properties as enamel and dentin (51). Vita Enamic has an elasticity of $30 \mathrm{GPa}$, which unlike no dental material is in the same range as human dentin (55). This material shows high flexural strength and a high level of color stability due to the ceramic composition (51).

Figure 1 compares the modulus of elasticity of some available CAD/CAM materials while table 2 summarizes the physical properties of Vita Enamic (54). 


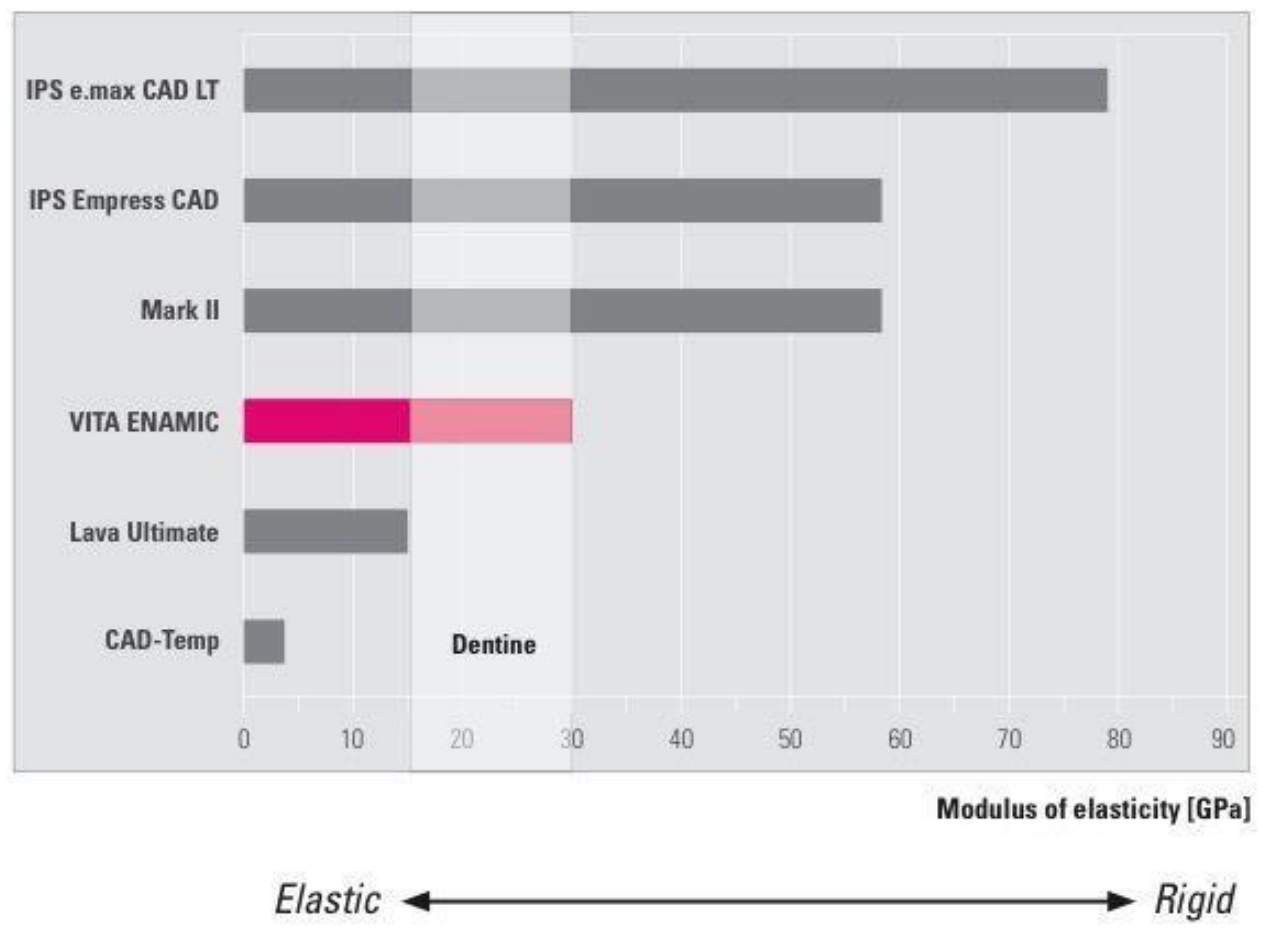

Figure 1: comparison of modulus of elasticity of different CAD/CAM material 
Table 2: summary of physical and mechanical properties of Vita Enamic

\begin{tabular}{|c|c|c|}
\hline & VITA ENAMIC & Standard value \\
\hline Static fracture load [N] (SD) & $2766(98)$ & None specified \\
\hline Density $[\mathrm{g} / \mathrm{cm} 3]$ & 2.1 & None specified \\
\hline Flexural strength [MPa] & $150-160$ & $\begin{array}{l}\text { ISO 10477: } \geq 50 \\
\text { ISO } 6872: \geq 100\end{array}$ \\
\hline Modulus of elasticity [GPa] (SD) & $30(2)$ & None specified \\
\hline Abrasion $[\mu \mathrm{m}]$ & $\begin{array}{l}\text { In the same range as Mark II, } \\
\text { veneering ceramics }\end{array}$ & None specified \\
\hline $\begin{array}{l}\text { Extension in the case of fracture [\%] } \\
\text { (SD) }\end{array}$ & $0.5(0.05)$ & None specified \\
\hline Weibull modulus & 20 & None specified \\
\hline Hardness [GPa] & 2.5 & None specified \\
\hline Fracture toughness [MPa $\sqrt{\mathrm{m}]}]$ & 1.5 & None specified \\
\hline $\begin{array}{l}\text { Adhesion with veneering material } \\
\text { [MPa] }\end{array}$ & $\begin{array}{l}\text { Without silane: } 12 \\
\text { With silane: } 27\end{array}$ & ISO $10477: \geq 5$ \\
\hline Shear strength, cementation [MPa] & $\begin{array}{l}\text { RelyX Unicem: approx. 21, } \\
\text { Variolink II: approx. 27, } \\
\text { RelyX Ultimate: approx. } 31\end{array}$ & None specified \\
\hline Shade stability & Excellent, $\Delta \mathrm{E}<2$ & None specified \\
\hline Machinability, edge stability & Excellent & None specified \\
\hline $\begin{array}{l}\text { Milling times, normal milling mode } \\
\text { MCXL }\end{array}$ & $\begin{array}{l}\text { Inlay: 7:56 min } \\
\text { Anterior crown: 7:10 min } \\
\text { Posterior crown: 9:07 min }\end{array}$ & None specified \\
\hline Milling times, fast milling mode MC XL & $\begin{array}{l}\text { Inlay: 4:40 min } \\
\text { Anterior crown: 4:19 min } \\
\text { Posterior crown: 5:13 min }\end{array}$ & None specified \\
\hline $\begin{array}{l}\text { Milling tool service life: posterior } \\
\text { crowns }\end{array}$ & $\begin{array}{l}\text { Normal: } 148 \\
\text { Fast: } 132\end{array}$ & None specified \\
\hline Biocompatibility & Confirmed & ISO 10993 \\
\hline Chemical solubility [ $\mu \mathrm{g} / \mathrm{cm} 2]$ & 0.0 & ISO 6872: $\leq 100$ \\
\hline Water absorption $[\mu \mathrm{g} / \mathrm{mm} 3]$ & 5.7 & ISO 10477: $\leq 40$ \\
\hline Solubility in water $[\mu \mathrm{g} / \mathrm{mm} 3]$ & $\leq 1.2$ & ISO 10477: $\leq 7.5$ \\
\hline
\end{tabular}




\section{iv. Marginal and internal fit}

Marginal and internal accuracy of fit has been considered essential in assuring clinical success of all ceramic crowns (56).

Some of the reported complications resulting from poor marginal fit are dissolution of the luting agent (2), microleakage $(3,6)$, caries $(2,3$, and 6$)$, hypersensitivity and periodontal inflammation $(5,7,57-59)$

However White et al. in 2005, found no correlation between marginal discrepancy and microleakage (60).

Holmes et al. introduced a classification for marginal gap in 1989. They measured "misfit" as internal gap, marginal gap, vertical marginal discrepancy, horizontal marginal discrepancy, overextended margin, underextended margin, absolute marginal discrepancy and seating discrepancy. According to their classification "the perpendicular measurement from the internal surface of the casting to the axial wall of the preparation is called the "internal gap", and the same measurement at the margin is called the "marginal gap". "Absolute marginal discrepancy "was defined as the angular combination of horizontal and vertical discrepancies and represents the total misfit of the restoration (13).

According to American Dental Association (ADA) specification No.8, the preferred cement space standard ranges from $25-50 \mu \mathrm{m}(61)$.

McLean and Von Fraunhofer proposed a marginal gap and cement thickness of less than $120 \mu \mathrm{m}$ for successful restorations after evaluating more than 1000 crowns after five years of service (14). Other authors have also agreed on this range of marginal discrepancy $(33,35)$.Christensen reported an acceptable range of 34-119 $\mu \mathrm{m}$ for marginal gap (62).A marginal gap width range from $1 \mu \mathrm{m}$ to $116 \mu \mathrm{m}$ for conventionally fabricated all-ceramic crowns can be found in the literature (32, 63-65). Bindl et al. reported marginal gap of $59 \mu \mathrm{m}$ for CEREC CAD/CAM anterior crowns. In this study CEREC 2 unit and Mark II (Vita) were used (66). 
Nakamura et al. reported that the marginal fit of CEREC 3 CAD/CAM all-ceramic crowns changed when the setting for cement space was altered from $10 \mu \mathrm{m}$ to $30-50 \mu \mathrm{m}$. The marginal fit of the crowns with the cement space setting of 30-50 $\mu \mathrm{m}$ created a marginal gap range of 53-67 $\mu \mathrm{m}$. When a cement space setting of $10 \mu \mathrm{m}$ was used marginal gap range of 95-108 $\mu \mathrm{m}$ was observed (67).

Bindle and Mormann evaluated the marginal and internal fit of ceramic crowns fabricated from Slip-cast (In-Ceram Zirconia), heat-pressing (Empress II) and CAD/CAM crown-copings (Cerec inLab, DCS, Decim and Procera). Marginal gaps ranged from 17 to $43 \mu \mathrm{m}(56)$.

Lee et al in 2007, compared the marginal gap of all-ceramic crowns fabricated using two different CAD/CAM systems (Procera and CEREC 3D crowns) (68).In the single layer system (CEREC 3D), the entire crown was milled from a single block. In the double layer technique (Procera crowns) a high strength core was milled using the CAD/CAM system, porcelain was then added to the copings and subjected to a porcelain firing cycle. This study reported a marginal gap of $94 \mu \mathrm{m}$ for the CEREC 3D crowns milled from ceramic blocks. No significant differences were found in the marginal discrepancies of crowns fabricated with either method. However, the marginal gaps of Procera copings were reported smaller than Procera crowns. This suggested a negative effect of the firing cycle on the fit of the crowns made from the double layer technique (26).

In a 2010 study, Riech et al. evaluated 20 single crowns made by the CAD/CAM system using lithium dicilicate (Emax CAD LT) blocks. They found mean marginal gaps of $100 \mu \mathrm{m}$ and mean internal gaps of 148-284 $\mu \mathrm{m}$ for the lithium disilicate CAD/CAM crowns (69).

Anadioti et al. evaluated the marginal fit of pressed and CAD/CAM lithium disilicate crowns made from digital and conventional impressions. Marginal gaps were less than $90 \mu \mathrm{m}$. In this study the conventional impression and press fabrication showed significantly smaller marginal gaps compared to CAD/CAM fabricated crowns. However, the mean marginal gaps were still less than $120 \mu \mathrm{m}(25,31)$. 


\section{v. Cement space and marginal fit}

In 1994 Wilson found a correlation between increased cement space and decreased seating discrepancy. His study showed that for a minimal amount of seating discrepancy, at least $40 \mu \mathrm{m}$ of cement space is required when luting an artificial crown with zinc phosphate cement. He further concluded that the amount of cement space has a significant effect on crown seating (70).

Cement thickness has been found to have an effect on the fracture resistance and flexural stress loads on the ceramic crowns (71).

Tuntiprawon and Wilson studied the effect of increasing cement thickness on the fracture resistance of all ceramic crowns. They used varying layers of tin foil as a spacer in three groups of aluminous porcelain jacket crowns. They subsequently cemented the crowns on the metal dies with zinc phosphate cements and applied load until fracture was occurred. Their study found that as the cement thickness increased above $70 \mu \mathrm{m}$ there was a decrease in fracture strength of the ceramic crowns can be observed (9).

Nakamura et al. achieved better marginal fit of CEREC 3 CAD/CAM all-ceramic crowns when the cement space was increased to $30-50$ um compared to 10 um cement space (67).

\section{vi. Type of finish line and marginal fit}

Different finish line designs can affect successful crown seating during cementation. The influence of various preparation finish lines (shoulder, chamfer, feather edge, and bevel) on the fit of PFM crowns

during cementation was investigated by Gavelis et al. in 1981. Cement thickness and the axial walls of the prepared tooth can affect the seating of the crown. When the walls of the prepared tooth and the internal surface of the crown closely align, there is a decrease in the escape pathway for the cement. This creates 
hydrostatic pressure equal to the biting force which prevents the crown from complete seating. This study concluded that certain finish line designs such as a 90 degree full shoulder can create a better escape pathway for the luting agent and therefore allows better seating of the crown (72).

A more recent study evaluated, cervical adaptation of metal crowns under three different conditions. The influence of the finish line (chamfer, 135 degree shoulder, and rounded shoulder), influence of internal relief (30 $\mu \mathrm{m}$ internal relief), and influence of the cement type (glass ionomer, Zinc phosphate and resin cement) was investigated on the marginal fit of the crowns. Results of this in vitro study indicated that the marginal adaptation of the crowns on the dies with a chamfer finish line regardless of the type of the cement and existence of internal relief were superior to that of the other groups (73).

The type of finish line is one of the factors that have been investigated in many studies for all-ceramic crowns $(31,32)$. Pera et al in 1994, advocated heavy chamfer and shoulder finish lines for all-ceramic crowns (12). Some other studies like Quintas et al, reported that the type of margin did not influence the marginal fit of ceramic crowns (74-78).

In 1998, Lin et al. investigated the effect of the tooth preparation on the fit of Procera copings. He measured the external marginal gaps of cemented copings using 4 different finish lines. Feather-edge, chamfer, $0.8 \mathrm{~mm}$ rounded shoulder and $0.5 \mathrm{~mm}$ rounded shoulder. According to the results of this study, a feather-edge finish line cannot be well reproduced while designing CAD/CAM crowns. Chamfer and shoulder finish lines showed similar marginal gaps (76).

Akbar et al. evaluated marginal adaptation of CEREC 3 CAD/CAM composite crowns using chamfer and shoulder finish lines. In this study two different methods for assessing marginal adaptation were used 1) modified United States Public Health Service (USPHS) criteria, 2) Scanning electron microscope (SEM).They reported no statistically significant difference in marginal adaptation between the two different finish lines tested (32). 
In 2007 Tsitrou et al. evaluated the marginal fit of three margin designs (shoulder, chamfer and bevel) of CAD/CAM composite crowns. The crowns were milled using the CEREC system. They measured marginal gap using two different techniques: replica technique and a cross sectioning technique. Crowns were cemented with resin composite cement and then sectioned and the margins were viewed with a travelling microscope. The result of their study showed that CEREC 3 generated shoulder, chamfer and bevel finish lines all offered the same level of marginal adaptation (31).

In 2012, Subasi et al. looked at marginal fit of two ceramic copings fabricated on machined stainless steel dies using chamfer and rounded shoulder finish lines. Copings were cemented with resin cement. A stereomicroscope was used for direct measurement of marginal gap of the copings. They concluded that neither ceramic types nor finish line designs influenced the marginal adaptation of the copings (78).

\section{vii. Cementation and marginal fit}

One of the factors that can influence the measurement of marginal fit of crowns is whether or not the marginal gap is measured on a cemented or an uncemented crown. Marginal discrepancy can be increased following cementation. Some studies have found a significant increase in marginal gap values after cementation of all-ceramic crowns. $(12,79-82)$

Ural et al. evaluated the marginal adaptation of restorations made with five different ceramic systems: 1.CAD/CAM, 2. heat-press, 3. glass-infiltration, and 4. conventional lost-wax techniques, before and after cementation. In their investigation ceramic restorations fabricated with the CEREC 3 system showed the least marginal discrepancy. The result of the comparison of marginal gap values before and after cementation suggested significantly higher marginal gap values after cementation (82).

Two factors that can influence the marginal fit of a crown following cementation are: the type of cement used (73) and the luting technique (83-85). 
In another study, Martinez et al. evaluated the effect of the different luting agents on marginal fit of zirconium oxide-based all-ceramic crowns. In this in vitro study, glass-ionomer cement and resin cement were used to cement crowns fabricated via two different ceramic systems. Marginal gap values were measured using SEM. Resin cement showed higher values of marginal discrepancy than did the glass ionomer cement (86).

Grajower and Pilo suggested that cementation techniques which cause oblique seating of a crown can result in incomplete seating. Uneven film thickness on axial walls during cementation can result from overfilling of the restoration with cement. Excess cement within the crown acts as a lubricant permitting slight movement of the crown during seating according to the direction of the applied seating force (87, 88). This may cause an uneven flow of cement with one axial wall having a thicker film than the opposite wall (87).

\section{viii. Measurement methods for marginal fit}

Multiple techniques have been used for measuring the marginal gap values of partial and full coverage restorations. Each method has its advantages and disadvantages.

In 1990, Sorenson categorized the measurement methods for marginal and internal discrepancies of crowns into 4 groups (89):

1) Direct view technique,

2) cross sectional,

3) impression technique,

4) Visual examination (explorer). 
One of the methods is the use of a dental explorer to detect marginal discrepancies. In a study by Hyashi et al. it was concluded that the diameter of the tip of the explorer can have an effect on detection of horizontal marginal openings but not the vertical gaps (90). They looked at the influence of instrument type and clinical experience level of the operator to detect a clinically acceptable crown margins in a laboratory setting. This study found no difference between the type of instrument used and detection of marginal gaps. Clinicians with higher levels of clinical experience did not accept crowns with smaller gaps compared with those clinicians with less clinical experience (91). One of the disadvantages of this method is the limitation for detecting crown marginal gaps with subgingival finish lines.

The methods reported in literature for measuring the marginal gap of crowns can be categorized into two groups:

1) Non-destructive (non-invasive): methods such as replica technique (31).

2) Destructive (invasive): methods such as cross-sectioning method (31).

A literature review reported in 2013, looked at 180 articles related to methods used for measuring the marginal adaptation of crowns and fixed partial dentures (37). According to this study, six methods of measurement had been reported in the literature. The direct view technique was used most frequently. The Cross-sectioning method and impression replica technique were the next most popular methods (37).

\section{Direct view technique}

This is an in vitro, non- destructive method that does not require any damaging of the restoration and die (31). This method can achieve more accurate results due to elimination of error accumulation from multiple steps (31).

However, this method has some disadvantages: 
1) Differentiation between the tooth margin and the cement layer can be challenging (31).

2) Accurately finding the points of measurements can be difficult $(31,92)$.

3) Projection error due to magnification can make the margins appear rounded (92-94).

Examples of this method are direct view of marginal adaptation of the restorations under high power microscopy or utilizing Scanning Electron Microscopy (SEM).

Sulaiman et al. used digital microscopy for measuring marginal gap utilizing three different types of allceramic restorations (In-Ceram, Procera, and IPS Empress). They reported significant differences in the marginal fit of all three all-ceramic systems (64).

Petteno et al. used a stereomicroscope to compare the marginal adaptation of different meta-ceramic systems (95).

Romeo et al. used a stereomicroscope (50X magnification) and computer software to measure the marginal gap of crowns fabricated from different CAD/CAM materials. This method of measuring marginal gap cannot be used if an overlay is present (96).

Tan, et al. used a digital camera to take images of a seated crown on a die. The image was then transferred to software for digital measurements. This study compared the marginal fit of CAD/CAM and conventionally fabricated restorations (97).

Albert et al. used a travelling microscope to evaluate marginal fit and adaptation of porcelain crowns cemented with 4 different types of cements (85). 


\section{Scanning Electron Microscopy (SEM)}

In another type of direct view technique the sample margins are viewed under the Scanning Electron Microscopy (SEM).The die and crown assembly are usually spattered with gold and viewed directly under SEM (56). To measure internal gap, the crowns are luted to the die and then cross sectioned. Measurements are made on the gap area filled with the cement (56).

Groten et al. compared the marginal fit of copy-milled ceramic crowns utilizing two different measuring techniques. They utilized light microscopy and SEM. The results of their study showed no significant difference in the accuracy between the two different methods. However according to the authors observations can be more realistic and appropriate with SEM than with light microscopy (93).

Gonzalo et al. compared the accuracy of Image analysis and SEM for measuring marginal discrepancy of posterior FPDs fabricated with two different materials. Zirconia using computer-aided design/manufacturing technology and metal-ceramic using the conventional lost-wax technique. Statistical analysis of the marginal gap values suggested a significant interaction between method of measurement and the material. The image analysis system showed lower values of marginal gap compared with those of SEM except for metal ceramic FPDs (98).

\section{Cross-sectioning method}

This system depends on sectioning the samples after cementation. The cement width at the margin level can be measured directly both in the vertical and horizontal planes (99).This method limits the number of sections and measurements on each specimen. The values might not represent the marginal adaptation of the complete crown (92). 
Another disadvantage of this destructive method is that it eliminates the possibility of making measurements before and after processing the samples $(100,101)$.

\section{Profilometery}

Profilometery is a nondestructive method used by Mitchell et al. to comparing the marginal fit of four types of complete crowns. They studied the influence of the type of crown (bonding alloy with chamfer finish line, gold alloy with chamfer finish line, porcelain with chamfer and porcelain with shoulder finish line) and tooth surface morphology (grooved, ungrooved) on the marginal adaptation of the crown. According to this study, profilometery can provide a comprehensive sequence of the changes in crowntooth relationship around a specimen. They found this method to be accurate for evaluation of absolute marginal discrepancy. However, profilometery provides an indirect method for measurement and cannot identify vertical overextensions $(92,100)$. With this method, accurate repositioning of the specimens in sequential analysis should be handled with care to eliminate re-profiling discrepancies (99).

\section{Replica Technique}

Several studies have used the replica technique as a non-invasive method to evaluate the fit of restorations $(1,92,102-107)$.

Two different techniques have been used. One replica method described by Molin and Karlsson was used to fabricate a replica from the intermediate space between the preparation surface of the tooth and inner surface of the crown. This was accomplished by filling the intaglio of the crown with light body silicone impression material before placing the crown on the die (92). After the impression material had set, the crown was removed. Heavy body silicone impression material was used to stabilize the thin layer of light 
body material inside the crown. The light body film could then be removed from the inside of the crown and sectioned for measuring thickness at different areas (1). Another method is making an external impression from the marginal gap after fixing the crown on the die (37).

Boeing et al. used the replica technique as an in vivo method to measure marginal gap of Procera allceramic crowns. They injected light body silicone inside the crown. The replica was then sectioned and the thickness of the film was measured under a light microscope (1).

This technique has several advantages:

-identifying the crown margin and the finish line can be challenging (37).

-With a replica technique only a limited number of measurements can be made for each specimen (92).

- The thin film layer can easily tear upon removal (102).

- Sectioning errors can lead to overestimated measurements (102).

There are studies that have used two different methods to measure the same samples and then compared the results. Shearer et al. evaluated the fit of In-Ceram crowns utilizing a direct sectioning technique prior to measurement and also via cement analogue technique using addition polyvinylsiloxane impression material. They reported the marginal fit of $8.3 \mu \mathrm{m}$ for sectioning method and and $28.6 \mu \mathrm{m}$ for cement analogue technique (replica technique). According to their results the accuracy of sectioning was superior to replica technique (108).

Tsitrou et al. used a combination of the replica technique and the cross sectioning method (crowns cemented with resin cement) to evaluate the marginal fit of CEREC crowns to fit two different finish lines (chamfer, bevel). The results of their study showed no statistical difference in the mean measurements of these two different techniques (31). 
Rahme at al. conducted a study to investigate the validity of the replica technique. In this study they challenged the theoretical rational of using the replica technique to evaluate marginal adaptation of crowns. In theory it has been assumed that light body silicone impression material used in the replica technique has the same film thickness as the luting agent used to cement a crown. Since silicone impression material and cements have different physical properties, this study aimed to compare the replica technique to the traditional cementation technique. Twenty replicas were fabricated for 10 incisors and 10 premolars. The Procera crowns were cemented on the same dies with Glass ionomer cement and sectioned. Measurements were made under an optical microscope. After comparison of the marginal gap values, it was concluded that there was no significant difference between the marginal gap values of the replica technique compared with the cementation method. This study reported the the replica technique was an accurate and reliable method for marginal space measurement $(109,110)$.

\section{3-D analysis of marginal fit}

A variation of the replica technique was employed by Luthardt et al., which it involved digitizing the dies and the replica film (the space between the die and the crown) with a digital scanner. In this study, a 3-D analysis of the internal fit of CAD/CAM crowns fabricated after direct optical versus indirect laser scan digitizing was made. Result s of this study showed that scanning the impression made from the master die can result in fabrication of crowns with better marginal fit compared to direct optical acquisition of the master die. However, the differences were minimal (110).

Later in 2011, a triple scan protocol for evaluation of 3D fit of crowns was used by Holst et al. They developed a new protocol to provide 3D information for virtual registration of the digitized crown with respect to the abutment. Ten CAD/CAM titanium crowns were fabricated for 5 gypsum molar master casts. The cement spaces between the fifty crowns and their abutments were measured three times. No 
significant difference between the measurements was found. The authors concluded that the triple scan protocol was a reliable registration approach for surface data sets in dental applications (111).

Anadioti et al. designed a study to validate the reliability of the triple scan measurement protocol. They used the triple scan protocol described by Holst et al. to evaluate the 2D and 3D marginal fit of pressed and CAD/CAM generated lithium disilicate crowns fabricated from digital and conventional impressions. Thirty casts were made from polyvinyl siloxane impression (PVS) of a detoform tooth \#30 and thirty resin models were made by digital impressions using a Lava scanner. Each group was divided in to two groups of fifteen for fabricating IPS emax pressed crowns and IPS emax CAD crowns. Three scans were made from: 1) The master die, tooth \#30, 2) the Intaglio surface of each crown, and 3) Each crown on the master die in the ideal clinical position. The STL data sets were made and used for measuring the marginal gap. Digital sections were delineated on the facial-lingual and the mesio-distal surfaces. The gaps were measured at four standardized points. Result of this study showed that there were no statistical differences between the 2D and 3D measurements of marginal fit for the crowns. It was concluded that this measurement protocol is reliable (31).

\section{Micro CT (microtomography)}

This new method is considered a non-invasive technique for evaluating restorations (112-114).Micro CT can be used for assessing 2D and 3D marginal and internal adaptation of the restorations. One other advantage of this technique is that it allows for multiple points and directions of measurements within the range of few micrometers (113).

Pelekanos et al. conducted a study to assess the marginal fit of different In-Ceram alumina cores fabricated by means of four different techniques using micro-CT. A microtomography device was used to 
scan the cores seated on the master die. Using the software, ten core microtomographic cross-sections (vertical sections) were made of each core. The marginal gap was measured in microscales (114).

Micro-CT as method of assessment for marginal and internal fit of all-ceramic three unit fixed partial dentures was reported by Borba et al. In this study ten fixed partial dentures were made from CAD/CAM blocks of two different ceramic materials (YZ - Vita In-Ceram YZ and IZ - Vita In-Ceram Zirconia). CEREC inLab was used for fabricating the restorations. One of the reported limitations of this system was difficulty in the $3 \mathrm{D}$ analysis of the limits between the die and the restorations due to small radiographic artifacts caused by the asymmetric shape of the fixed partial dentures (112).

\section{ix. Experimental set-up for marginal gap measurement}

Different experimental set-ups have been designed by many researchers to measure the marginal adaptation of restorations. As a result of all the inconsistency in experimental designs, conflicting conclusions have been reported regarding marginal adaptation of different ceramic systems (37).

\section{In vivo vs. in vitro studies}

In vivo experiments because of the conditions of oral cavity, preparing teeth and accessibility to the margins can be challenging (1). Also environmental factors such as, salivary flow, bleeding, location of the finish line and patient compliance can jeopardize the quality of impressions in an in vivo setting (115). For marginal gap assessment the only in vivo method used in the literature is the replica technique. All other methods have been reported in in-vitro studies (92)

To minimize the effect of environmental factors and replicate optimized clinical conditions a welldesigned in vitro study should be conducted (92). In an in vitro setting, experiments can be performed 
under standardized and ideal conditions. An almost perfect preparation and margins can be achieved (37, 92).

\section{x. Number of measurements per sample}

Adequacy of data has an important role in the strength of the statistical analysis and the conclusions drawn from the results (37). Different suggestions have been made concerning the sample size for assessment of marginal fit of restorations $(94,116)$. For greater precision in data analysis a larger number of measurements per sample are necessary (116).

Groten et al. conducted a study to determine the minimum number of marginal gap measurements in an in vitro study. He measured the marginal gap of 10 all-ceramic crowns fabricated of on a master steel die before and after cementation via SEM. For assessment of marginal adaptation they recommended a larger number of measurements to compensate for the smaller sample size. He suggested 50 marginal gap measurements per sample. This limits the numerical variance to _ $+5 \mu \mathrm{m}(94)$.

A study by Lee et al. compared the marginal adaptation of all-ceramic crowns fabricated from two different CAD/CAM systems (Procera and CEREC 3). The marginal gap measurement was made on ten CAD/CAM generated.samples. Fifty measurements were made of each sample (23).

Gassino et al. argued that the number of measurements suggested by Groten in an in vitro study in 2004 concluded that 18 measurement sites per sample is necessary for marginal gap assessment of experimental crowns that are fabricated on laboratory made abutments and 90 measurement points for crowns that are fabricated from an intra-oral impression (116).

A literature review study of 183 articles on the methods used for investigating marginal adaptation of dental restorations concluded that reliable results for marginal adaptation of restorations can be achieved by fifty measurements per sample (37). 


\section{b. REVIEW OF COMPUTER-AIDED DESIGN/COMPUTER- AIDED MANUFACTURING (CAD/CAM) SYSTEMS AND MATERIALS}

With the advancement of technology and introduction of newly produced materials in dentistry the conventional lost wax techniques is being substituted by computer assisted fabrication system (CAD/CAM) (117).

The pioneers in CAD/CAM dentistry were Duret et al. in early 1970s. They even introduced the commercial Sopha system which did not gain popularity at the time. The profession was not ready for such application due to limitations of digitizing and computer systems at that time $(117,118)$.

The chairside CEREC system was developed by Mormann and colleagues in mid 1980s and since then demand for CAD/CAM technology in dentistry has increased dramatically. Using computer assisted technology the first generation of the CEREC system was designed for fabrication of ceramic inlays and onlays (119).

A Swiss dentist, Dr. Werner Mörmann, and an Italian electrical engineer, Marco Brandestini, introduced the first digital intraoral scanner. It evolved into CEREC ${ }^{\circledR}$ by Sirona Dental Systems LLC (Charlotte, NC) in 1987, and was the first commercially available CAD/CAM system for dental restorations (120121).

Today many different digital impression systems and CAD/CAM milling systems have been introduced to the dental market. With availability of systems capable of capturing 3D virtual images from the tooth preparation, the restorations can be made directly chairside with CAD/CAM systems or can be made in a remote dental laboratory from an accurate master model of the tooth preparation (120). 
The CAD/CAM process is capable of three types of production:

1) Chairside production: in this type of production all of the system components are available at the dental office. Scanning, data processing and fabrication all happens chairside.

2) Laboratory production: the work flow in this type is similar to the traditional methods of communication between the dentist and laboratory. An impression is sent to the laboratory and all the $\mathrm{CAD} / \mathrm{CAM}$ equipment for design and fabrication of the prosthesis are located at the laboratory. The scan of master cast, 3D design of the prosthesis and milling the products takes place remotely.

3) Centralized production: in this type of production the scanner and software is located at the dental office. The imaging and restoration design are under the control of the dentist. Data sets are sent to the laboratory for CAD/CAM fabrication of the product. Production of full arch restorations for extended rehabilitation can be conducted on centralized CAD services (122).

According to Beuer et al. all three components can be identified for all CAD/CAM systems (123).

\section{Scanner (digitalization tool):}

a. optical scanner: This type of scanner uses a "Triangulation procedure" for capturing 3D structures. The illumination source is either white light projection such as Everest scan (KaVo), Lava scan ST (3M ESPE) or laser beam such as esl (etkon).

b. Mechanical scanner: This type of scanner uses a "ruby ball" to read the master cast for 3D measurements. This measurement technique has very high accuracy; however it is complicated and expensive. An example of this system is Procera scanner (Nobel Biocare)

\section{The data processing software}

Different softwares are available for designing various types of restorations. Most softwares collect data in the standard transformation language (STL) format. Some systems use their own construction format which is designed for that specific manufacturer. 


\section{A production (milling) system}

Three categories of milling devices exist based on their milling axis:

a. 3- axis milling device has degrees of movement in three spatial directions (X-, Y-and Z-values).

"Therefore calculation investment is minimal. A milling of subsections, axis divergence and

convergences are not possible. In the dental area these devices can turn the component by 180 degree in the course of processing inside and the outside. They have the advantages of short milling time and simplified control by means of three axes."

Examples: Inlab (Sirona), Lava (3M ESPE), Cercon brain (DeguDent)

b. 4-axis milling device has three spatial axes and a rotational tension bridge. With this device bridge construction with a large vertical height displacement can be adjusted into the usual mould dimensions and thus save material and milling time.

Example: Zeno (Wieland-Imes)

c. 5-axis milling device has the three spatial axes, rotatable tension bridge and rotation of the milling spindle. With this device milling of complex structures with subsections and convergence is possible.

Examples: Everest Engine (KaVo).

HSC Milling Device (etkon).

There are two variants of milling:

Dry processing: used for zirconium oxide blanks with a low degree of pre-sintering.

Wet processing: The milling burs are protected with a spray of cold liquid mainly to protect all metals and glass ceramic material from heat damaging (123). 
CAD/CAM material can be processed in different density stage.

Green stage processing occurs when the block has neither been heat treated nor pre-sintered. The material is soft and processing with carbide burs is easy and cooling is not necessary. The problem with green stage processing is low stability of the material and open porosity which causes $5 \%$ linear shrinkage after firing. Green stage processing is not used for zirconium oxide.

White stage processing is when the blank has been heat treated and pre-sintered therefore exhibits more stability and 5\% of the shrinkage has already took place due to pre-sintering. CAD/CAM material can be milled with carbide burs without cooling or diamond burs with cooling (123).

In a study by Beuer et al. CAD/CAM materials are classified into 5 categories (123):

1. Metals: titanium, titanium alloys, chrome cobalt alloy,

Exp: Coron (etkon: non precious metal alloy)

Everest Bio T-Blank ( KaVo, pure titanium)

\section{Resin Material:}

They are available for both single crowns and fixed partial denture frameworks for long term provisional restorations.

Exp: CAD-Waxx (Vita)

Cercon base cast (deguDent)

Everest C-Cast $(\mathrm{KaVo})$

CAD-Temp Block (Vita)

Artegral imcrown (Merz)

3. Silica based ceramics: Are used for inlays, onlays, veneers, partial crowns, full crowns.

They are produced in monochromatic and polychromatic layered blocks [Vitablocs TriLuxe (Vita), IPS Empress CAD Multi (IvoclarVivadent)]. 
Many studies have been conducted on lithium disilicate which belongs to this group of materials. It demonstrates high mechanical stability of $360 \mathrm{MPa}(32,124-126)$.

Lithium disilicate blocks are used for full anatomical anterior and posterior crowns, copings and anterior FPD frameworks.

Glass ceramics are aesthetically pleasing and show translucency characteristics similar to tooth structure.

They are etchable due to their high proportion of ceramic and can be luted with adhesive cement systems (127).

\section{Infiltration ceramics:}

The blocks are chalky and porous in processing and then they are infiltrated with lanthanum glass.

The Vita In-Ceram system has three variants of this class of material
a. Vita In-Ceram Alumina (A12 O3 )

Used for anterior and posterior crowns and anterior three unit FPD frameworks.

b. Vita In-Ceram Zirconia (70\% A12 O3, 30\% ZrO2 )

Used for anterior and posterior crown copings, anterior and posterior three unit FPD frameworks. This material has masking ability suitable for discolored abutments.

c. VITA In-Ceram Spinell (MgAl2 O4 )

This material exhibits high translucency and can be used for highly aesthetic anterior crown copings.

\section{Oxide high performance ceramics}

a. Aluminum Oxide (A12O3)

This material is milled in a pre-sintered phase and then sintered at a temperature of $1520{ }^{\circ} \mathrm{C}$.

Indication: anterior and posterior crown copings, primary crowns and three-unit anterior fixed partial denture frameworks.

Exp: In-Ceram AL Block (Vita)

inCoris $\mathrm{Al}$ (Sirona) available in an ivory-like color (Color F 0.7). 
b. Yttrium stabilized zirconium oxide (ZrO2, Y-TZP)

An yttria-stabilized tetragonal zirconia polycrystalline (Y-TZP) ceramic is formed by addition of a stabilizer, such as yttria, to zirconia-based ceramics which stabilizes the zirconia in the tetragonal phase $(128,129)$.

Stabilizing the tetragonal phase at room temperature can prevent the transition to the monoclinic phase and progression of cracks in the ceramic which is referred to transformation strengthening (130-132).

Exp: Lava Frame (3M ESPE)

Cercon Smart Ceramics (DeguDent)

Everest ZS und ZH (KaVo)

inCoris Zr (Sirona)

In-Ceram YZ (Vita)

zerion (etkon)

Zeno Zr (Wieland-Imes) 


\section{i. REVIEW OF INTRA-ORAL SCANNERS}

Since the 1987 introduction of CEREC® by Sirona Dental Systems LLC (Charlotte, NC), the first commercially CAD/CAM system for dental restorations, other manufacturers have improved their technology to create intra-oral scanners that can be used in a dental office for fabrication of accurate restorations (133).

Intra-oral scanning devices can capture three dimensional virtual images of tooth preparations; Using CAD/CAM systems restorations may be directly fabricated from these images, or accurate master models can be made in dental laboratory (120).

The technology of capturing digital impressions using intra-oral scanners was designed to overcome some of the problems and disadvantages of the traditional impression techniques, such as, instability of the impression material, pouring of the impression, laceration of margins, geometrical and dimensional discrepancy between the die and the mould. Some of the main advantages of using intra-oral scanners are the high accuracy of models, creation of 3D files, surgery simulation and simplifying the process (133).

In 2011 Logozzo et al. published a paper on comprehensive analysis of 3D dimensional scanners used in dentistry. They reviewed the characteristics and components of ten commercially available intra-oral scanning devices listed as below (133).

1. CEREC $®$ - by Sirona Dental System GMBH (DE)

2. iTero - by CADENT LTD (IL)

3. E4D - by D4D TECHNOLOGIES, LLC (US)

4. Lava $^{\mathrm{TM}}$ C.O.S. - by $3 \mathrm{M}$ ESPE (US)

5. IOS FastScan - by IOS TECHNOLOGIES, INC. (US)

6. DENSYS 3D - by DENSYS LTD. (IL)

7. DPI-3D - by DIMENSIONAL PHOTONICS INTERNATIONAL, INC. (US) 


\section{3D Progress - by MHT S.p.A. (IT) and MHT Optic Research AG $(\mathrm{CH})$ \\ 9. directScan - by HINT - ELS GMBH (DE) \\ 10. Trios - by 3 SHAPE A/S (DK)}

In a 2011 clinical trial, Cardelli et al evaluated the accuracy of fit of CAD/CAM zirconia single crowns fabricated using digital intraoral impressions with active wavefront sampling technology. A comparative table is presented from this study that summarizes the available digital impression systems of and their characteristics. Among the available digital impression systems E4D and CEREC are combined with a chairside milling machine CEREC system. They can also send the data to centralized milling services (134).Two new intra-oral scanning devices are not included in the table are the new models of 3M ESPE (i.e. True Definition Scanner) and of Sirona Dental System (i.e. CEREC® AC- Omnicam), which they have been added to the table below (31).

This study used the CEREC® AC- Bluecam by Sirona Dental System GMBH (DE) for scanning the master die. A description of the system as described in manufacturer's brochure follows below. 
Table 3: Digital impression systems

\begin{tabular}{|c|c|c|c|c|c|c|c|}
\hline $\begin{array}{l}\text { Intraoral } \\
\text { scanners }\end{array}$ & company & $\begin{array}{c}\text { Working } \\
\text { principles }\end{array}$ & $\begin{array}{c}\text { Light } \\
\text { source }\end{array}$ & $\begin{array}{l}\text { Imaging } \\
\text { type }\end{array}$ & coating & $\begin{array}{l}\text { In- } \\
\text { office } \\
\text { milling }\end{array}$ & $\begin{array}{l}\text { Output } \\
\text { format }\end{array}$ \\
\hline $\begin{array}{c}\text { CEREC® } \\
\text { AC- } \\
\text { Omnicam }\end{array}$ & $\begin{array}{l}\text { Sirona Dental } \\
\text { System } \\
\text { GmbH (DE) }\end{array}$ & $\begin{array}{l}3 \text { dimentional video } \\
\text { based scanning } \\
\text { technology }\end{array}$ & White light & video & None & Yes & Proprietary \\
\hline $\begin{array}{l}\text { CEREC®A } \\
\text { C-Bluecam }\end{array}$ & $\begin{array}{l}\text { Sirona Dental } \\
\text { System } \\
\text { GmbH (DE) } \\
\end{array}$ & $\begin{array}{l}\text { Active triangulation } \\
\text { and optical microscopy }\end{array}$ & $\begin{array}{c}\text { Visible } \\
\text { blue light }\end{array}$ & $\begin{array}{l}\text { Multiple } \\
\text { images }\end{array}$ & Yes & Yes & Proprietary \\
\hline iTero & $\begin{array}{l}\text { Cadent Inc } \\
\text { (IL) }\end{array}$ & $\begin{array}{l}\text { Parallel confocal } \\
\text { microscopy }\end{array}$ & Red laser & Multiple & None & No & $\begin{array}{c}\text { Proprietary } \\
\text { or selective } \\
\text { STL } \\
\end{array}$ \\
\hline E4D & $\begin{array}{c}\text { D4D } \\
\text { Technologies } \\
\text {, LLC (US) } \\
\end{array}$ & $\begin{array}{l}\text { Optical coherence } \\
\text { tomography and } \\
\text { confocal microscopy }\end{array}$ & Laser & Multiple & Occasional & Yes & Proprietary \\
\hline $\begin{array}{l}\text { Lava }^{\mathrm{TM}} \\
\text { C.O.S. }\end{array}$ & $\begin{array}{l}\text { 3M ESPE } \\
\text { (US) }\end{array}$ & $\begin{array}{l}\text { Active wavefront } \\
\text { sampling }\end{array}$ & $\begin{array}{c}\text { Pulsating } \\
\text { visible blue } \\
\text { light }\end{array}$ & video & Yes & No & Proprietary \\
\hline $\begin{array}{c}\text { IOS } \\
\text { FastScan }\end{array}$ & $\begin{array}{c}\text { IOS } \\
\text { Technologies } \\
, \text { Inc (US) } \\
\end{array}$ & $\begin{array}{c}\text { Active triangulation } \\
\text { and Schleimpflug } \\
\text { principle }\end{array}$ & laser & 3 images & Yes & No & STL \\
\hline MIA3d & $\begin{array}{l}\text { Densys Ltd } \\
\text { (IL) }\end{array}$ & $\begin{array}{c}\text { Active } \\
\text { stereophotogrammetry }\end{array}$ & $\begin{array}{c}\text { Visible } \\
\text { light }\end{array}$ & 2 images & Yes & No & $\mathrm{ASCH}$ \\
\hline DPI-3D & $\begin{array}{l}\text { Dimensional } \\
\text { Photonics } \\
\text { International, } \\
\text { Inc (US) }\end{array}$ & $\begin{array}{c}\text { Accordion fringe } \\
\text { interferometry (AFI) }\end{array}$ & $\begin{array}{c}\text { Wavelengt } \\
\text { h 350-500 } \\
\mathrm{nm}\end{array}$ & $\begin{array}{l}\text { Multiple } \\
\text { images }\end{array}$ & None & No & STL \\
\hline 3D Progress & $\begin{array}{c}\text { MHT SpA } \\
\text { (IT)-MHT } \\
\text { Optic } \\
\text { Research AG } \\
\text { (CH) } \\
\end{array}$ & $\begin{array}{l}\text { Confocal microscopy } \\
\text { and Moireİ` effect }\end{array}$ & $\begin{array}{c}\text { Not } \\
\text { disclosed }\end{array}$ & 3 images & Occasional & No & STL \\
\hline directScan & $\begin{array}{c}\text { Hint-Els } \\
\text { GmbH (DE) }\end{array}$ & Stereoscopic vision & $\begin{array}{c}\text { Not } \\
\text { disclosed }\end{array}$ & $\begin{array}{c}\text { Multiple } \\
\text { images }\end{array}$ & $\begin{array}{c}\text { Not } \\
\text { disclosed }\end{array}$ & No & $\begin{array}{c}\text { Not } \\
\text { disclosed }\end{array}$ \\
\hline Trios & $\begin{array}{c}\text { 3Shape A/S } \\
\text { (DK) }\end{array}$ & Confocal microscopy & $\begin{array}{c}\text { Not } \\
\text { disclosed }\end{array}$ & $\begin{array}{l}\text { Multiple } \\
\text { images }\end{array}$ & None & No & $\begin{array}{c}\text { Proprietary } \\
\text { or STL }\end{array}$ \\
\hline $\begin{array}{c}\text { True } \\
\text { Definition } \\
\text { scanner } \\
\end{array}$ & $\begin{array}{c}\text { 3M ESPE } \\
\text { (US) }\end{array}$ & Not disclosed & $\begin{array}{c}\text { Not } \\
\text { disclosed }\end{array}$ & $\begin{array}{l}\text { Multiple } \\
\text { images }\end{array}$ & Yes & No & $\begin{array}{c}\text { Cloud- } \\
\text { based or } \\
\text { STL } \\
\end{array}$ \\
\hline
\end{tabular}




\section{ii. CEREC® BY SIRONA DENTAL SYSTEM GMBH (DE) CEREC® (an acronym for Chairside Economical Restoration of Esthetic Ceramics)}

This system was introduced by Sirona Dental System GMBH (DE) in 1987, and it has undergone a series of technological improvements, culminating in the CEREC AC® powered by BlueCam®, launched in January 2009.

The latest version of the CEREC $®$ system are capable of producing inlays, onlays, crowns, laminate veneers, and even fixed partial dentures. It combines a 3D digital scanner with a milling unit to create inoffice dental restorations from commercially available blocks of ceramic or composite material in a single appointment (120).

The latest version of the milling system, CEREC inLab® MC XL, is capable of milling a crown in as little as 4 minutes. CEREC $®$ systems may be described as measurement devices that operate according to the basic principles of confocal microscopy and according to the active triangulation technique $(121,135$ 137).

A camera projects a changing pattern of blue light onto the object using projection grids that have a transmittance random distribution and which are formed by sub regions containing transparent and opaque structures (138).

Moreover, by means of elements for varying the length of the optical path it is possible, for each acquired profile to state a specific relationship between the characteristic of the light and the optical distance of the image plane from the imaging optics $(121,135)$.

The intensity of light detected by each sensor element is a direct measure of the distance between the scanner head and a corresponding point on the target object (122). 
As a disadvantage of the system, lies in the fact that the triangulation technique requires a uniform reflective surface since different materials (as dentin, amalgam, resins, gums) reflect light differently. Consequently it is necessary to coat the teeth with reflective powders prior to the scanning to provide uniformity in the reflectivity of the surfaces to be recorded. Earlier versions of CEREC® employed an acquisition camera with an infrared laser light source. The Bluecam version employs blue light-emitting diodes (LEDs); the intense blue light with a shorter wavelength projected by the blue LEDs allows for greater precision of the produced virtual model (see Figure 4). Even at the periphery, the images are distortion-free, so multiple images (e.g. of a complete quadrant) can be stitched together with great accuracy. The CEREC $®$ AC Bluecam offers image stabilization systems. This means that the practitioner does not have to rest the camera wand on a tooth to get a steady focus. The camera automatically captures an image when the wand is motionless, avoiding the need for a foot pedal (as the previous model required). It is now possible to scan full arches. Earlier versions of the device made a single image from one perspective. At the end of the scanning stage, the preparation is shown on the monitor and can be viewed from every angle to focus or magnify areas of the preparation. The "die" is virtually cut on the virtual model, and the finish line is delineated by the dentist directly on the image of the die on the monitor screen. Then, a CAD system, called "biogeneric", provides a proposal of an idealized restoration. The dentist can then make adjustments to the proposed design using a number of simple and intuitive onscreen tools. Once the dentist is satisfied with the restoration, he can mount a block of ceramic or composite material of the desired shade in the milling unit and proceed with fabrication of the physical restoration. During the design stage of the process the use of color-coded tools to determine the degree of interproximal contact helps to ensure finished restorations that require minimal, if any, adjustments prior to cementation. If the dentist has a standalone CEREC AC® system and he cannot perform in-office fabrications of restorations, can forward the digital impression data, using CEREC Connect ${ }^{\circ}$, directly to dental laboratory (121). 


\section{c. RESEARCH OBJECTIVES}

The purpose of this study was:

1. To compare the marginal fit of CAD/CAM copings made from two different CEREC blocks. (Lithiumdisilicate blocks after crystallization vs. Hybrid ceramic blocks) and determine if there is a relationship between the type of ceramic material and marginal adaptation.

2. To measure the marginal gap of lithium-disilicate blocks in two stages (before and after crystallization firing) and determine if there is a relationship between the firing cycle and marginal fit of lithiumdisilicate copings.

\section{d. RESEARCH HYPOTHESIS}

H0 (1): There is no difference in marginal fit of CAD/CAM copings made Hybrid ceramic (Vita Enamic) blocks and lithium-disilicate (IPS e-max CAD- Ivoclar Vivadent) blocks.

HA (1): There is a difference between marginal fit of CAD/CAM copings made with Hybrid ceramic (Vita Enamic) blocks and lithium-disilicate (IPS e-max CAD- Ivoclar Vivadent) blocks.

H0 (2): There is no difference between marginal fit of CAD/CAM copings made with lithium-disilicate (IPS e-max CAD- Ivoclar Vivadent) blocks before and after crystallization firing.

HA (2): There is a difference between marginal fit of CAD/CAM copings made with lithium-disilicate (IPS e-max CAD- Ivoclar Vivadent) blocks before and after crystallization firing. 


\section{CHAPTER 2}

\section{METHODS AND MATERIALS}

\section{i. Fabrication of the master die}

A standardized master stainless steel die was designed and fabricated at University of Pittsburgh, Swanson School of Engineering. Several CAD/CAM studies have used master metal dies (31, 68, 140146). The advantages of using a master metal die are a standard preparation, as well as wear resistance during fabrication procedures and measurements (68).

The finish line design for the master die in this study was designed to be a circumferential shoulder. In the literature there are studies that have investigated the influence of finish line design on the fit of CAD/CAM ceramic crowns. All studies concluded that there is no significant difference between marginal fit of ceramic crowns using finish lines of different designs $(23,24)$.

Specifications of metal master die are shown in figure 2:

The 8 degree tapered preparation had a 90 degree shoulder for a finish line.

A buccal anti-rotation flat surface with a 12 degree taper was prepared to enable identification of the buccal, lingual, mesial and distal surfaces to aid orientation of the coping under the microscope. The coping was designed to have a $2 \mathrm{~mm}$ thickness on the occlusal surface and a $1.5 \mathrm{~mm}$ thickness of the axial walls. A plastic coping was fabricated along with the master die to be used for scanning with CEREC $®$ AC Bluecam (Sirona) unit as a biogeneric reference. 
The stainless steel master die was mounted in a stone block. A Ney dental surveyor (Densply) was used to mount the mater die parallel to the base without any tilting. Rock Solid stone (Whip Mix) was poured into the base and was allowed to set for 30 min before removing the surveyor.

The base was trimmed to be square and was labeled on each surface. The surface facing the flat antirotation feature of the die was labeled as buccal. Mesial, distal and lingual surfaces were labeled accordingly (figure 2).

Two strips of red rope wax (HENRY SCHEIN) were placed on the mesial surface and the distal surfaces. On one side the rope wax was bent into the shape of a chevron and on the other side it was bent to form a half circle (figure 8). This was done to aid the CEREC software to be able to distinguish between the mesial and distal surfaces for the proper orientation of the coping. 


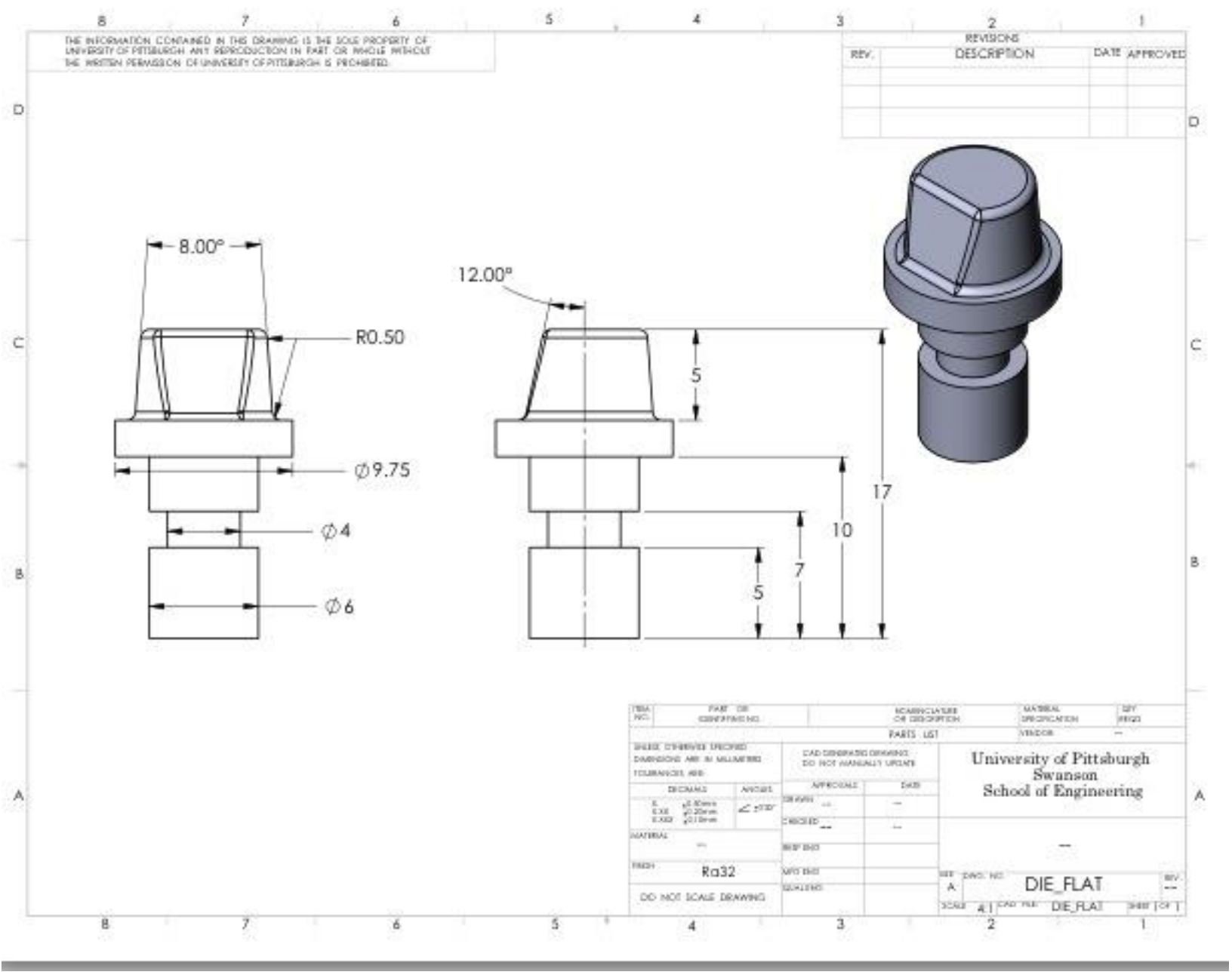

Figure 2: Stainless steel master die design 


\section{ii. Coping Design and fabrication}

CEREC 3 system (Sirona) with software version 4.3 .1 was used to scan and design the copings.

Tooth \#19 was selected as the site for crown fabrication with the setting of biogeneric copy.

The master die along with the rope wax markers on the base were sprayed with CEREC Optispray (Sirona).

The die was then scanned using the CEREC $®$ AC Bluecam. Multiple images were made of the master die including wax markers. Overlapped images were evaluated for satisfactory capture of all margins and surfaces of the master die.

A prefabricated coping was placed on the master die and sprayed with CEREC Optispray (Sirona). The die and the coping were scanned with CEREC $®$ AC Bluecam for a biogeneric copy. The overlapped images of the die and the coping were evaluated for proper seating of the coping.

System parameters were set according to the CEREC 3 (Sirona) manual for fabrication of all ceramic crowns. Cement space was set to $80 \mu \mathrm{m}$.

After the margins were traced on the virtual model, the final image was saved for fabrication of all the IPS e-max CAD (Ivoclar Vivadent) and Vita Enamic samples used in this study.

Two groups of Samples were then milled (lithium disilicate and hybrid ceramic).

A new set of burs (Sirona CEREC/inlab step bur 10 and Cylinder pointed bur) were inserted into CEREC inlab 3 milling unit (Sirona) for milling of the 15 lithium disilicate specimens. Anew set of burs were inserted into the milling unit to fabricate 15 hybrid ceramic samples. All the samples were designed and milled under the supervision of one operator assisted by one lab technician. The water supply was changed according to the software's notification. All samples were steam cleaned to remove any milling 
residue from the intaglio of the copings after the milling process. The samples were numbered according to the milling sequence.

\section{iii. Measuring marginal gap}

A design macroscope in the Biomedical Science Department at University of Pittsburgh Medical Center was used to image and evaluate the marginal sites. Images were captured on Olympus MVX10 Macroview Microscope (Olympus America, Center Valley PA) using Metamorph version 7.7(Molecular Devices, Sunnyvale CA) (figure 14 B).

Each coping was seated on the master die and secured with a clamp (figure 14.A). The clamp assured the seating of the copings with a standard pressure of $5.5 \mathrm{Ibs}$. The copings were viewed under a magnification of 14X. The images were transferred to image analyzing software (Metamorph) and if satisfactory were saved and labeled according to the surface recorded. Four images were taken of each coping at the interface of the margin and the die and saved. Four consistent sites (buccal, distal, lingual and mesial) were recorded for each sample. At the end of each imaging session a standard millimeter ruler was imaged to be used for calibration of the measurements on the pictures taken in that session (figure 16). Using the same image analyzing software pictures of each marginal area (buccal, distal, lingual and mesial) was then magnified. The marginal gap was measured in micrometers with a line measurement tool which measured the vertical distance between the margin of the coping and the margin of the die according to Holmes definition of marginal gap (13) (figure 17).

Fifteen line measurements were recorded per surface. A total of sixty measurements were made for each coping. The measurements were saved in Microsoft Office Excel 2007 software for future statistical analysis. 


\section{iv. Crystallization firing for lithium disilicate copings}

Following the first set of measurements the, lithium disillicate copings were crystallized using a ceramic furnace with settings recommended by Ivoclar Vivadent Company for firing IPS e-max CAD blocks. Following the manufacturers manual the copings were mounted on the crystallization tray using a crystallization pin and IPS Object Fix Putty (Ivoclar Vivadent). All coping were labeled (figure 18, 19)

Crystallized copings were then seated on the master die and marginal gap measurements were remade in the same manner as described for the pre-crystallized lithium disillicate and hybrid ceramic copings.

\section{v. Pilot Study}

Prior to initiation of the study, a pilot study was designed to determine the appropriate methodology and sample size. In this pilot study three samples were examined.

Images of the die and the die with its coping were obtained. Using the biogeneric copy setting the Sample (test) coping was designed. Lithium-disilicate (IPS e-max CAD- Ivoclar Vivadent) was chosen as the milling material. Three copings were milled using \#12 IPS e-max CAD (Ivoclar Vivadent) blocks.

Each coping was designed with a different cement spacer value. Coping \#1 was designed with spacer value of $40 \mu \mathrm{m}$. For \#2 and \#3 copings the spacer value was set to $50 \mu \mathrm{m}$ and $80 \mu \mathrm{m}$ respectively. When the lithium disilicate copings were milled with CEREC 3/In lab (Sirona) the milled copings were in their pre-crystallized state. The copings were seated on the master die and the marginal area was viewed with a $3 \mathrm{X}$ dental loop to confirm complete seating of the copings. With copings \#1 and \#2 complete seating of the coping was not confirmed but coping \#3 showed complete seating with no significant rotation on the master die. Based on the seating of coping \#3 copings it was decided that the spacer for this specific 
master die needs to be set above $40 \mu \mathrm{m}$ or $50 \mu \mathrm{m}$ for complete seating. Since the seating of coping \#3 was satisfactory only coping \#3 was used for further measurements.

A clamp was used to hold the coping in place during measurements. Another reason for using a clamp was to place a standard pressure on all the copings. The clamp pressure was measured $5.5 \mathrm{Ibs}$.

The metal die, the IPS e-max (Ivoclar Vivadent) coping and the clamp were stabilized under the Macroview Microscope. A magnification of $14 \mathrm{X}$ was used to observe each side of the sample. Each side of the base was labeled (mesial, distal, buccal and lingual). Two digital images were obtained from each side with the interface of the coping and the metal die at the center of the image. Calibration for magnification was made by taking an image of a millimeter ruler at the same magnification that the images were obtained from the coping and die assembly.

All the images were transferred to the MataMorph software for image analysis. Ten line measurements were made on each side of the sample (buccal, lingual, mesial and distal). All measurements were recorded in microns. A total of forty measurements were made on each coping (table 4).

The same measurements were made for coping \#3 after the firing cycle (crystallized phase).

Marginal gap measurements for the lithium disilicate test sample \#3 was repeated for both before and after the crystallization state to verify the reliability of the measuring system. Two measurements were taken in two different sessions to assure the reliability of the measuring technique. 
Table 4: mean measurements for marginal gap between the lithium disilicate (IPS-Emax) precrystallized coping and the metal die

\begin{tabular}{|l|l|l|l|l|}
\hline \multicolumn{6}{|l|}{ Measurements of marginal gaps, sample \#3 } \\
\hline Mean buccal $(\mu \mathrm{m})$ & Mean distal $(\mu \mathrm{m})$ & Mean lingual $(\mu \mathrm{m})$ & Mean mesial $(\mu \mathrm{m})$ & Total mean $(\mu \mathrm{m})$ \\
\hline 62.79816 & 37.04966 & 53.80059 & 88.75401 & 69.1015 \\
\hline
\end{tabular}

Table 5: mean measurements of marginal gap between the lithium disilicate (IPS-Emax) crystallized coping and the metal die.

\begin{tabular}{|l|l|l|l|l|}
\hline \multicolumn{2}{|l|}{ Measurements of marginal gaps, sample \#3 } \\
\hline Mean buccal $(\mu \mathrm{m})$ & Mean distal $(\mu \mathrm{m})$ & Mean lingual $(\mu \mathrm{m})$ & Mean mesial $(\mu \mathrm{m})$ & Total mean $(\mu \mathrm{m})$ \\
\hline 35.86612 & 43.53961 & 47.47334 & 71.59166 & 49.61768 \\
\hline
\end{tabular}

The mean marginal gap measurements obtained from sample \#3 were very similar to the results found in a recent study by Gold et al (38). In this pilot study, the lithium disilicate coping marginal gap width decreased by $20 \mu \mathrm{m}$ after firing cycle. This is in contrast with results reported in the study of Gold et al. in 2013. In their study marginal gap increased after crystallization for lithium disilicate crowns. In this pilot 
study the marginal gap decreased after crystallization and better marginal adaptability was gained after firing cycle. All the marginal gap values were clinically acceptable $(<120 \mu \mathrm{m})$. To be able to find a meaningful correlation between marginal gap size and the crystallization process of lithium disilicate CAD/CAM blocks more samples need to be studied. Comparisons should also be made with other types of $\mathrm{CAD} / \mathrm{CAM}$ material that do not need to undergo a crystallization process. Plans for this study were to use a newly introduced hybrid ceramic material for CAD/CAM crowns.

As a result of the pilot study, the following changes were made to the study protocol:

1) It was decided to increase the number of samples to 15 copings per group

2) The number of measurements for each surface was increased to 15 per surface with the total number of measurements of 60 per each coping.

3) The spacer parameter was set at $80 \mu \mathrm{m}$ which provided better marginal gap values for the specific design of our study master die and coping.

\section{vi. Power analysis}

Historical data was used to calculate the sample size for this study (38). Assuming an alpha level of 0.05 and power of $80 \%$, at least 12 samples were needed to determine if a there was a significant difference between the marginal fit of milled lithium disilicate crowns before and after crystallization. 


\section{vii. Study Samples}

A total of thirty samples were used in this study. Samples were divided in two groups: fifteen lithium desilicate samples and fifteen hybrid ceramic samples.

\section{viii. Methods for data analysis}

Three sets of data were collected during this study:

1) Marginal gap values for lithium disilicate copings before firing (pre-crystallized phase)

2) Marginal gap values for lithium disilicate copings after firing (crystallized state)

3) Marginal gap values for hybrid ceramic copings.

A paired t-test was used to statistically analyze the difference in marginal gap of lithium disilicate copings and hybrid ceramic copings; the same test was used to analyze the difference in marginal gap of lithium disilicate copings before and after crystallization firing. 


\section{CHAPTER 3}

\section{RESULTS}

A Paired t-test and a two-sample t-test statistical analysis were used to test the difference in marginal gap of copings made with lithium disilicate and hybrid ceramic. Three different comparisons of marginal gap were made in this study:

1) A comparison of the marginal gap of copings milled from lithium disilicate blocks before and after firing.

2) A comparison of marginal gap of pre-crystallized lithium disilicate copings and hybrid ceramic copings.

3) A comparison of marginal gap of crystallized lithium disilicate copings and hybrid ceramic copings.

\section{i. A comparison of the marginal gap of copings milled from lithium disilicate blocks before and after firing.}

A paired t-test was used to compare differences in marginal gap of lithium disilicate copings before and after crystallization firing. The mean difference in marginal gap showed that lithium disilicate samples, on average had an increase of $62 \mathrm{um}$ in marginal gap after the firing cycle. This difference was significant for lithium disilicate copings milled from IPS e-max CAD (Ivoclar Vivadent) blocks. 
Table 6: Emax (lithium disilicate group): pre-crystallized (unfired) copings vs. crystallized (fired) copings

\begin{tabular}{|l|l|l|l|l|ll|}
\hline Variable & Obs & mean & Std. Err. & Std. Dev. & [95\% conf. interval] \\
\hline Emax fired & 15 & $132.2544 \mathrm{um}$ & 11.537 & 44.67758 & 107.5128 & 156.996 \\
\hline Emax unfired & 15 & $70.0742 \mathrm{um}$ & 7.86941 & 30.47666 & 53.19678 & 86.95161 \\
\hline
\end{tabular}

\section{ii. A comparison of marginal gap of pre-crystallized lithium disilicate copings and hybrid ceramic copings.}

A two-sample t-test was used to compare differences in marginal gap between the pre-crystallized lithium disilicate copings and the hybrid ceramic copings. The mean marginal gap for the lithium disilicate group before firing was $70.07 \mu \mathrm{m}$ while the mean marginal gap of hybrid ceramic group was $47.91 \mu \mathrm{m}$. The difference in marginal gap width between two groups was statistically significant $(p<0.04)$

Table 7: Emax (lithium disilicate group) before firing vs. Enamic (hybrid ceramic group) (Two-Sample t-test with equal variances)

\begin{tabular}{|l|l|l|l|l|l|}
\hline Variable & Obs & mean & Std. Err. & Std. Dev. & [95\% conf. interval] \\
\hline Emax (unfired) & 15 & $70.0742 \mathrm{um}$ & 7.869041 & 30.47666 & $53.19678 \quad 86.95161$ \\
\hline Enamic & 15 & $47.9160 \mathrm{um}$ & 6.455512 & 25.00209 & 34.703261 .76171 \\
\hline
\end{tabular}




\section{iii. A comparison of marginal gap of crystallized lithium disilicate copings and hybrid ceramic copings.}

A two-sample t.test was used to analyze for differences in marginal gap between the crystallized e-max group and the Enamic group. The mean marginal gap width for the lithium disilicate copings was 132.25 $\mu \mathrm{m}$. The hybrid ceramic coping group demonstrated a mean marginal gap of $47.91 \mu \mathrm{m}$. The difference in marginal gap width between the two groups was statistically significant $(\mathrm{p}<0.01)$

Table 8: Emax (lithium disilicate group) after Firing vs. Enamic (hybrid ceramic group) (Two-Sample $t$ test with equal variances)

\begin{tabular}{|l|l|l|l|l|l|l|}
\hline Variable & Obs & mean & Std. Err. & Std. Dev. & [95\% conf. interval] \\
\hline Emax (fired) & 15 & $132.2544 \mathrm{um}$ & 11.5357 & 44.67758 & 107.5128 & 156.996 \\
\hline Enamic & 15 & $47.91601 \mathrm{um}$ & 6.4555 & 34.07032 & 34.07032 & 61.76171 \\
\hline
\end{tabular}




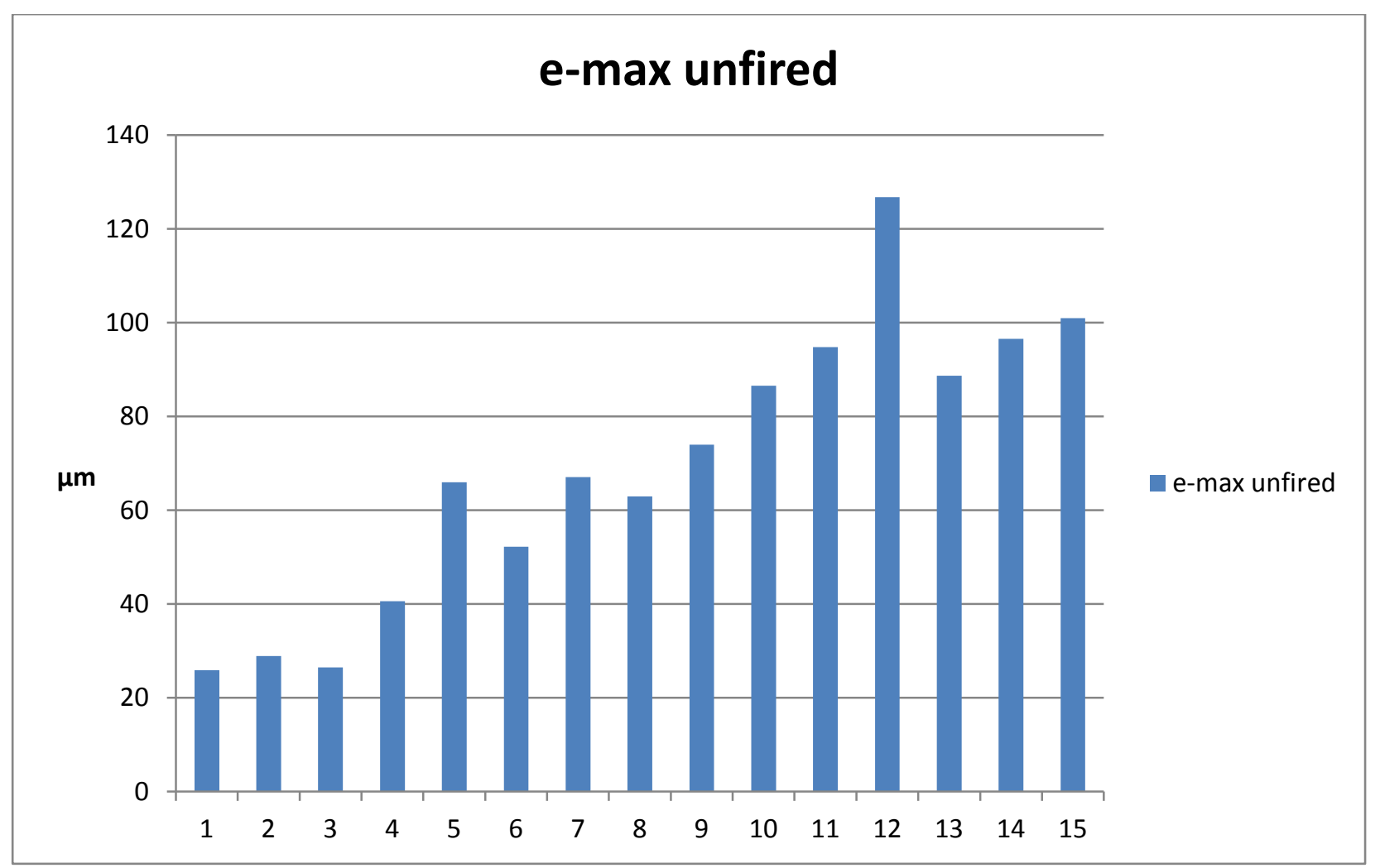

Figure 3: Mean marginal gap of pre-crystallized Lithium disilicate (e-max unfired) samples \#1-15 


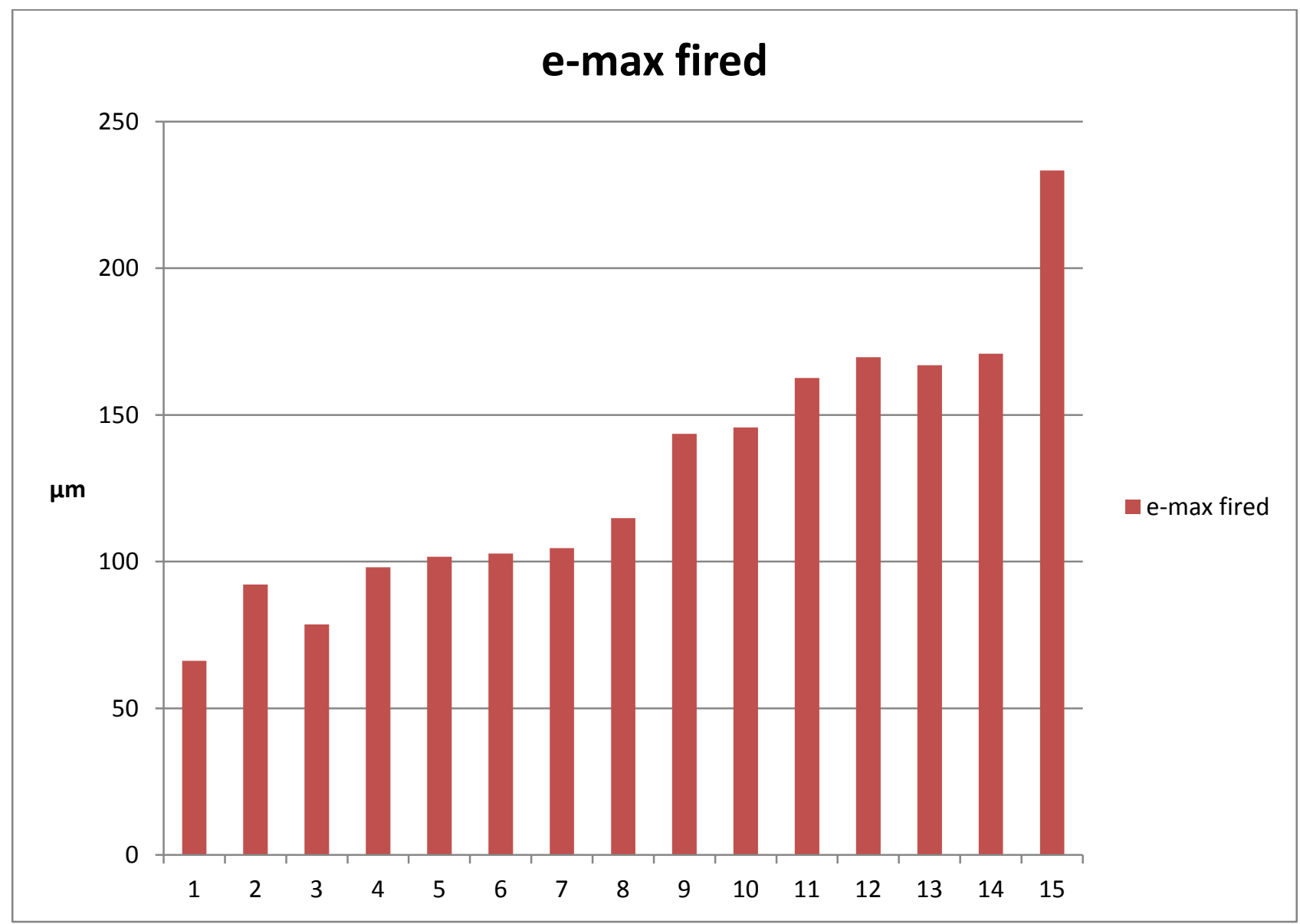

Figure 4: Mean marginal gap of crystallized Lithium disilicate (e-max fired) samples \#1-15 


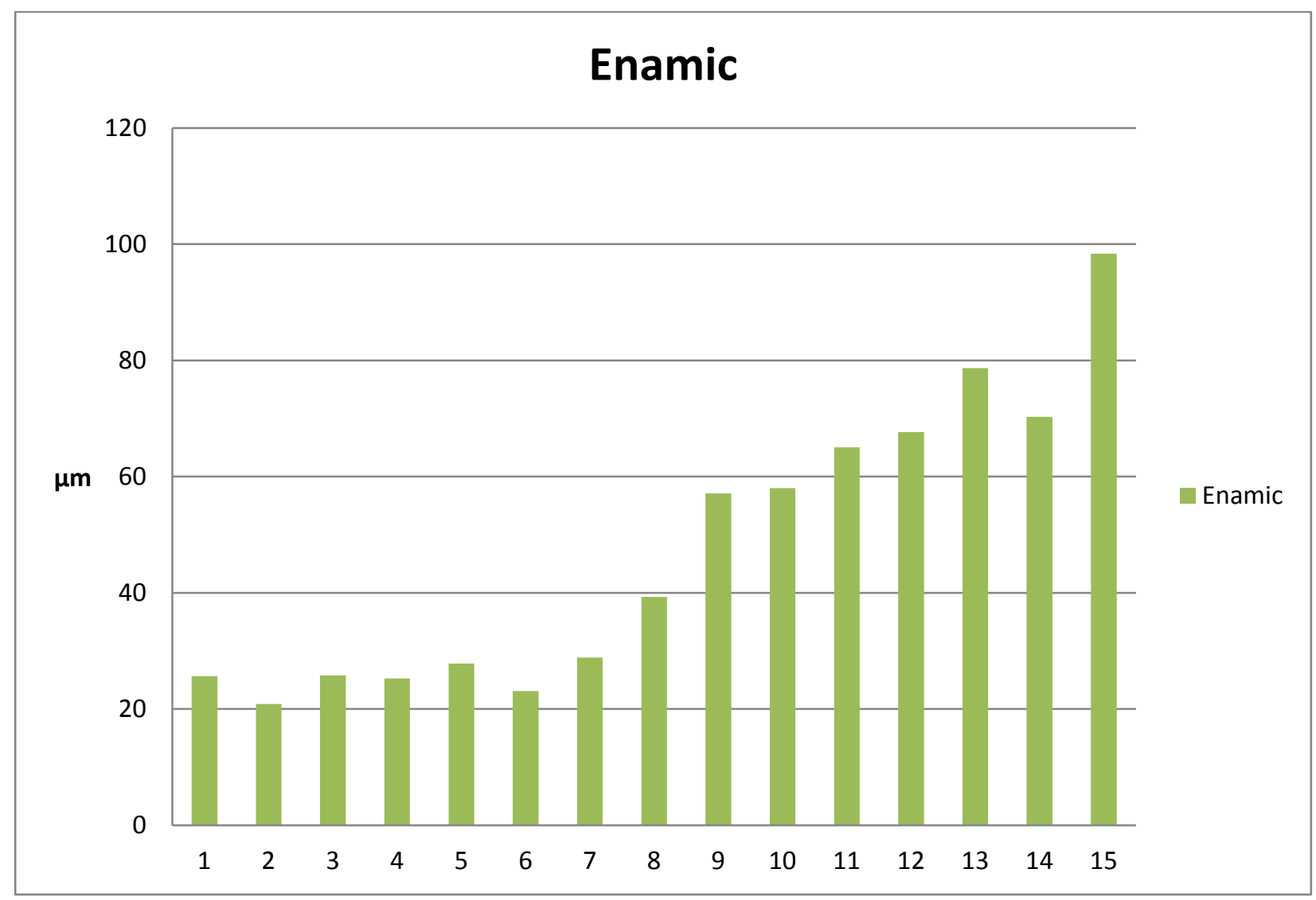

Figure 5: Mean marginal gap of hybrid ceramic (Enamic) samples \#1-15 
Copings in all three groups showed an increase in marginal gap from coping \#1 to coping \#15.

In the group of crystallized lithium disilicate copings (e-max fired), coping \#1 up to coping \#8 show a marginal gap less than $120 \mu \mathrm{m}$. marginal gaps measured for copings \#9 through \#15 were greater than $120 \mu \mathrm{m}$.

In pre-crystallized lithium disilicate group (e-max unfired) all the copings had marginal gap below 120 $\mu \mathrm{m}$ except for coping \#12.

All the marginal gaps measured for hybrid ceramic group (Enamic) were less than $120 \mu \mathrm{m}$.

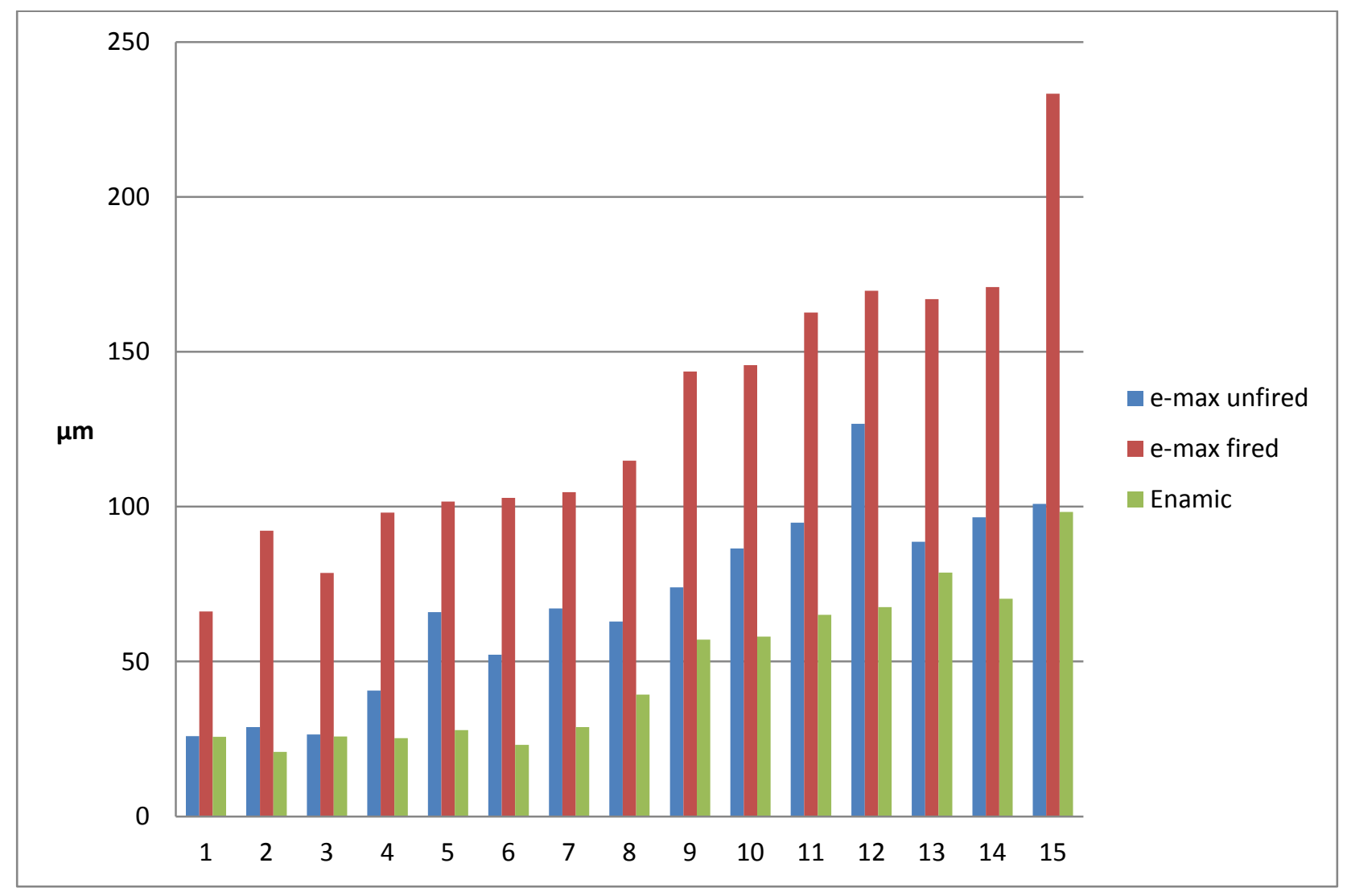

Figure 6: Bar chart summarizing the mean marginal gap differences between pre-crystallized lithium disilicate, crystallized lithium disilicate and hybrid ceramic copings 
A stratified analysis of marginal gap within each region using paired t-tests showed that marginal gap was significantly different before firing than it was after firing for each of the four regions. The greater gap appeared after firing

While comparing the Enamic and pre- crystallized e-max copings, it was seen that the marginal gap was significantly different only in the lingual region $(\mathrm{p}<0.001)$. However, the mesial region was marginally statistically significant $(\mathrm{p}=0.047)$.

When comparing the Enamic and crystallized e-max copings, the marginal gap was significantly different for all four regions of measurement after firing, the gaps were larger for the e-max copings after the firing cycle.

The Kruskal-Wallis test was used to evaluate whether or not the marginal gap was significantly different across the region of measurement within each group. Marginal gap was not significantly different among the four regions in the Emanic group $(\mathrm{p}=0.054)$. However, marginal gap was significantly different among the four regions in the e-max unfired group $(\mathrm{p}=0.015)$ and among the same four regions after firing $(\mathrm{p}=0.003)$ 


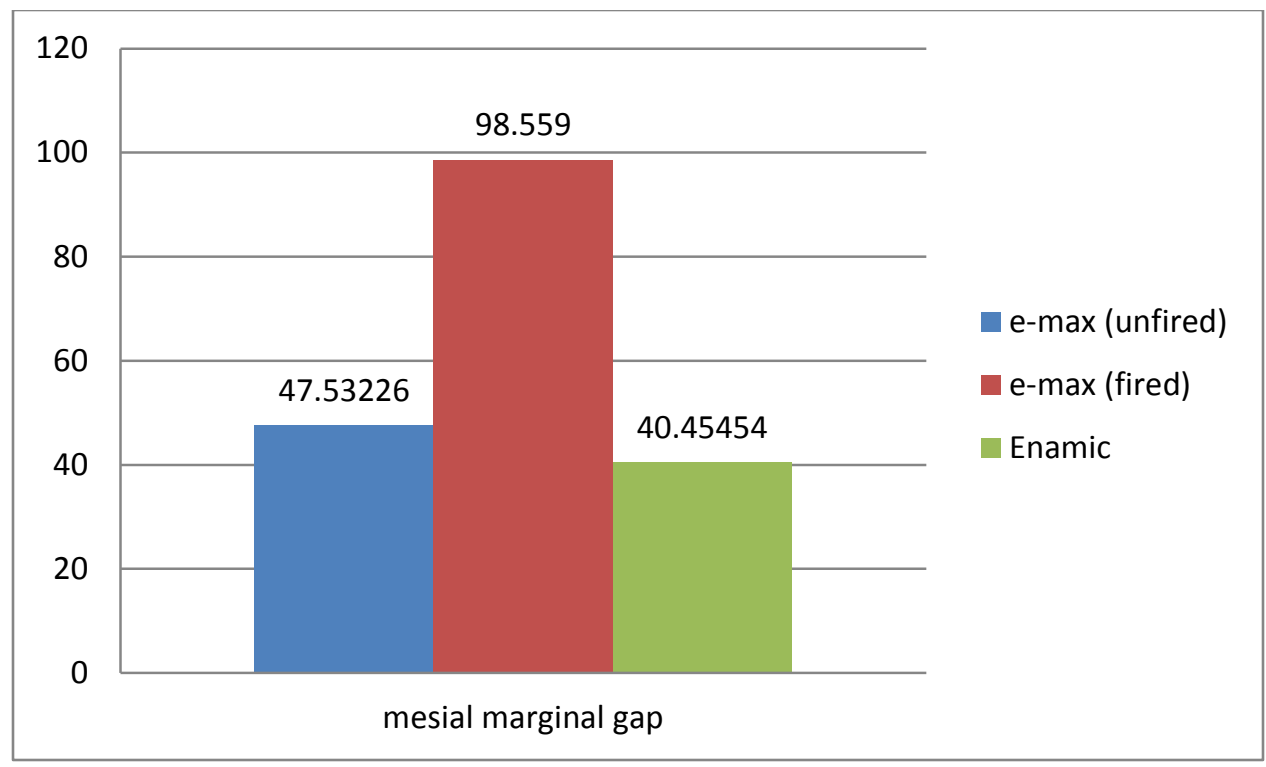

Figure 7: Comparison of the mean buccal marginal gaps in 3 groups

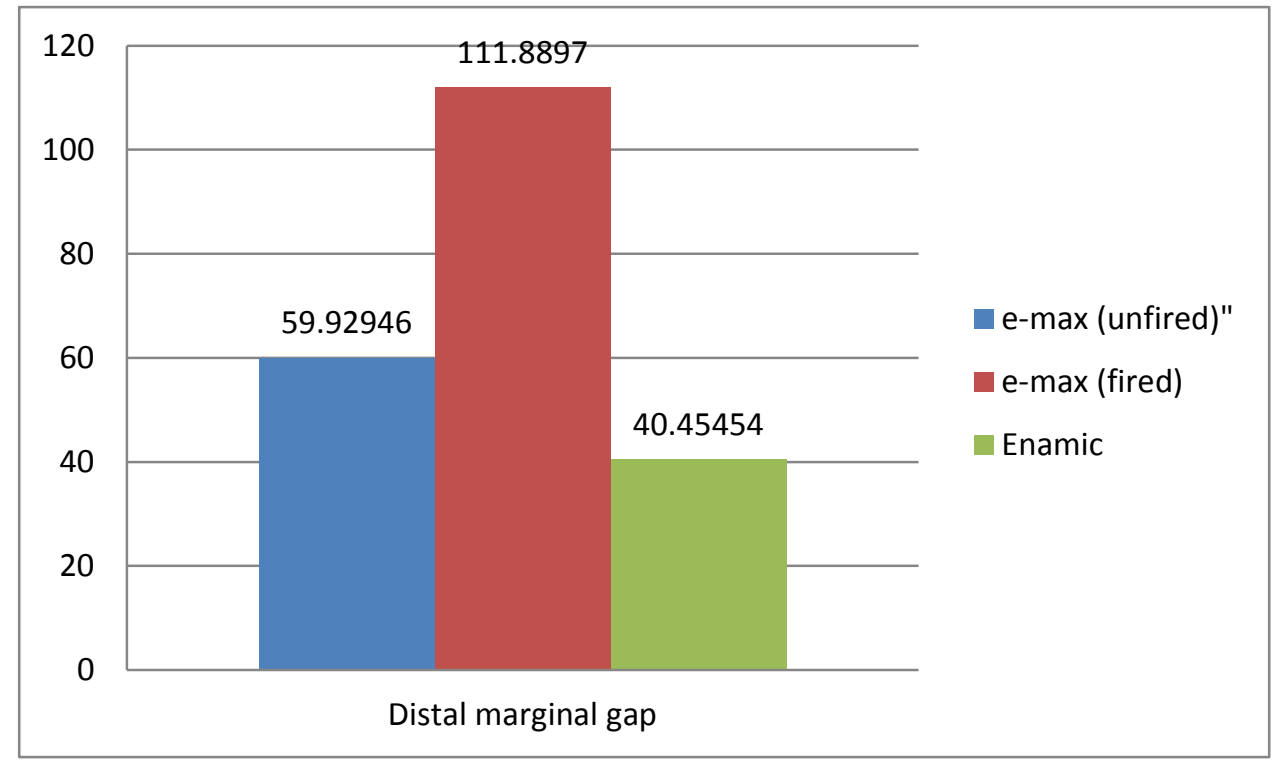

Figure 8: Comparison of the mean distal marginal gaps in 3 groups 


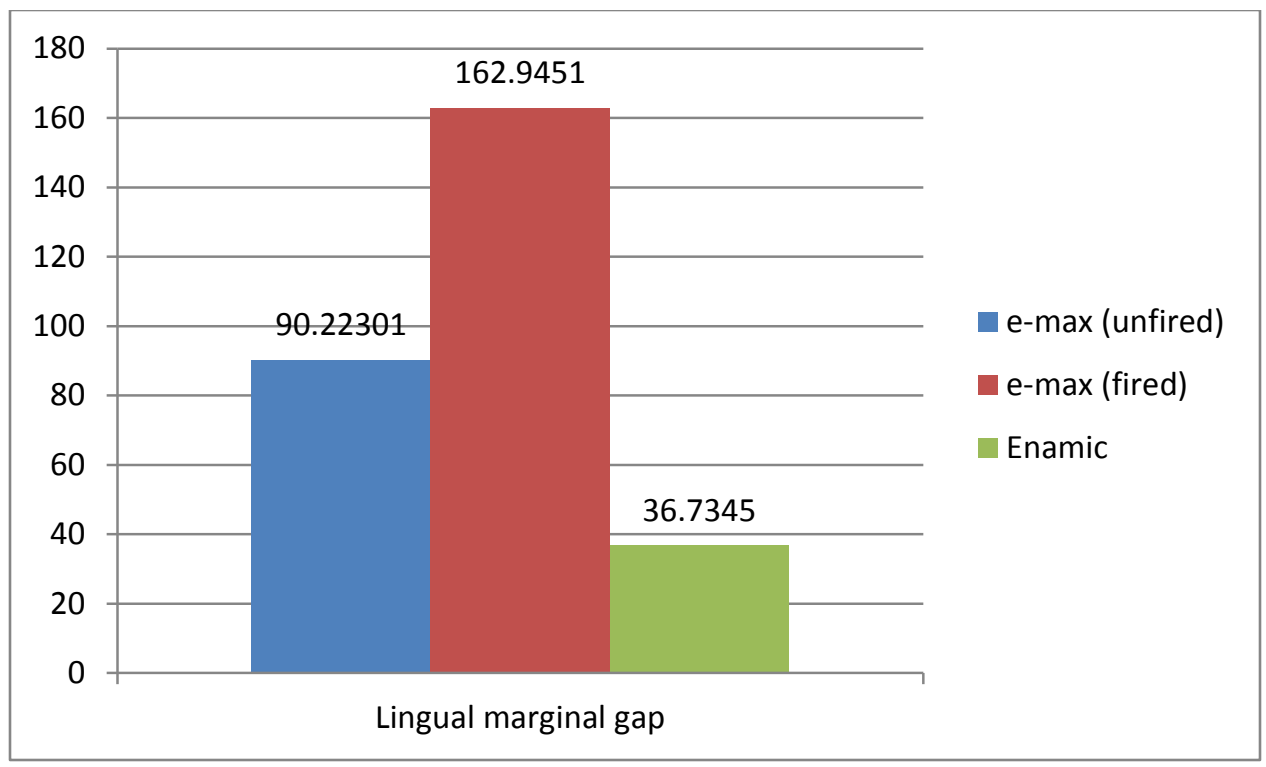

Figure 9: Comparison of the mean lingual marginal gaps in 3 groups

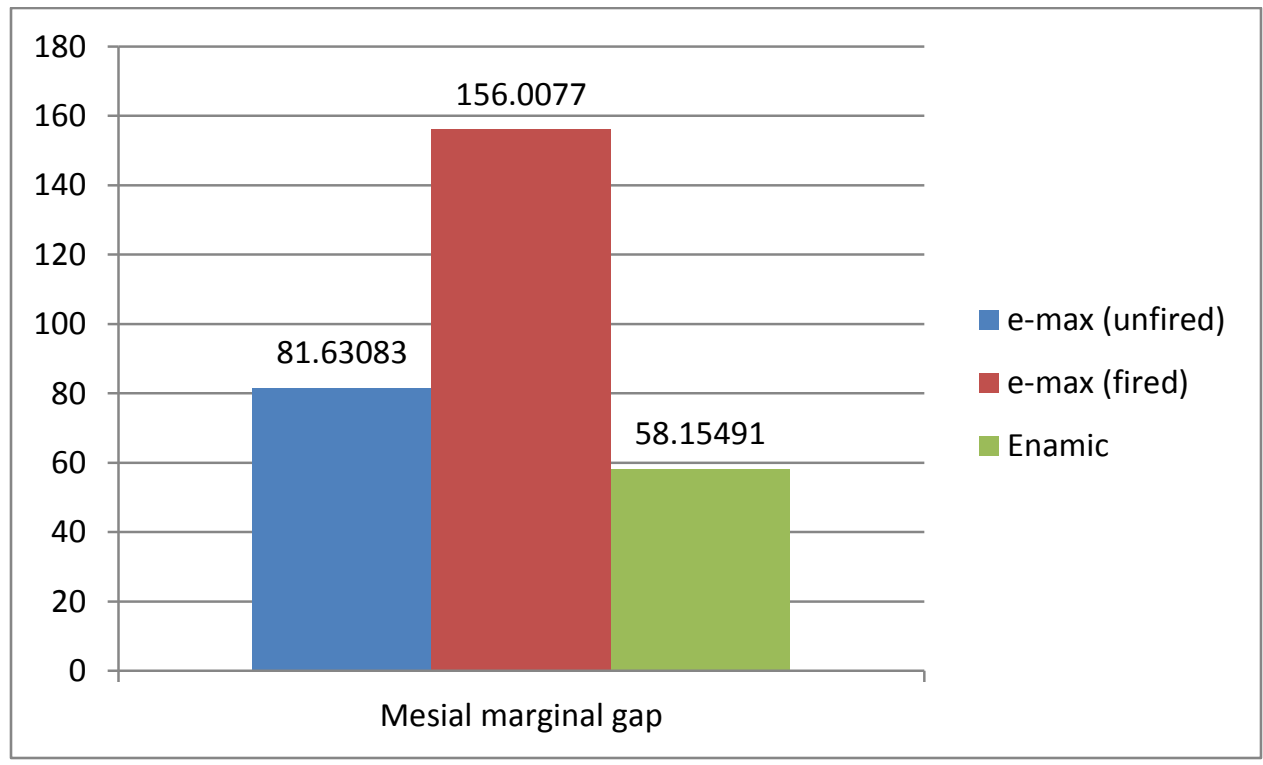

Figure 10: Comparison of the mean mesial marginal gaps in 3 groups 


\section{CHAPTER 4}

\section{DISCUSSION}

The purpose of this investigation was to determine whether the material selection for fabrication of CEREC CAD/CAM crowns could affect the marginal fit of the restoration. Two different commercially available CEREC blocks were used to mill single unit crown restorations using the CEREC 3 system (Sirona). Lithium disillicate blocks, used since 2007, were compared with a recently introduced hybrid ceramic block. According to the manufacturer this ceramic hybrid promises marginal integrity, strength and more conservative tooth preparation in the posterior region of the mouth (especially where minimum interocclusal space is available) (53). Restorations made from hybrid ceramic material do not need the additional firing cycle for crystallization as do the lithium disillicate CAD/CAM crowns. The use of a hybrid ceramic can save chair time and offers more conservative tooth preparation in the posterior region of the mouth. No studies are available that have evaluated the marginal adaptation of this newly introduced hybrid ceramic or which have compared it to any other available CAD/CAM blocks intended for posterior crown fabrication. This study evaluated the marginal gap of copings fabricated from hybrid ceramic (Vita Enamic) blocks and lithium-disilicate (IPS e-max CAD- Ivoclar Vivadent) blocks. Three different comparisons were made of the marginal gap of the milled copings. The first test compared the marginal adaptation of pre-crystallized lithium disilicate copings with the marginal adaptation of hybrid ceramic copings. Results indicated that there was a significant difference between the mean marginal gap values of uncrystalized lithium disillicate copings fabricated from the IPS-emax CAD blocks (Ivoclar Vivadent) and the marginal gap values of hybrid ceramic copings fabricated with Enamic blocks (vita). 
The lithium disillicate copings before crystallization showed a mean marginal gap of $70 \mu \mathrm{m}$ which is clinically acceptable according to studies done by McLean and Von Fraunhofer $(<120 \mathrm{um})(33,35)$.

A second test compared the marginal gap of pre-crystallized lithium disilicate copings with those of copings that have undergone final firing. According to some studies significant changes were experienced in the marginal adaptation and integrity following the final firing cycle for CAD/CAM crowns fabricated with lithium disillcate blocks $(23,24)$. The results of this study were similar to those reported by Gold et al. They concluded that lithium disilicate CAD/CAM crowns experienced an increase in marginal gap following crystallization firing (139). However; they did report clinically acceptable marginal gaps before and after crystallization for litium disilicate crowns $(<120 \mu \mathrm{m})$. This present study found clinically unacceptable marginal gap for lithium disilicate copings after crystallization firing (> $120 \mathrm{um}$ ). This finding is in contrast with findings of recent similar studies conducted by Anadioti and Gold. They reported marginal gaps of less than $120 \mathrm{um}(84 \mu \mathrm{m}$ and $59 \mu \mathrm{m}$ respectively) for crystallized lithium disilicate CAD/CAM crowns $(31,139)$. The significant effect of the crystallization cycle on marginal gap can mainly be due to the shrinkage of the material causing distortion of the margins.

Different studies on marginal adaptation of ceramic CAD/CAM crowns have been inconsistent in their findings. Such differences could be due to several things such as: study design variations, scanning systems, milling systems, abutment design (stainless steel die, typodont teeth, extracted teeth, etc.), and measurement system used.

The present study followed manufactures recommendations for milling the copings in both groups. New burs were used in the milling unit at the start of each group. The mean marginal gap of the copings in both groups showed a gradual increase in value from milled coping \#1 to milled coping \#15. Although all the variables such as coping design, milling system and the operator were kept the same for all samples, within the same group there was a significant difference between the mean marginal gap values of the first milled coping vs. the final milled copings. The only variables that were not kept consistent for the samples were the burs used for the milling unit. This could be a possible explanation for the gradual 
increase of marginal gap values within a group. According to the manufacturer's recommendation the CEREC system will notify the operator when the burs need to be changed. The burs were not changed during milling fifteen lithium disilicate and fifteen hybrid ceramic copings. The mean marginal gap of the first 13 milled copings in the e-max fired group were within the clinically acceptable range (119.04 um). However, after the milling continued for fabrication of copings up to number 15 , a significant increase in marginal gap from coping \#9 to \#15 was observed which increased the mean marginal gap of the 15 copings to $132 \mathrm{um}$. This is above the suggested clinically acceptable marginal gap (>120 um). Results of marginal gap measurement in the e-max group shows that coping \#1 up to coping \#8 had marginal gap less than $120 \mu \mathrm{m}$ (clinically acceptable marginal gap), therefore due to the fact that bur wear can affect the cutting efficiency, it is suggested that the milling burs be changed after fabrication of 8 lithium disilicate coping with CEREC inlab 3 milling unit (Sirona).

Wear on the milling burs during consecutive milling could play a role in the efficacy of their cutting ability and therefore may have resulted in discrepancies in the marginal area of the copings. The mean marginal discrepancy within the hybrid ceramic group was significantly less than that of the lithium disilicate group. This difference could be explained considering the difference in their physical properties. Hybrid ceramic blocks are softer (dual network of ceramic and composite) than lithium disilicate CAD/CAM blocks they can be milled faster and cause less wear of the milling burs. No studies could be found in the literature that addresses the effect of milling bur wear on the marginal discrepancy of the milled crowns. There is a need for research to investigate the correlation between the milling bur wear and marginal discrepancy of CAD/CAM crowns.

Earlier studies on marginal discrepancies of ceramic crowns and CAD/CAM generated crowns have been conducted using a variety of methods and materials. The present study used a standardized stainless steel die due to its resistance to wear. A flat die surfaces was created on the buccal aspect of the die to provide antirotation and ease of identification of the four surfaces. Although all the die surfaces and angles were rounded, it is a possible that cutting the angles of the flat surface may have become less efficient due to 
wear of the milling burs. This in return could have affected seating of the copings. Wear occurred less when milling the hybrid ceramic blocks than with the lithium disilicate blocks due to the softer composition of the material.

\section{-Future Studies}

Besides future investigation of advanced CAD/CAM materials and techniques, the effect of bur wear on milling efficacy of CAD/CAM systems is also suggested. 


\section{CHAPTER 5}

\section{CONCLUSION}

The purpose of this study was to measure and compare the marginal adaptation of CAD/CAM copings milled from two different blocks using the CEREC 3 (Sirona) system.

The results of this study rejected the null hypotheses number one and two and concluded that:

- Crystallization firing has a significant effect on the marginal gap of lithium disilicate (IPS e-max CAD- Ivoclar Vivadent) CAD/CAM crowns fabricated with CEREC 3 (Sirona) system.

- The marginal gap after crystallization firing for lithium disilicate CAD/CAM crowns was not within the range of clinically acceptable marginal gaps ( $<120 \mathrm{um})$. ). However the mean marginal gap of copings \#1 to \#13 was within the clinically accepted range of marginal gap $(<120$ um). According to this finding it has been suggested that the milling burs for lithium disilicate blocks be changed more frequently for gaining more accurate marginal fit of the lithium disilicate restorations.

- Hybrid ceramic (Vita Enamic) copings fabricated with the CEREC 3 system showed marginal adaptation superior to that of lithium disilicate copings.

- The mean marginal gap for Hybrid ceramic blocks was clinically acceptable (<120 um). 
Unlike lithium disilicate block,s hybrid ceramic does not require the additional step of crystallization firing. They have less marginal discrepancy. However, long term studies are needed to verify the durability and stability of this material for the fabrication of CAD/CAM restorations. 


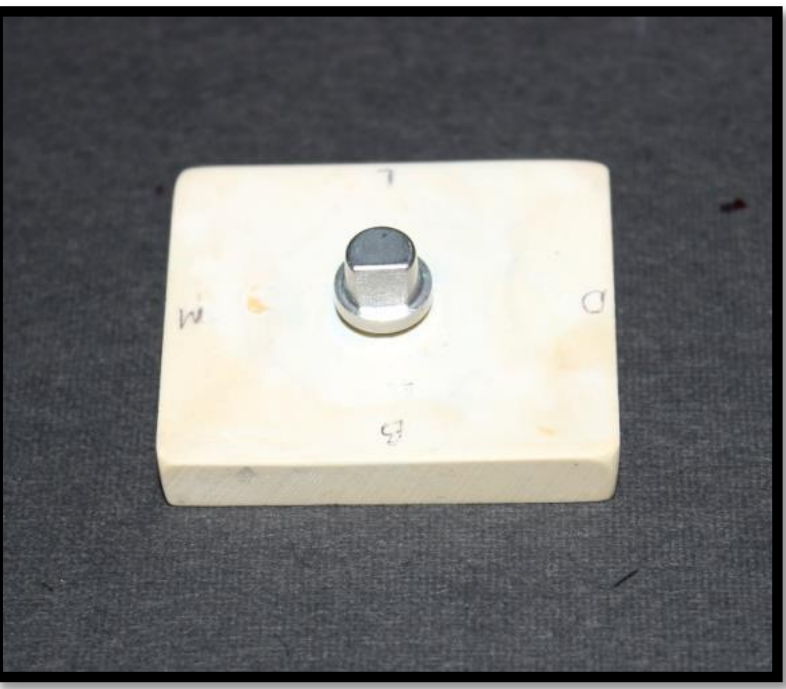

A

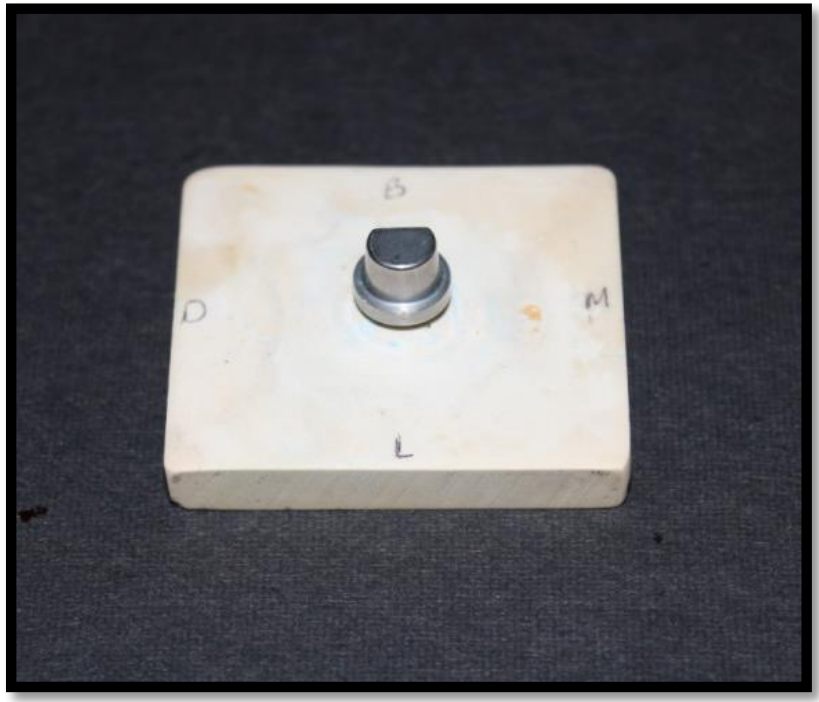

Figure 11: A and B, stainless steel master die mounted in stone 

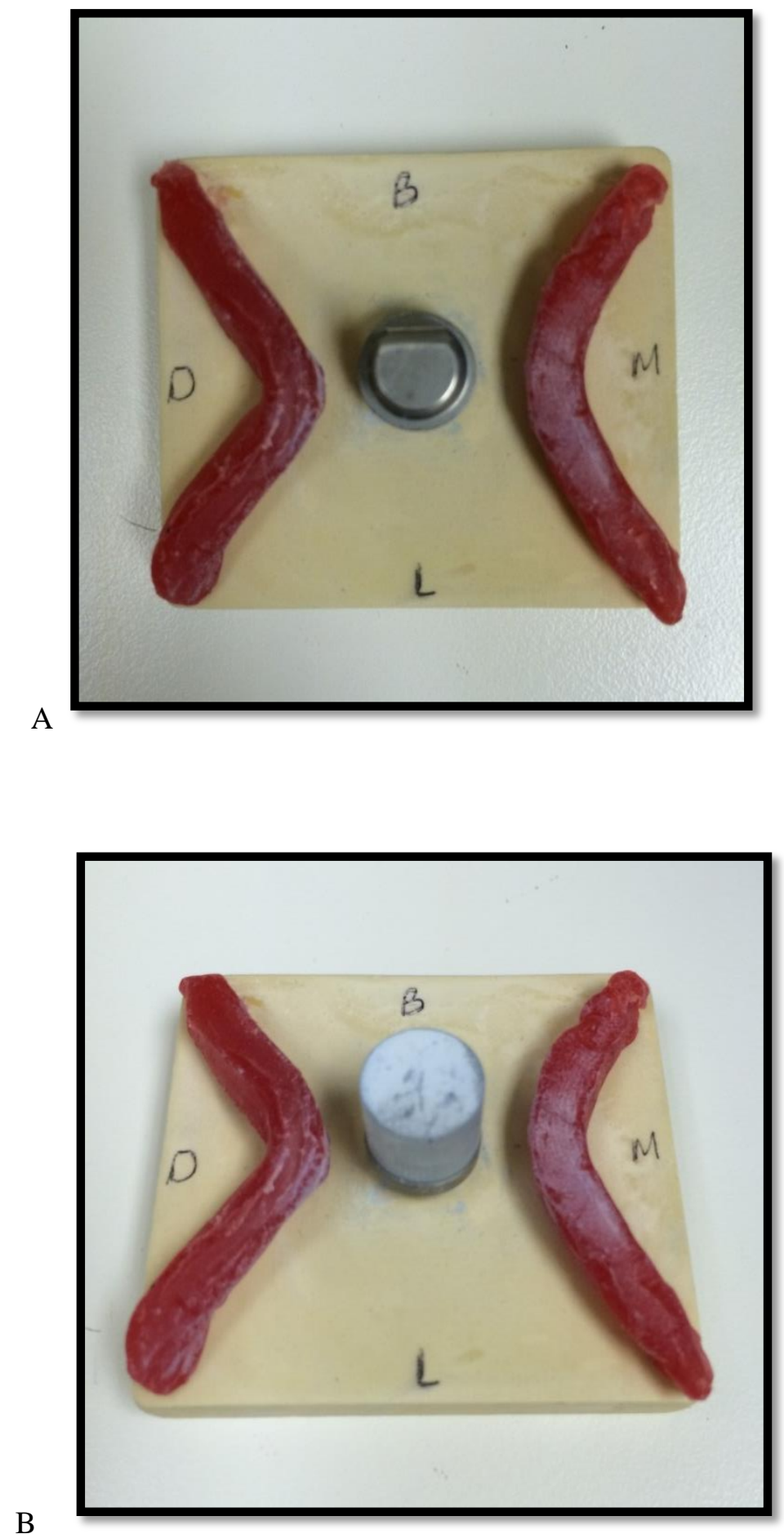

Figure 12: Master die

A. orientation of master die with the wax strips, B.resin coping placed on master die used as the biogeneric copy. 


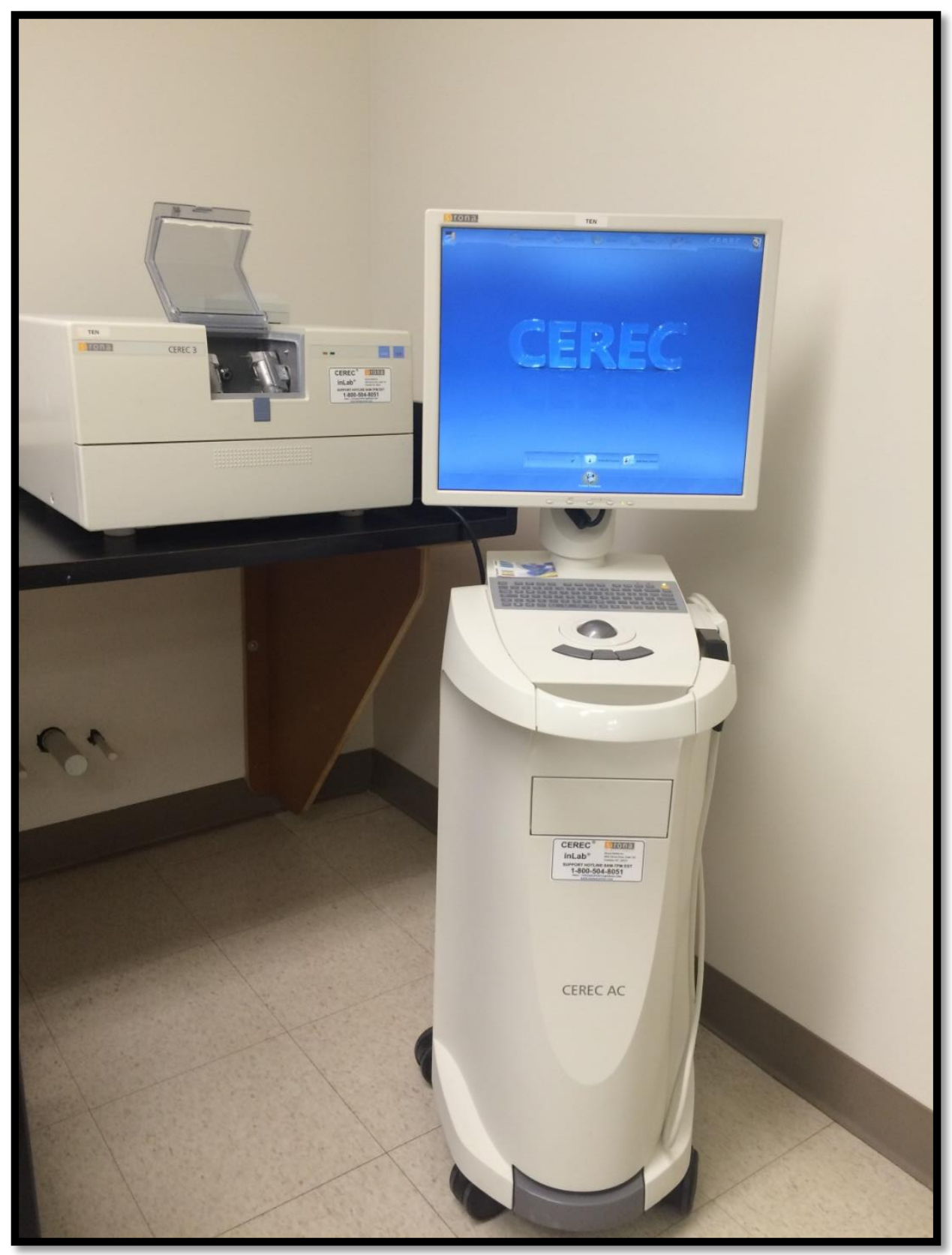

Figure 13: CEREC (Sirona) unit with Bluecam scanner and CEREC inLab (Sirona) milling unit. 


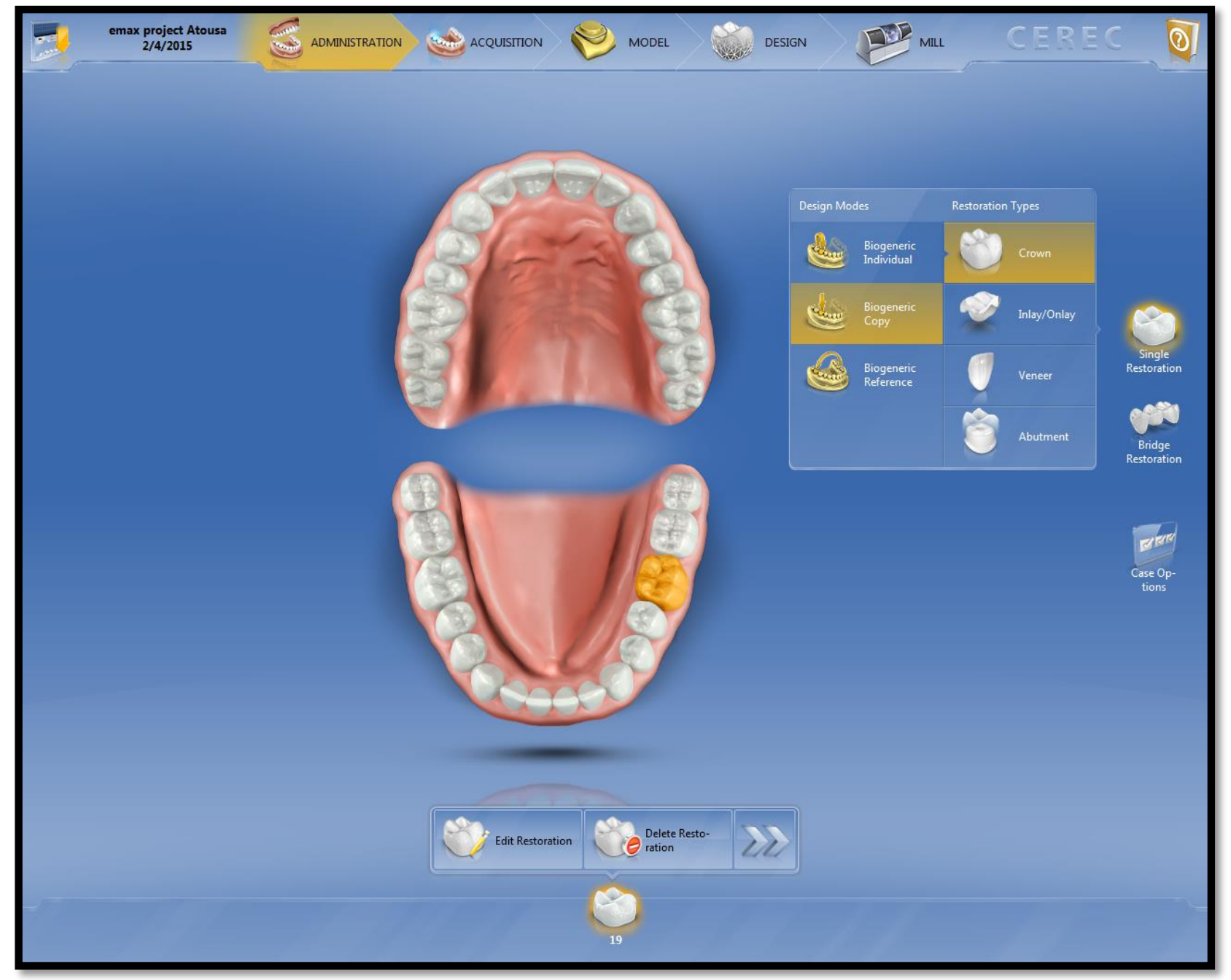

Figure 14: Initial settings for coping design (CEREC software version 4.3.1) 


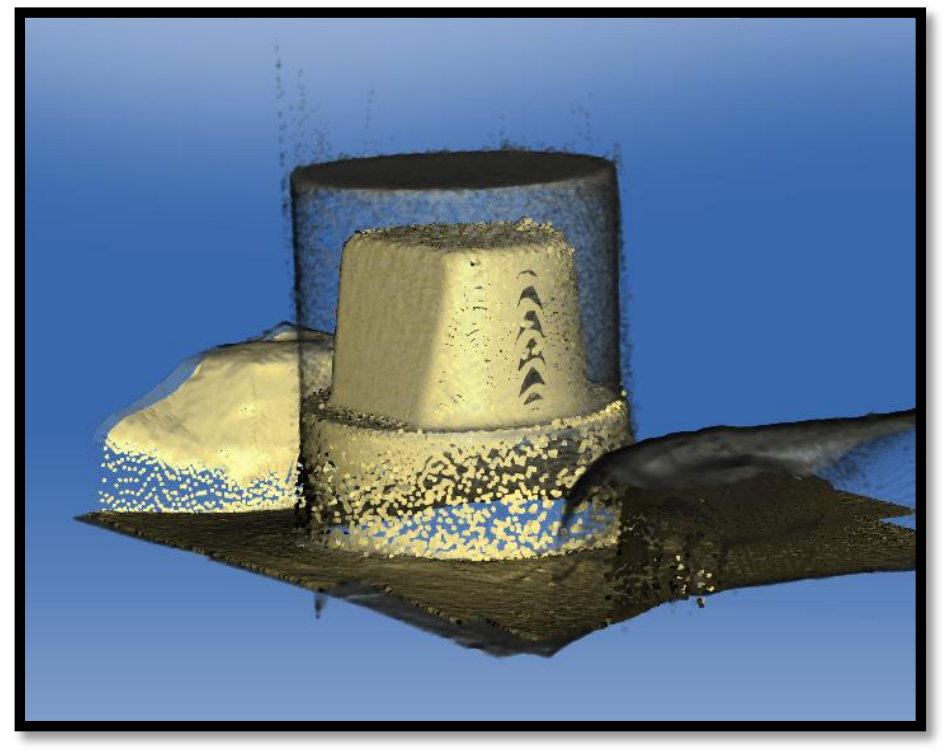

Figure 15: image acquisition of master die and biogeneric copy assembled

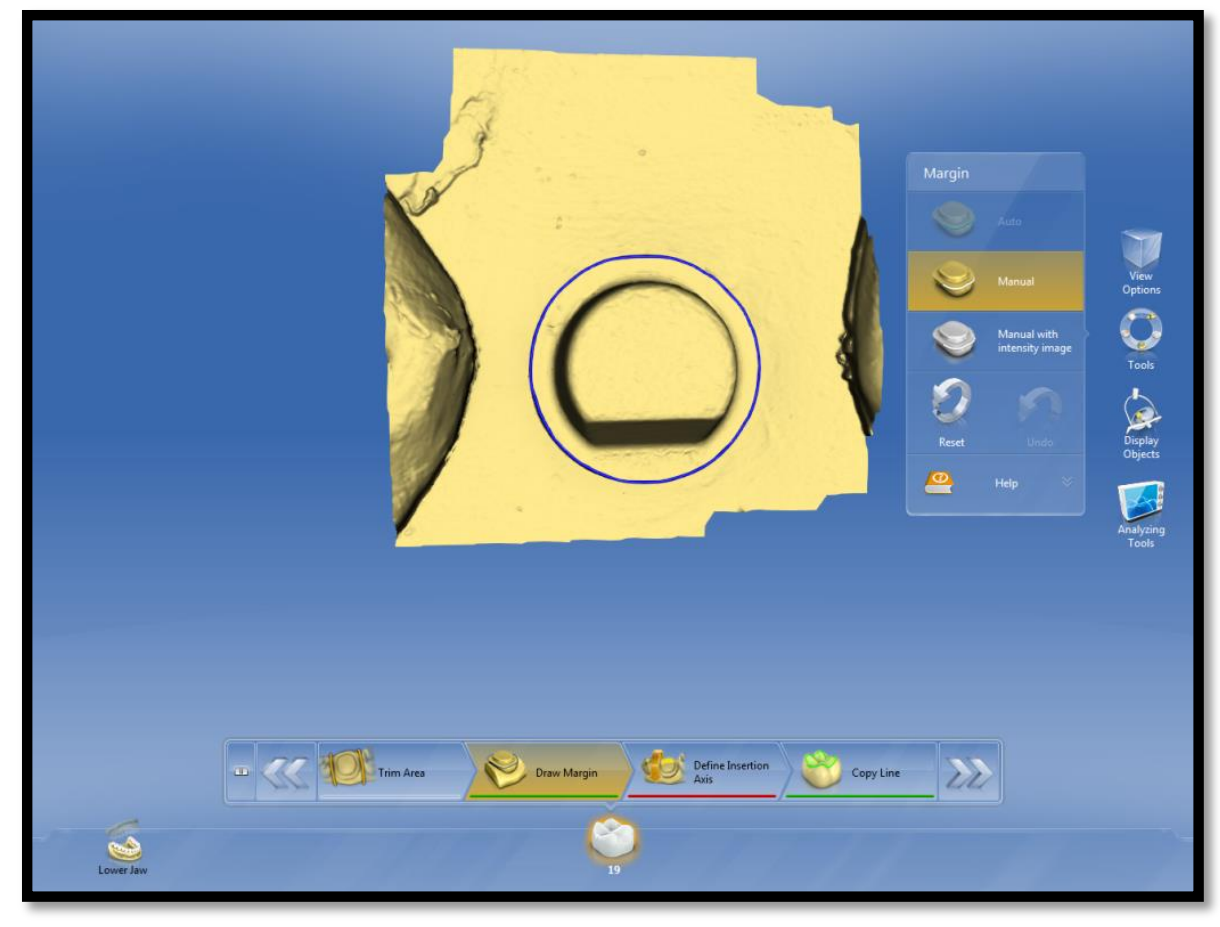

Figure 16: margin drawn on master die. 


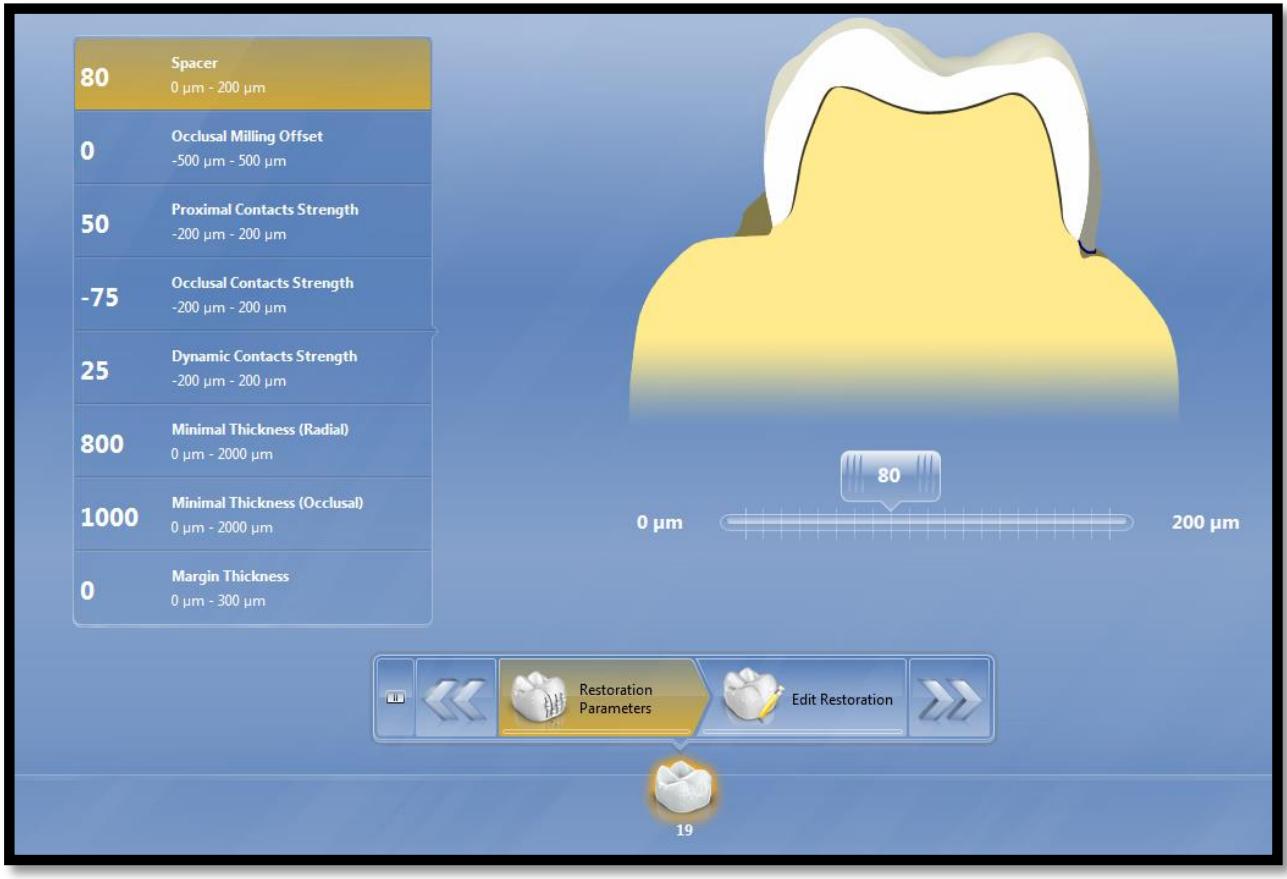

A

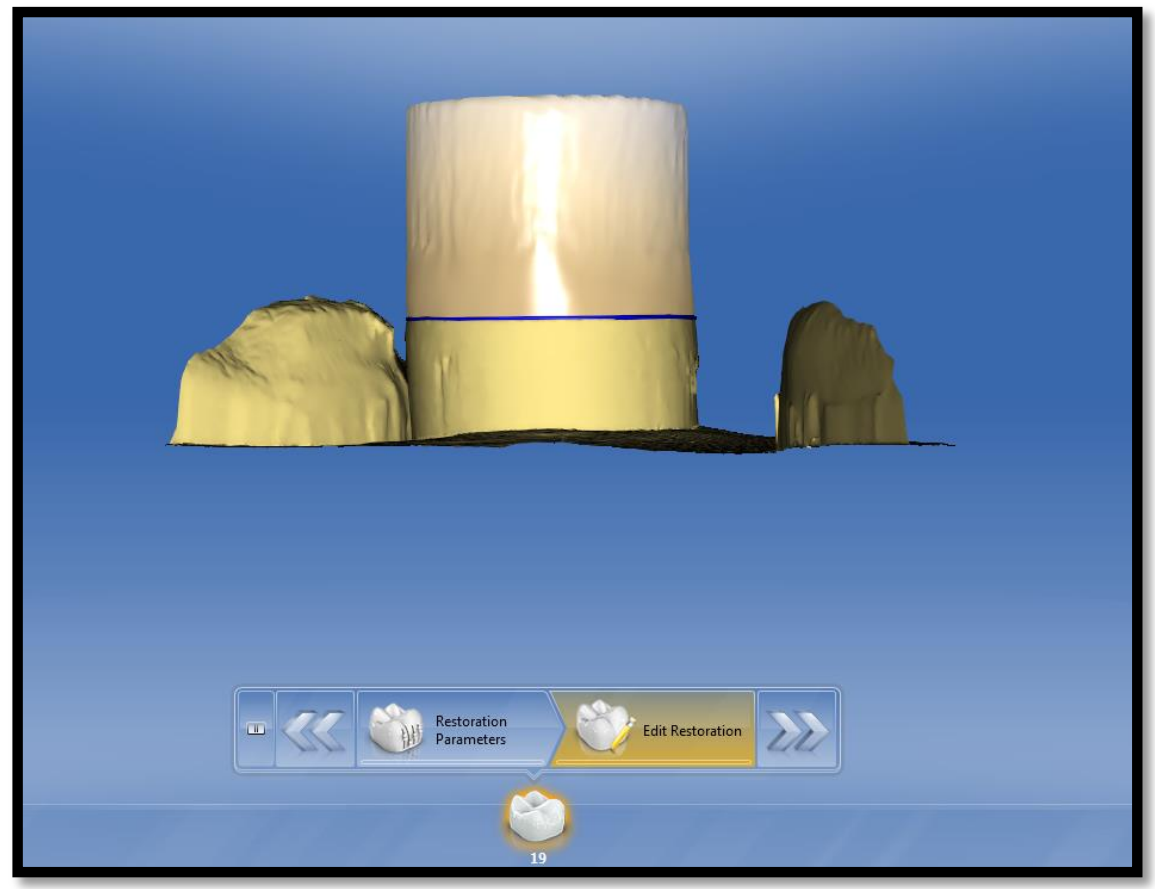

Figure 17: Designing the coping with CEREC 3 software.

A: setting proper parameters for the restoration. B: Coping has been created according to the parameters set for the restoration 

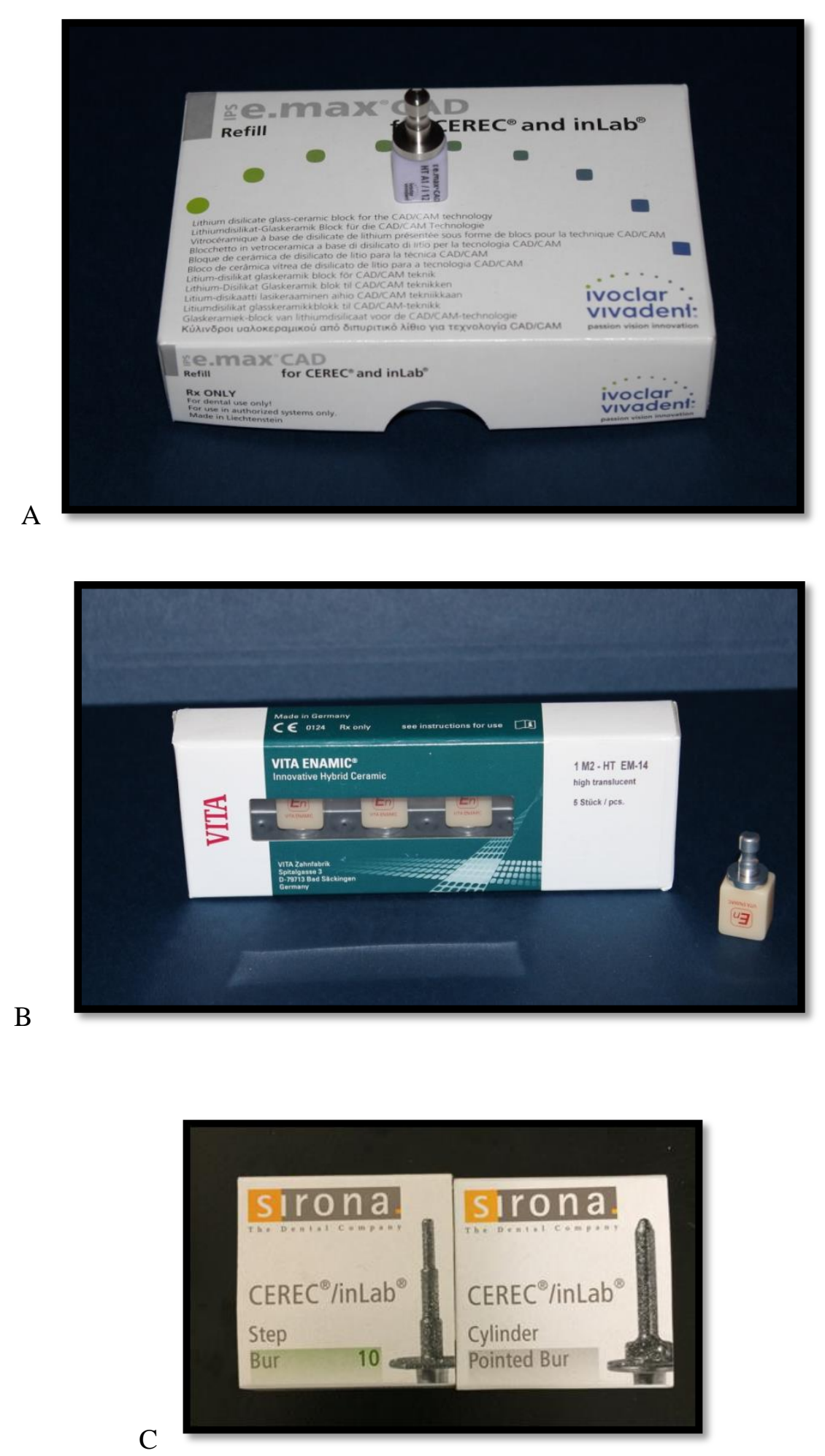

Figure 18: Copings were milled using (A) IPS e-max CAD and (B) Enamic, (C) burs for the Milling unit 


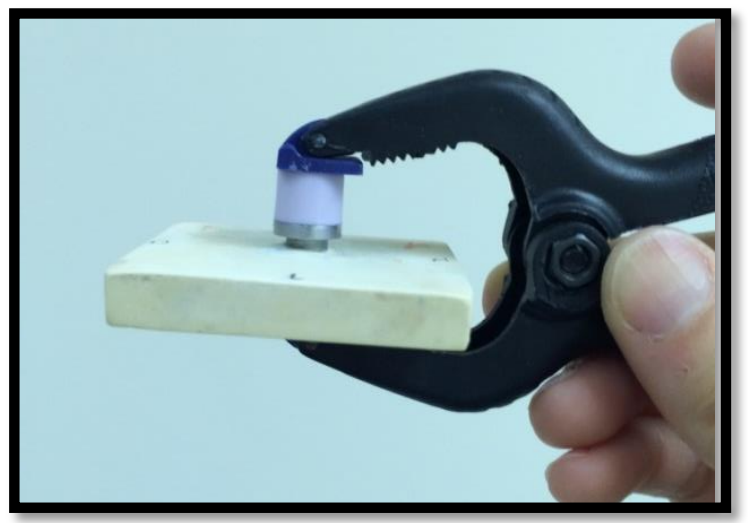

Figure 19: lithium disilicate coping in blue phase seated in the mater die with standardized pressure.

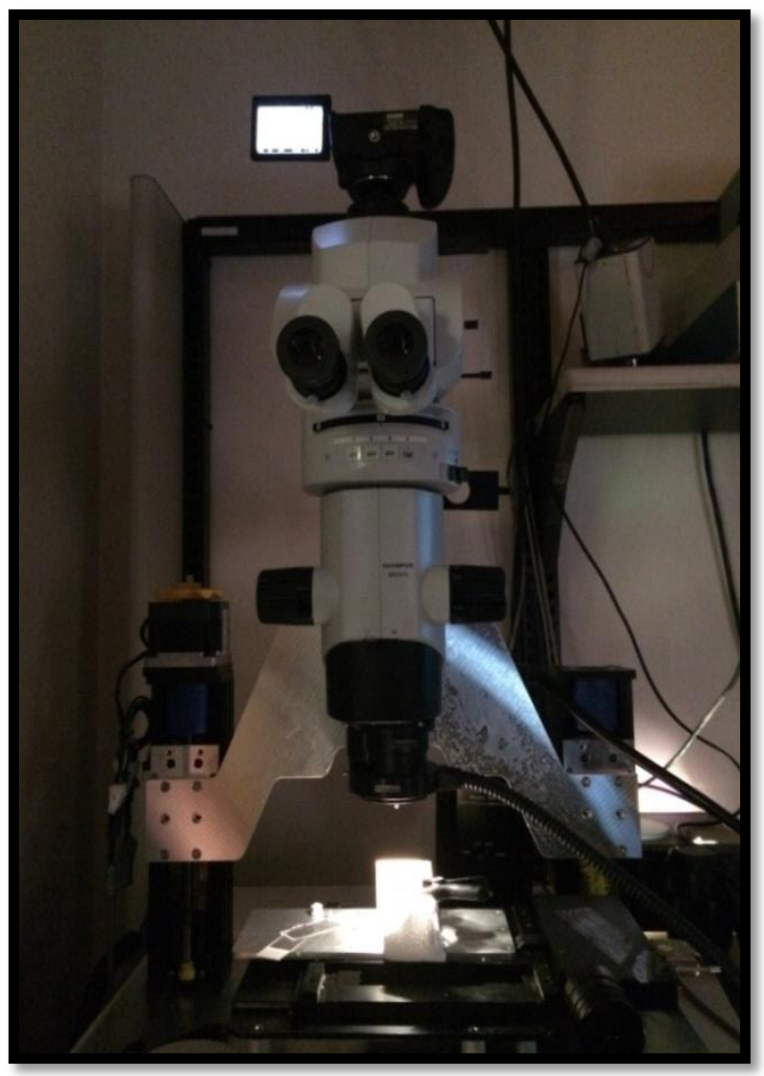

Figure 20: Olympus MVX10 Macroview Microscope (Olympus America, Center Valley PA) used for direct view and imaging of the marginal area 


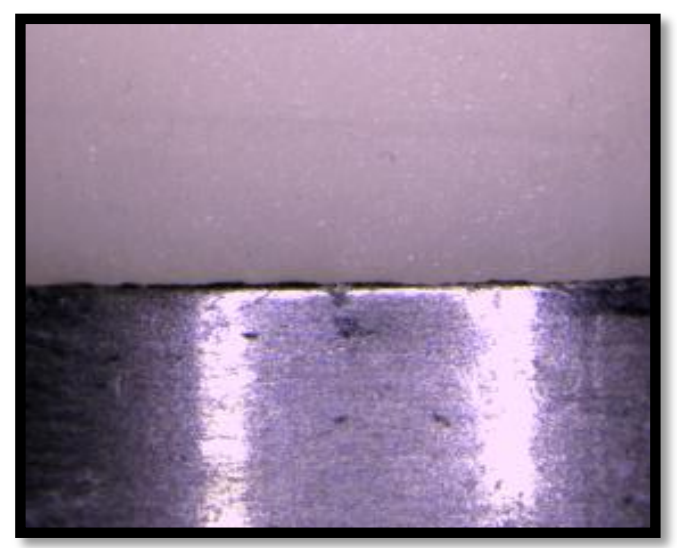

A

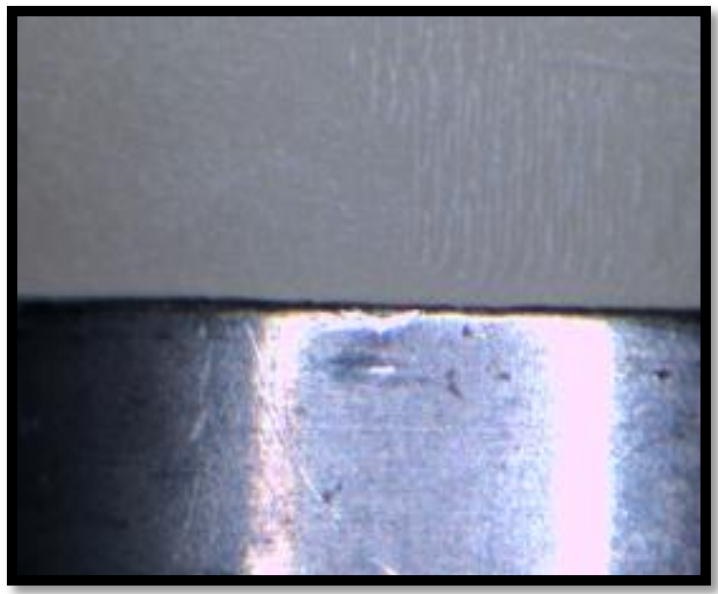

$\mathrm{C}$

Figure 21: Images of marginal gaps under magnification.

A. Image of the buccal surface of lithium disilicate coping \#3 in blue phase.

B: Image of the buccal surface of crystallized lithium disilicate coping \#3.

c. Image of buccal surface of hybrid ceramic coping \#3. 


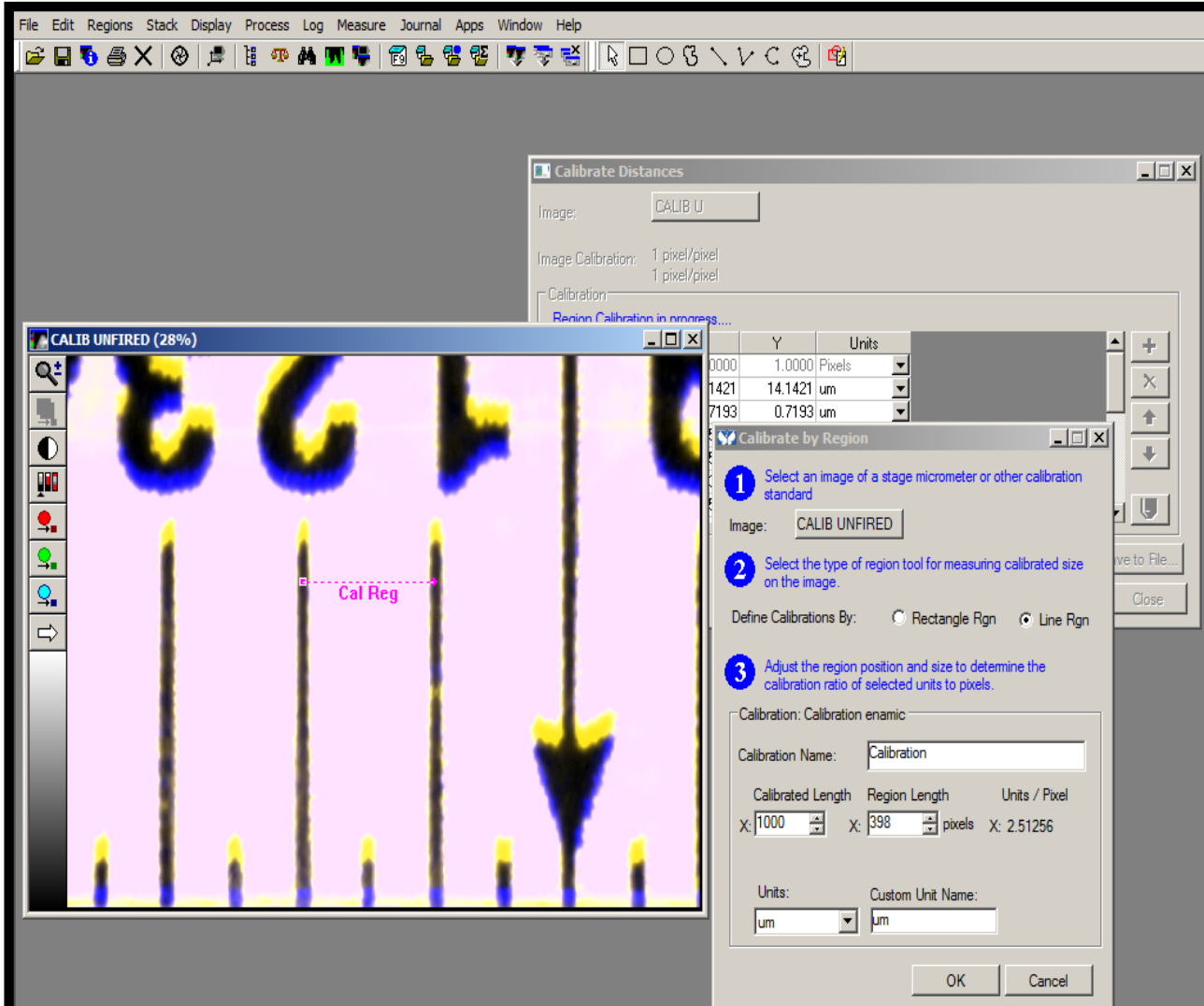

Figure 22: Calibration of image distances in micrometers. 


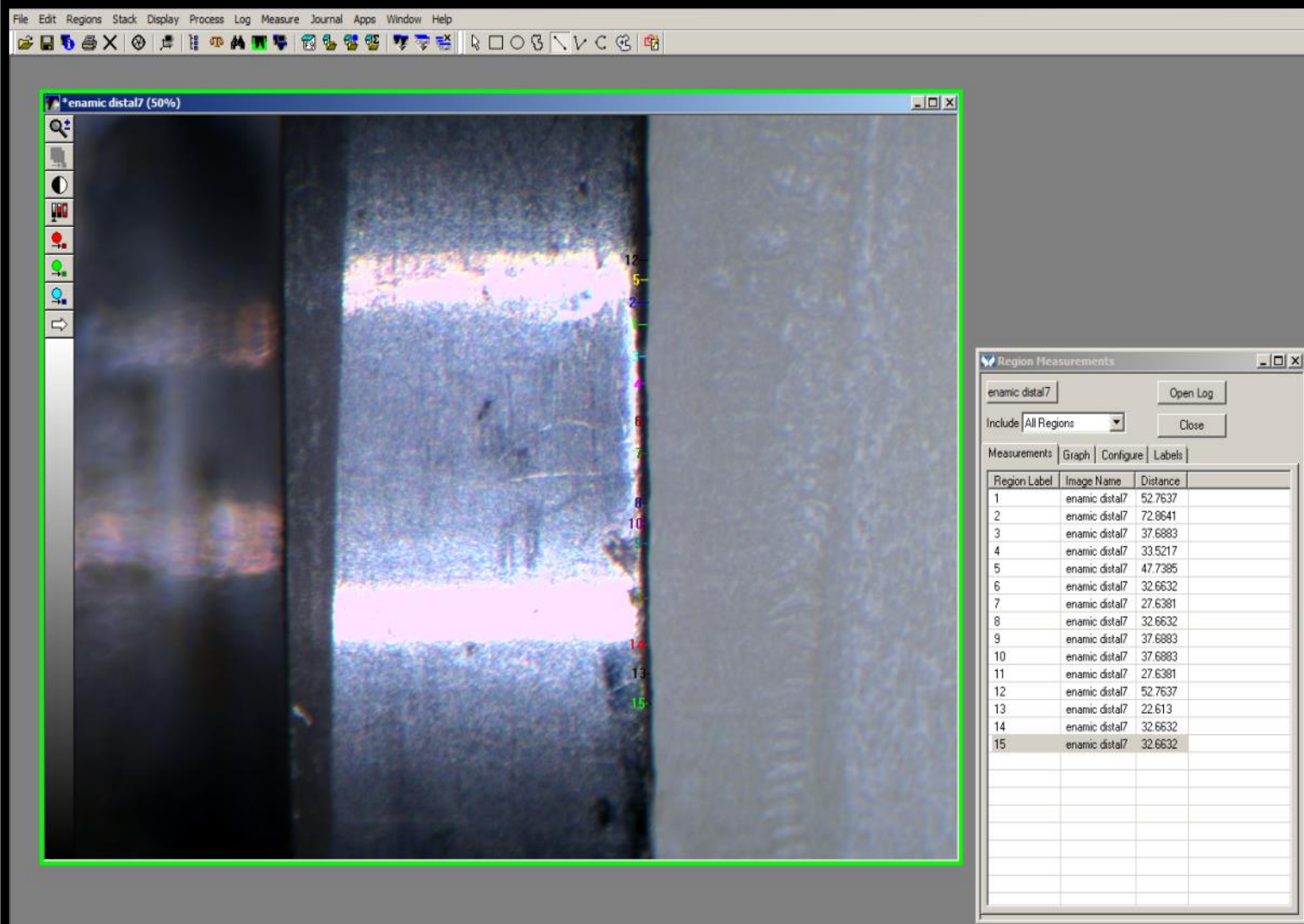

Figure 23: line measurements of marginal gap area made using image analyzing software 


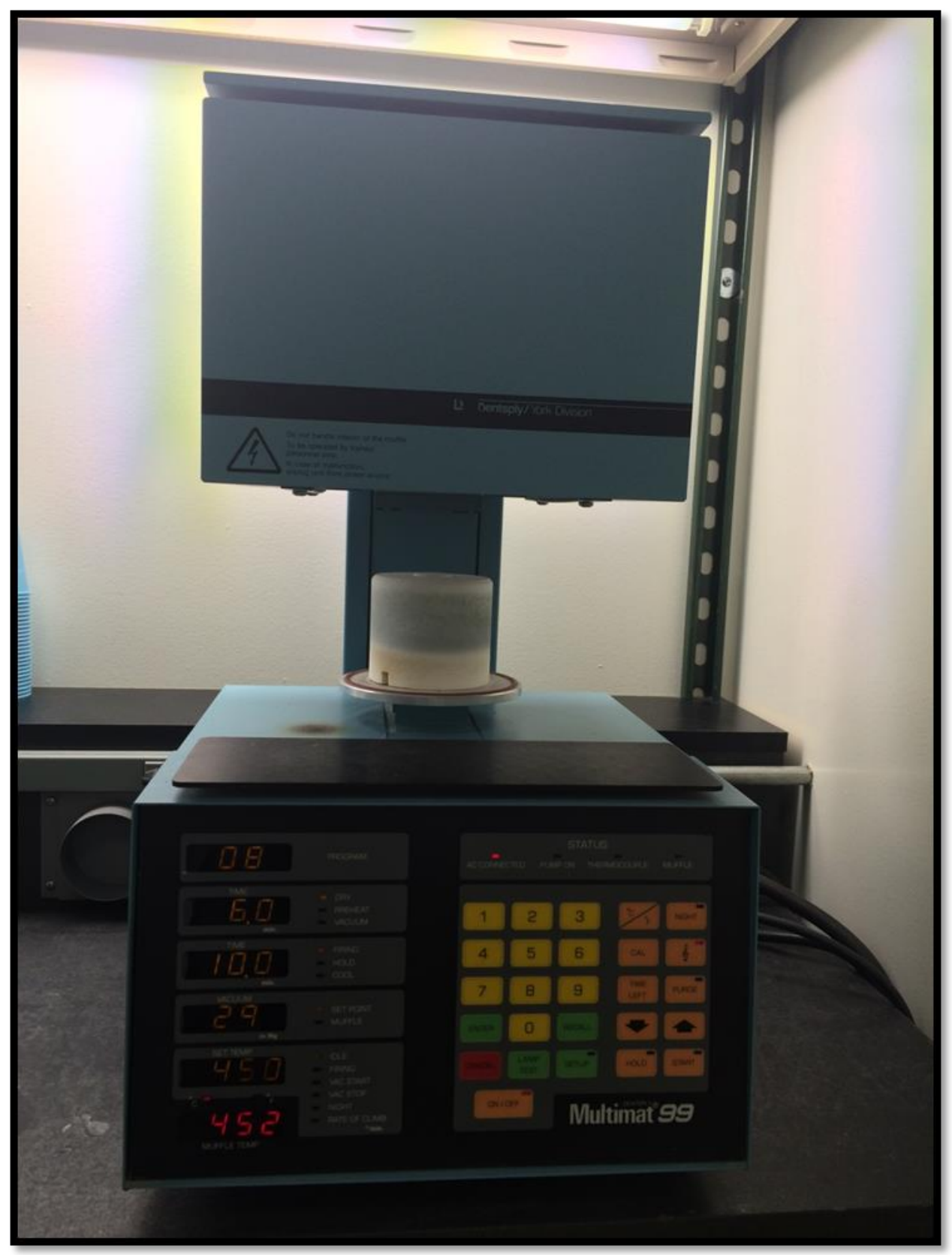

Figure 24: Furnace used for crystallization firing cycle of lithium disilicate copings. 

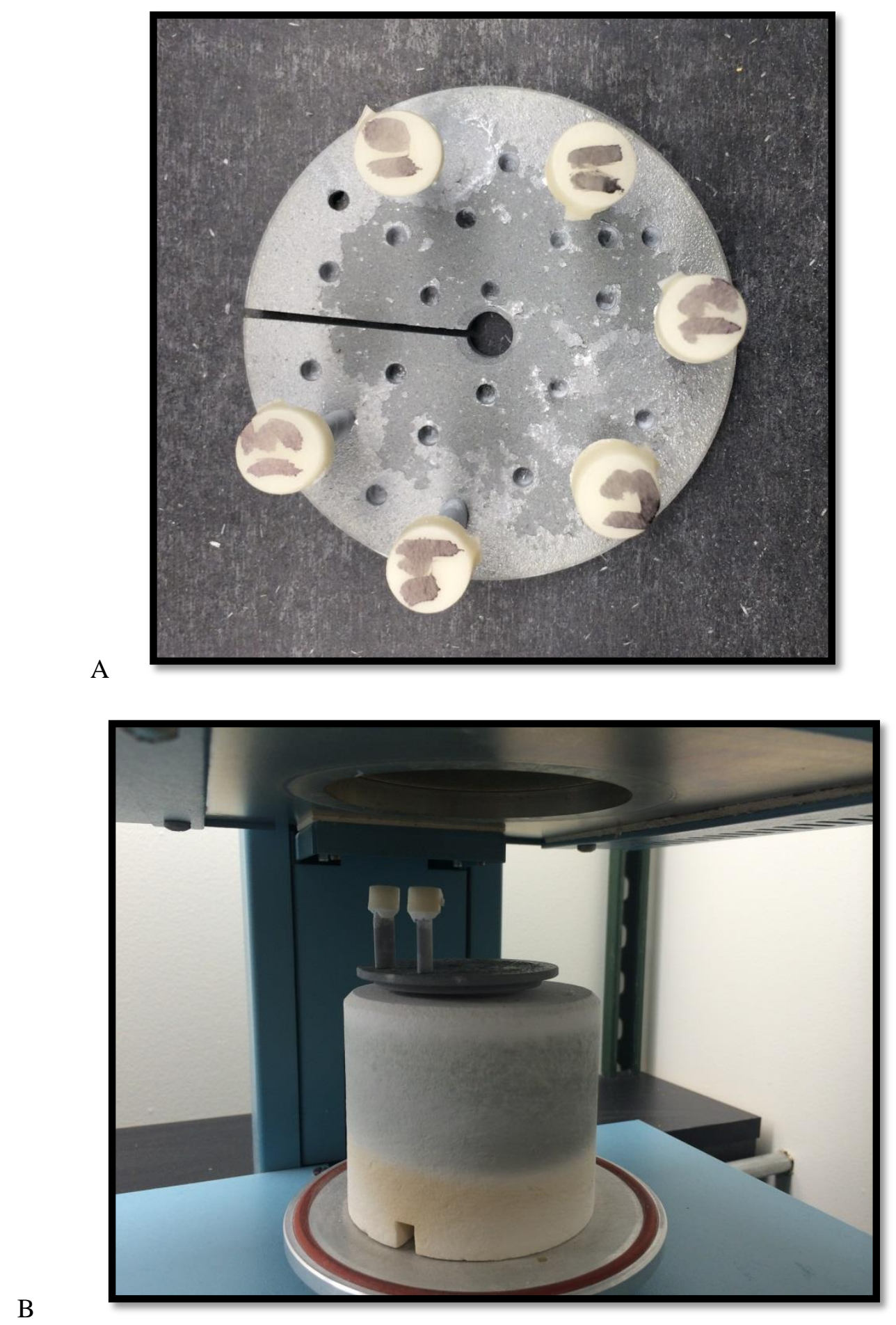

Figure 25: A. labeled lithium disilicate copings mounted on the crystallization tray.

B. Two lithium disillicate copings in furnace. 


\section{BIBLIOGRAPHY}

1. Boeing KW, Wolf BH, Schmidt AE,Kastner K, Walter MH. Clinical fit of Procera AllCeram crowns, J Prosthet Dent 2000;84:419-24.

2. Jacob MS, Windeler AS. An investigation of dental luting cements solubility as a function of the marginal gap. J Prosthet Dent. 1991;65:436-442.

3. Felton DA, Kanoy BE, bayn SC, et al: Effect of invivo crown margin discrepancies on periodontal health. J prosthet dent. 1991; 65:357-364.

4. Goldman M, Laosonthorn p, White RR. Microleakage-Full crowns and the Dental Pulp. J Endo. 1982;18:473-475.

5. Kukubo Y, Ohkubo C, Tsumita m, Kano T, Sakurai S, Fukushima S (2005). Clinical marginal and internal gaps of Procera allceramic crowns. J Oral Rehabil 32: 526-530.

6. Valderhuag j, Birkeland JM. Periodontal conditions in patients 5 years following insertion of fixed prostheses. J Oral Rehabil. 1976;3:237-243.

7. Valderhaug $\mathbf{J}$, Heloe LA. Oral hygiene in a group of supervised patients with fixed prostheses. $\mathbf{J}$ Periodontal. 1977;48:221-224.

8. Lang NP, Kiel RA, Anderhalden k. clinical and microbiological effects of subgingival restorations with overhanging or clinical perfect margins. J Clin Periodontol.1983;10:563-578.

9. Tuntiprawon M, Wilson T: the effect of cement thickness on the fracture strength of all-ceramic crowns. Aust Dent J. 1995;40:17-21.

10. Reiss B: Long-term clinical performance of CEREC restorations and the variables affecting treatment success. Compend Contin Educ Dent 2001;22:14-18.

11. Kohorset P, Brinkmann H, Li J, et al: marginal accuracy of four-unit zirconia fixed dental prostheses fabricated using different computer-aided design/computer -aided manufacturing systems. Eur J Oral Sci. 2009;117:319-325.

12. Pera P, gilodi S, Bassi f, etal: In Vitro marginal adaptation of alumina porcelain ceramic crowns. J Prosthet Dent. 1994; 74:585-590. 
13. Holmes JR, Bayne SC, Holland GA, et al: considerations in measurements of marginal fit. J Prosthet Dent. 1989;62:405-408.

14. Miyazaki T, Hotta Y: CAD/CAM systems available for the fabrication of crown and bridge restorations. Aust Dent J 2011;56 Suppl 1:97-106.

15. Skramstad Michael. The clinical application of CAD/CAM technology and material. Dental learning. www.dental learning.net. Sep 2012 ;volume 1(6):1-19

16. Reich S, Wichmann m, Nkenke E, proeschel P. Clinical fit of all ceramic three-unit fixed partial dentures, generated with three different CAD/Cam systems. Eur J Oral Sci. 2005;113(2):174-9.

17. Tinschert j, Natt G, hassenpflug S, Speikmann H. Status of current CAD/CAM technology in Ddental medicine. INT J Comput dent. 2004;7(1):25-45. [pubmed:17112579].

18. Sjogren G: Marginal and internal fit of four different types of ceramic inlays after luting. An in vitro study. Acta Odontol Scand 1995;53:24-28.

19. Sturdevant JR, Bayne SC, Heymann HO: Marginal gap size of ceramic inlays using second generation CAD/CAM equipment. J Esthet Dent 1999;11:206-214.

20. Bindl A, Mormann WH: Clinical and SEM evaluation of all-ceramic chair-side CAD/Camgenerated partial crowns. Eur J Oral Sci 2003;111:163-169.

21. Denissen H, Dozic A, Van der Zel J, et al: Marginal fit and short-term clinical performance of porcelain-veneered CICERO, CEREC and Procera onlays. J Prosthet Dent 2000;84:506-513.

22. . Ellingsen LA, Fasbinder DJ. An in vitro evaluation CAD/CAM ceramic crowns. J. Dent Res 2002;81:331.

23. Tsitrou A, Northest S.E, Van Noort R. Evaluation of the marginal fit of three margin designs of resin composite crowns using CAD/CAM. J of Dentistry. 2007; 35(1):68-73.

24. Akbar JH, Petrie CS, et al. Marginal adaptation of Cerec 3 CAD/CAM composite crowns using two different finifsh line preparartion designs. J Prosthodont 2006;15:155-163.

25. Alkumra H, Hullah WR, Marquis PM, Wilson HJ. Factors affecting the fit of porcelain jacket crowns. Br Dent J 1988;164:39-43.

26. Balkaya Mc, Cinar A, Pamuk S. influence of firing cycles on the margin distortion of 3 all ceramic crown systems. J Prosthet Dent 2005;93:346-355. 
27. Dederich DN, Svare CW, Peterson LC, Turner KA. The effect of repeated firing on the margins of nonprecious ceramometals. J Prosthet Dent 1984; 51:628-630.

28. Gemalmaz D, AlKumra HN. Marginal fit changes during porcelain firing cycles. J Prosthet dent 1995;73:49-54.

29. Sorenson JA, Sorenson PN, Mizuro k. Marginal Fidelity of crowns made with optical versus conventional impressions. IADR Abstract \#1599. April 2009.

30. Hirayama H, Chang YC. Fit of Zirconia copings generated from a digital impression technique and a conventional impression technique.Tufts University of Dental Medicine Master's Thesis.

31. Anadioti, Evanthia. Internal and marginal fit of pressed and cad lithium disilicate crowns made from digital and conventional impressions.MS thesis, University of Iowa, 2013.

32. Tinschert J, Natt G, Mautsch W, Speikermann H, Anuasavice KJ. Marginal fit of alumina-and zirconia-based fixed partial dentures produced by a CAD/CAM system. Operative Dentistry 2001;26:367-74.

33. Fransson B, Oilo g, Gjeitanger R. The fit of metal-ceramic crowns, a clinical study. Dental Materials 1985;1:197-9.

34. Molin m, Karlsson S. The fit of Gold inlays and three ceramic inlay systems. A clinical and in vivo study. Acta Odontologica Scandinavica 1993;51:201-6.

35. Mclean JW, Von Frounhofer JA. The estimation of cement film thickness by an invivo technique. Br Dent J 1971;131:107-111.

36. Nawafleh NA, Mack f, Evans J, Mackay J, Hatamleh MM. Accuracy and reliability of methods to measure marginal adaptation of crowns and FPDs: a literature review. J Prosthodont. 2013 Jul;22(5):419-28.

37. Land CH. Porcelain dental art: No.II. Dent Cosmos 1903;45:615-20.

38. McLean Jw, Hughes TH. The reinforcement of dental porcelain with ceramic oxides. Br Dent J 1965;119:251-67.

39. Piconi C, Maccauro G. Zirconia as a ceramic biomaterial. Biomaterials 1999;20:1-25. 
40. Christel P, Meunier A, Dorlot JM, Crolet JM, Witvoet J, Sedel 1, et al.

Biomechanicalcompatibility and design of ceramic implants for orthopedic surgery. Ann NY

Acad Sci 1988;523:234-56.

41. Denry IL. Recent advances in ceramics for dentistry. Crit Rev Oral Biol Med 1996;7: 134-43. [2]

42. Kelly JR. Ceramics in restorative and prosthetic dentistry. Ann Rev Mater Sci 1997;27: 443-68.

43. Kelly JR. Dental ceramics: Current thinking and trends. Dent Clin North Am. 2004 Apr;48(2):viii, 513-30.

44. Dong JK, Luthy H, Wohlwend A, Scharer P. Heat-pressed ceramics: technology and strength. Int J Prosthodont 1992; 5(1):9-16.

45. El-Mowafy O, Brochu JF. Longevity and clinical performance of IPS-empress ceramic restorations--a literature review. J Can Dent Assoc. 2002 Apr;68(4):233-7.

46. Fradeani M, Rademangi M. an 11- year clinical evaluation of leucite-reinforced glass-ceramic crowns: a retrospective study. quintessence Int 2002;33:503-10.

47. Conrad HJ, Seong WJ, Pesun IJ. Current ceramic materials and systems with clinical recommendations: A systematic review. J Prosthet Dent 2007;98(5):389-404.

48. Tysowsky G. the science behind lithium disilicate: today's surprisingly versatile, esthetic and durable metal-free alternative. Oral Health J 2009;March:93-97.

49. Fasbinder DJ, Dennison JB, Heys D, Neiva G. A clinical evaluatioin of chairside lithium disilicate CAD/CAM Crowns: two year report. Journal of American dental Association 2010;141 $(10 \mathrm{~S}): 14 \mathrm{~S}$.

50. Ivoclar Vivadent. IPS e.max CAD: Scientific Documentation. 2011; www.Ivoclarvivadent.us

51. Ed MacLaren, Sameer Puri. CEREC materials overview: Different selection for milling restorations. Cerendoctors.com, Quarter 1, 2013.

52. Karen M, Sasse M, Wolfart S. Ten-year outcome of three-unit fixed dental prostheses made from monolithic lithium disilicate cermic. J Am Dent Assoc. 2012 Mar; 143(3):234-40.

53. Vita Enamic. The first hybrid with dual network structure for superior absorption of masticatory forces. Manufacturers manual. 
54. VITA ENAMIC Technical and Scientific Documentation. VITA Zahnfabrik H. Rauter GmbH \& Co.KG. Vitanorthamerica.com. 2013.

55. Internal studies, VITA R\&D: VITA Zahnfabrik H. Rauter GmbH \& Co. KG Research and Development Division, Inorganic Chemistry Spitalgasse 3,79713 Bad SackingenDr. Enno Bojemuller, Project Manager ENAMIC, R\&D - Inorganic Chemistry,Bad Sackingen Dipl.-Ing. Andrea Coldea, Material Development, R\&D Inorganic Chemistry, Bad Sackingen Dr. Norbert Thiel, Head of R\&D - Inorganic Chemistry, Bad Sackingen

56. Bindl A, Mormann WH. Marginal and internal fit of all-ceramic CAD/CAM crown copings on chamfer preparations. J Oral Rehabil 2005;32:441-7

57. Bader JD, Rozier RG, McFall WT,Jr, Ramsey DL. Effect of crown margins on periodontal conditions in regularly attending patients. J Prosthet Dent. 1991 Jan;65(1):75- 9.

58. Zoellner A, Bragger U, Fellmann V, Gaengler P. Correlation between clinical scoring of secondary caries at crown margins and histologically assessed extent of the lesions. Int $\mathbf{J}$ Prosthodont. 2000 Nov-Dec;13(6):453-9.

59. Reeves WG. Restorative margin placement and periodontal health. J Prosthet Dent. 1991 Dec;66(6):733-6.

60. White SN, Ingles S, Kipnis V. Influence of marginal opening on microleakage of cemented artificial crowns. J Prosthet Dent. 1994 Mar;71(3):257-64.

61. American Dental Association: ANSI/ADA Specification No.8 for zinc phosphate cement. In: Guide to dental material and devices. $5^{\text {th }}$ ed. Chicago: American Dental Association; 1970-1971.

62. Christensen GJ. Marginal fit of gold inlay castings. J Prosthet Dent. 1966 MarApr;16(2):297-305.

63. Schaerer P, Sato T, Wohlwend A. A comparison of the marginal fit of three cast ceramic crown systems. The Journal of Prosthetic Dentistry 1988;59:534-42.

64. Sulaiman F, Chai J, Jameson LM, Wozniak WT. A comparison of the marginal fit of In-Ceram, IPS Empress, and Procera crowns. The International Journal of Prosthodontics 1997;10:478-84.

65. Davis DR. Comparison of fit of two types of all ceramic crowns. J Prosthet Dent 1988;59:534542 
66. Bindl A, Windisch S, Mormann WH. Full-ceramic CAD/CIM anterior crowns and copings. International Journal of Computerized Dentistry 1999;2:97-1

67. Nakamura T, Dei N, Kojima T, Wakabayashi K. Marginal and internal fit of Cerec 3 CAD/CAM all-ceramic crowns. The International Journal of Prosthodontics 2003;16:244-8.

68. Lee K, Park C, Kim k, Kwon T. Marginal and internal fit of all-ceramic crowns fabricated with Different CAD/CAM systems. Dental Materials Journal 2008; 27(3):422-426.

69. Reich S,Uhlen S, Gozdowski S, et al: Measurement of cement thickness under lithium disilicate crowns using an impression material technique. Clin Oral Investig 2010;15:521-526.

70. Wilson PR. Effect of increasing cement space on cementation of artificial crowns. J Prosthet Dent. 1994 Jun;71(6):560-4.

71. Kim JH, Miranda P, Kim DK, at al: Effect of an adhesive interlayeron the fracture of a briitle coatingon a supporting substrate. J Mater Res 2003;18:222-227.

72. Gavelis JR, Morency JD, Sozio RB: The effects of various finish line preparations on the marginal seal and occlusal seat of full crown preparations. J Prosthet Dent. 1981; 45:138-145.

73. Bottino MA, Valandro LF, Buso L, Ozcan M. The influence of cervical finish line, internal relief, and cement type on the cervical adaptation of metal crowns. Quintessence Int. 2007 JulAug;38(7):e425-32.

74. Assuncao Souza RO, Ozcan M, Augusto Pavanelli C, Buso L, Leao Lombardo GH, Araujo Michida SM, et al. Marginal and internal discrepancies related to margin design of ceramic crowns fabricated by a CAD/CAM System. J Prosthodont 2012;21:94-100.

75. Quintas AF, Oliveira F, Bottino MA. Vertical marginal discrepancy of ceramic copings with different ceramic materials, finish lines, and luting agents: an in vitro evaluation. J Prosthet Dent. 2004;92:250-257.

76. Lin MT, Sy-Munoz J, Munoz CA, Goodacre CJ, Naylor WP. The effect of tooth preparation for on the fit of Procera copings. Int J Prosthodont. 1997;10(5):478-84.

77. Komine F, Iwai T, Kobayashi K, Matsumura H. Marginal and internal adaptation of zirconium dioxide ceramic copings and crowns with different finish line designs. Dent Mater J. 2007;26:659-664.

78. Subasi G, Ozturk N, Inan O, Bozogullri N.Evaluation of marginal fit of two all-ceramic copings with two finish lines. Eur J Dent. 2012 Apr; 6(2): 163-168. 
79. Beschnidt SM, Strub JR. Evaluation of the marginal accuracy of different all-ceramic crown systems after simulation in the artifi- cial mouth. J Oral Rehabil 1999;26:582-93.

80. Quintas AF, Oliveira F, Bottino MA. Vertical marginal discrepancy of ceramic copings with different ceramic materials, finish lines, and luting agents: an in vitro evaluation. J Prosthet Dent. 2004;92:250-257.

81. Okutan M, Heydecke G, Butz F, Strub JR. Fracture load and marginal fit of shrinkagefree ZrSiO4 all-ceramic crowns after chewing simulation. J Oral Rehabil 2006;33:827-32.

82. Ural C, Burgaz Y, Sarac D. In vitro evaluation of marginal adaptation in five ceramic restoration fabricating techniques. Quintessence Int 2010;41:585-90.

83. Pilathadka S, Slezak R, Vahaloa D, Kudiyirickal MG, Sukumar S. Influence of different luting agents on the marginal discrepancy of Procera Allceram alumina crown copings: an experimental study. Acta Medica (Hradec Kralove) 2008;51:13-8.

84. Yuksel E, Zaimoglu A. Influence of marginal fit and cement types on microleakage of all-ceramic crown systems. Braz Oral Res 2011;25:261-6.

85. Albert FE, El-Mowafy OM. Marginal adaptation and microleakage of Procera AllCeram crowns with four cements. Int J Prosthodont 2004;17:529-35

86. Martínez-Rus F, Suárez MJ, Rivera B, Pradíes G. Influence of CAD/CAM systems and cement selection on marginal discrepancy of zirconia-based ceramic crowns. Am J Dent. 2012 Apr;25(2):67-72.

87. Raphael Pilo,Harold S. Cardash. In vivo retrospective study of cement thickness under crowns. J Prosthet Dent 1998;79:621-5.

88. Grajower R, Lewinstein I, Zeltser C. The effective minimum thickness of zinc phosphate cement for luted non-precious crowns. J Oral Rehabil 1985;12:235-45.

89. Sorensen JA. A standardized method for determination of crown margin fidelity. J Prosthet Dent. $1990 \mathrm{Jul} ; 64(1): 18-24$.

90. Hayashi M, Watts DC, Ebisu S, Wilson NH. Influence of vision on the evaluation of marginal discrepancies in restorations. Oper Dent. 2005 Sep-Oct;30(5):598-601.

91. Leknius C, Giusti L, Chambers D, Hong C. Effects of clinical experience and explorer type on judged crown margin acceptability. J Prosthodont. 2010 Feb;19(2):138- 43. 
92. Contrepois M, Soenen A, Bartala M, Laviole O. Marginal adaptation of ceramic crowns: A systematic review. J Prosthet Dent 2013;6:447-454

93. Groten M, Girthofer S, Probster L. Marginal fit consistency of copy-milled all-ceramic crowns during fabrication by light and scanning electron microscopic analysis in vitro. J Oral Rehabil 1997;24:871-81.

94. Groten M, Axmann D, Probster L, Weber H. Determination of the minimum number of marginal gap measurements required for practical in-vitro testing. J Prosthet Dent 2000;83:40-9.

95. Petteno D, Schierano G, Bassi F, et al: Comparison of marginal fit of 3 different metal-ceramic systems: an in vitro study. Int J Prosthodont. 1995;8:303-310.

96. Romeo E, Iorio M, Storelli S, Camandona M, Abati S. Marginal adaptation of fullcoverage CAD/CAM restorations: In vitro study using a non-destructive method. Minerva Stomatol. 2009 Mar;58(3):61-72.

97. Tan PL, Gratton DG, Diaz-Arnold AM, Holmes DC. An in vitro comparison of vertical marginal gaps of CAD/CAM titanium and conventional cast restorations. J Prosthodont. 2008 Jul;17(5):378-83.

98. Gonzalo E, Suarez MJ, Serrano B, Lozano JF. Comparative analysis of two measurement methods for marginal fit in metal-ceramic and zirconia posterior FPDs. Int J Prosthodont. 2009 Jul-Aug;22(4):374-7.

99. Good M, Mitchell C, Pintado M, et al: Quantification of all-ceramic crown margin surface profile from try-in to 1-week post-cementation. J Dent. 2009;37: 65-75.

100. Mitchell CA, Pintado MR, Douglas WH: Nondestructive, in vitro quantification of crown margins. J Prosthet Dent. 2001; 85: 575-584.

101. Shearer B, Gough MB, Setchell DJ: Influence of Marginal configuration and porcelain addition on the fit of Procera crowns. J Contemp Dent Pract. 2008; 9:25-32.

102. Coli P, Karlsson S. Fit of a new pressure-sintered zirconium dioxide coping. Int J Prosthodont. 2004 Jan-Feb;17(1):59-64.

103. Nakamura T, Tanaka H, Kinuta S, Akao T, Okamoto K, Wakabayashi K, et al. In vitro study on marginal and internal fit of CAD/CAM all-ceramic crowns. Dent Mater J. 2005 Sep;24(3):456-9.

104. Kokubo Y, Nagayama Y, Tsumita M, Ohkubo C, Fukushima S, Vult von Steyern P. Clinical marginal and internal gaps of in-ceram crowns fabricated using the GN-I system. J Oral Rehabil. 2005 Oct;32(10):753-8. 
105. Kokubo Y, Ohkubo C, Tsumita M, Miyashita A, Vult von Steyern P, Fukushima S. Clinical marginal and internal gaps of procera AllCeram crowns. J Oral Rehabil. 2005 Jul;32(7):526-30.

106. Reich S, Uhlen S, Gozdowski S, Lohbauer U. Measurement of cement thickness under lithium disilicate crowns using an impression material technique. Clin Oral Investig. 2011 Aug;15(4):521-6.

107. Wolfart S, Wegner SM, Al-Halabi A, et al.: Clinical evaluation of marginal fit of a new experimental all-ceramic system before and after cementation. Int J prosthodont.2003;16: 587592.

108. Shearer B, Gough MB, Setchell DJ: Influence of marginal configuration and porcelain addition on the fit of In-Ceram crowns. Biomaterials. 1996; 17:1891-1895.

109. Rahme HY, Tehini GE, Adib SM, Ardo AS, Rifai KT. In vitro evaluation of the "replica technique" in the measurement of the fit of procera crowns. J Contemp Dent Pract. 2008 Feb $1 ; 9(2): 25-32$.

110. Luthardt RG, Bornemann G, Lemelson S, Walter MH, Huls A. An innovative method for evaluation of the 3-D internal fit of CAD/CAM crowns fabricated after direct optical versus indirect laser scan digitizing. Int J Prosthodont. 2004 Nov-Dec;17(6):680-5.

111. Holst S, Karl M, Wichmann M, Matta RE. A new triple-scan protocol for 3D fit assessment of dental restorations. Quintessence Int. 2011 Sep;42(8):651-7.

112. Borba M, Cesar PF, Griggs JA, Della Bona A. Adaptation of all-ceramic fixed partial dentures. Dent Mater 2011;27: 1119-26.

113. Seo D, Yi Y, Roh B. The effect of preparation designs on the marginal and internal gaps in Cerec3 partial ceramic crowns. J Dent. 2009;37(5):374-82.

114. Pelekanos S, Koumanou M, Koutayas SO, Zinelis S, Eliades G. Micro-CT evaluation of the marginal fit of different In-Ceram alumina copings. Eur J Esthet Dent. 2009;4(3):278-92.

115. Syrek A, Reich G, Ranftl D, Klein C, Cerny B, Brodesser J. Clinical evaluation of allceramic crowns fabricated from intraoral digital impressions based on the principle of active wavefront sampling. J Dent 2010;38: 553-9.

116. Gassino G, Barone Monfrin S, Scanu M, Spina G, Preti G. Marginal adaptation of fixed prosthodontics: a new in vitro 360-degree external examination procedure. Int J Prosthodont 2004; 17: 218-23. 
117. Miyazaki T, Hotta Y. CAD/CAM systems available for the fabrication of crown and bridge restorations. Aust Dent J. 2011 Jun;56 Suppl 1:97-106.

118. Duret F, Preston JD. CAD/CAM imaging in dentistry. Curr Opin Dent 1991;1:150-154.

119. Mormann WH, Brandestini M, Lutz F, Barbakow F. Chairside computer-aided direct ceramic inlays. Quintessence Int 1989;20:329-339.

120. Birnbaum NS, Aaronson HB, Stevens C, Cohen B: 3D Digital Scanners: A High-Tech Approach to More Accurate Dental Impressions. Inside Dentistry; 2009; 5: 70-74.

121. Brandestini M, Moermann WH, inventors: Method and apparatus for the three dimensional registration and display of prepared teeth. US Patent 4837732; 1989.

122. Scotti R, Cardelli P, Baldissara P, Monaco C. Clinical fitting of CAD/CAM zirconia single crowns generated from digital intraoral impressions based on active wavefront sampling. J Dent. 2011 Oct 17.

123. Beuer F, Schweiger J, Edelhoff D. Digital dentistry: An overview of recent developments for CAD/CAM generated restorations. Br Dent J. 2008 May 10;204(9):505-11.

124. Sorensen J A, Choi C, Fanuscu M I, Mito W T. IPS Empress crown system: three-year clinical trial results. J Calif Dent Assoc 1998; 26: 130-136.

125. Sorensen J A, Cruz M, Mito W T, Raffeiner O et al. A clinical investigation on three-unit fi xed partial dentures fabricated with a lithium disilicate glassceramic. Pract Periodontics Aesthet Dent 1999; 11: 95-106.

126. Taskonak B, Sertgoz A. Two-year clinical evaluation of lithia-disilicate based all-ceramic crowns and fi xed partial dentures. Dent Mater 2006; 22: 1008-1013.

127. Sorensen J A, Kang S K, Avera S P. Porcelaincomposite interface microleakage with various porcelain surface treatments. Dent Mater 1991; 7: 118-123. 17. Sorensen J A, Munksgaard E C. Ceramic inlay movement during polymerization of resin luting cements. Eur J Oral Sci 1995; 103: $186-189$

128. Curtis A R, Wright A J, Fleming G J. The infl uence of surface modification techniques on the performance of a Y-TZP dental ceramic. J Dent 2006; 34: 195-206 
129. Swain MV, Garvie RC, Hannink RHJ. Influence of thermal decomposition on the mechanical properties of magnesia stabilized cubic zirconia. Journal of the American Ceramic Society 1983;66:358-62. 21.

130. Masaki T. Mechanical properties of toughened $\mathrm{ZrO} 2-\mathrm{Y} 2 \mathrm{O} 3$ ceramics. Journal of the American Ceramic Society 1986;69: 638-40

131. Swain M V. Limitation of maximum strength of zirconia-toughened ceramics by transformation toughening increment. J Am Ceramic Soc 1985; 66: 358-362. 27.

132. Swain M V, Hannink R H J. Metastability of the martensitic transformation in a 12 mol\% ceriazirconia alloy: grinding studies. J Am Ceramic Soc 1989; 72: 1358-1364.

133. Logozzo S, Franceschini G, Kilpelä A, Caponi M, Governi L, Blois L. A comparative analysis of intraoral 3d digital scanners for restorative dentistry. The Internet Journal of Medical Technology [Internet]. 2011;5(1).

134. Cardelli $\mathrm{P}$, et al. Clinical fitting of CAD/CAM zirconia single crowns generated from digital intraoral impressions based on active wavefront sampling. Journal of Dentistry (2011), doi:10.1016/j.jdent.2011.10.005.

135. Schwotzer A, inventor: Measuring device and method that operates according to the basic principles of confocal microscopy. US Patent 2007/0296959; 2007.

136. Thiel F, Pfeiffer J, Fornoff P, inventors: Apparatus and method for optical 3D measurement. International Publication WO 2008/092791 A1; 2008.

137. Schmidt V, inventor: 3D dental camera for recording surface structures of a measuring object by means of triangulation. International Publication WO 2010/012838 A1; 2010.

138. Faulstich A, invertor: Optical projection grid and method for generating an optical projection grid. US patent 2007/029695;2007.

139. S.A Gold, J.B DA Costa, J.L Ferracane. Effect of Crystalization Firing on Marginal Fit of Lithium Disilicate Cowns. IADR/AADR/CADR General Session and Exibition 2013.

140. Yucel MT, Aykent F,Avunduk MC. In vitro evaluation of the marginal fit of different allceramic crowns. J Dental Science 2013;8:225-230.

141. Luthardt RG, Bornemann G, Lemelson S, Walter MH, Huls A. An innovative method for evaluation of the 3-D internal fit of CAD/CAM crowns fabricated after direct optical versus indirect laser scan digitizing. Int J Prosthodont. 2004 Nov-Dec;17(6):680-5. 
142. Hmedat $S$, Ibraheem A. An invitro evaluation of fit of the crowns fabricated by Zirconium oxide-based ceramic CAD/CAM systems, before and after porcelain firing cycles and after glaze cycles. J Bagh Coll dentistry 2013;25(1):43-48.

143. Kim SJ, et al. A comparison of the fidelity of various Zirconia-based all-ceramic crowns fabricated with CAD/CAM systems. J Korean ACAD Prosthodont. 2009 Apr;47(2):148-155.

144. Fahmy A.M. Comparison of marginal fit between collarless metal ceramic and two all ceramic restorations. Journal of American Science. 2012;8(6):528-534.

145. Srikakula NK, et al. comparison of marginal fit of zirconium oxide copings generated using four different CAD/CAM systems-An in vitro study. J Res Adv Dent 2014;3:1:163-171.

146. Alghazzawi TF, Liu PR, Essig ME. The effect of fifferent fabrication steps on the marginal adaptation of two types of glass-infiltered ceramic crown copings fabricated by CAD/CAM technology. J of Prosthodontics. 2012;21(3):167-172. 